University of Louisville

ThinkIR: The University of Louisville's Institutional Repository

8-2007

\title{
Comparative linear accuracy and reliability of cone beam CT derived 2-dimensional and 3-dimensional images constructed using an orthodontic volumetric rendering program.
}

Danielle R. Periago

University of Louisville

Follow this and additional works at: https://ir.library.louisville.edu/etd

\section{Recommended Citation}

Periago, Danielle R., "Comparative linear accuracy and reliability of cone beam CT derived 2-dimensional and 3-dimensional images constructed using an orthodontic volumetric rendering program." (2007). Electronic Theses and Dissertations. Paper 1116.

https://doi.org/10.18297/etd/1116

This Master's Thesis is brought to you for free and open access by ThinkIR: The University of Louisville's Institutional Repository. It has been accepted for inclusion in Electronic Theses and Dissertations by an authorized administrator of ThinkIR: The University of Louisville's Institutional Repository. This title appears here courtesy of the author, who has retained all other copyrights. For more information, please contact thinkir@louisville.edu. 
COMPARATIVE LINEAR ACCURACY AND RELIABILITY OF CONE BEAM CT DERIVED 2-DIMENSIONAL AND 3-DIMENSIONAL IMAGES CONSTRUCTED USING AN ORTHODONTIC VOLUMETRIC RENDERING PROGRAM.

By

Danielle R. Periago

B.A., Oral Roberts University, 2000

D.M.D., University of Louisville, 2005

\author{
A Thesis \\ Submitted to the Faculty of the \\ Graduate School of the University of Louisville \\ in Partial Fulfillment of the Requirements \\ for the Degree of \\ Masters of Science in Oral Biology \\ Department of Orthodontics and Pediatric Dentistry \\ University of Louisville \\ Louisville, KY
}

August, 2007 
COMPARATIVE LINEAR ACCURACY AND RELIABILITY OF CONE BEAM CT DERIVED 2-DIMENSIONAL AND 3-DIMENSIONAL IMAGES CONSTRUCTED USING AN ORTHODONTIC VOLUMETRIC RENDERING PROGRAM.

By

Danielle R. Periago

B.A., Oral Roberts University, 2000

D.M.D., University of Louisville, 2005

A Thesis Approved on

June 12, 2007

by the following Thesis Committee:

Thesis Director 


\section{DEDICATION}

This thesis is dedicated to my husband

Juan, who always gives me

unconditional love and support in all of my endeavors, and to my daughter Hope, who gives me the hope and strength to persevere. 


\section{ACKNOWLEDGEMENTS}

I would like to sincerely thank my thesis director, Dr. William C. Scarfe, for his guidance and patience in this project. A special thanks needs to be given to the Department of Radiology, Dr. William C. Scarfe and Dr. Allan G. Farman, for providing me with the opportunity to access and use the Cone Beam CT. I would also like to thank my other thesis committee members, Dr. Anibal Silveira and Dr. James Scheetz for their guidance and support. I would finally like to express a special thanks to my co-resident, Dr. Mazyar Moshiri, for his help and collaboration throughout this project. 


\begin{abstract}
COMPARATIVE LINEAR ACCURACY AND RELIABILITY OF CONE BEAM CT DERIVED 2-DIMENSIONAL AND 3-DIMENSIONAL IMAGES CONSTRUCTED USING AN ORTHODONTIC VOLUMETRIC RENDERING PROGRAM.
\end{abstract}

Danielle R. Periago, D.M.D.

June 12, 2007

The purpose of this project was to compare the accuracy and reliability of linear measurements made on 2D projections and 3D reconstructions using Dolphin 3D software (Chatsworth, CA) as compared to direct measurements made on human skulls.

The linear dimensions between 6 bilateral and 8 mid-sagittal anatomical landmarks on 23 dentate dry human skulls were measured three times by multiple observers using a digital caliper to provide twenty orthodontic linear measurements.. The skulls were stabilized and imaged via PSP digital cephalometry as well as CBCT. The PSP cephalograms were imported into Dolphin (Chatsworth, CA, USA) and the 3D volumetric data set was imported into Dolphin 3D (Version 2.3, Chatsworth, CA, USA). Using Dolphin 3D, planar cephalograms as well as 3D volumetric surface reconstructions were (3D CBCT) generated. The linear measurements between landmarks of each three modalities were then computed by a single observer three times. For 2D measurements, a one way ANOVA for each measurement dimension was calculated as well as a post hoc Scheffe multiple comparison test with the anatomic distance as the control group. 3D measurements were compared to anatomic truth using Student's t test ( $\mathrm{P} \leq 0.05)$. The intraclass correlation coefficient (ICC) and absolute linear and percentage error were determined as indices of intraobserver reliability. 
Our results show that for 2D mid sagittal measurements that Simulated LC images are accurate and similar to those from PSP images (except for Ba-Na), and for bilateral measurements simulated LC measurements were similar to PSP but less accurate, underestimating dimensions by between $4.7 \%$ to $17 \%$. For $3 \mathrm{D}$ volumetric renderings, $2 / 3^{\text {rd }}$ of CBCT measurements are statistically different from actual measurements, however this possibly is not clinically relevant 
TABLE OF CONTENTS

PAGE

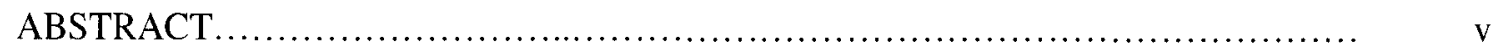

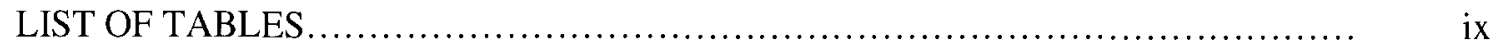

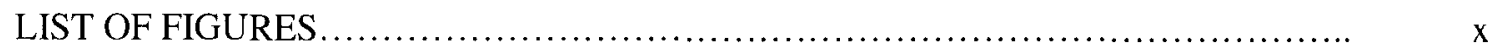

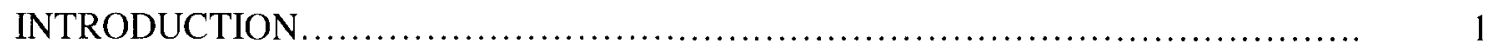

Limitations of Conventional Film Based Cephalometric Analysis............... 3

Digital Cephalometrics............................................. 3

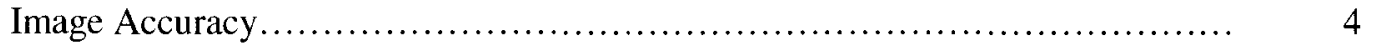

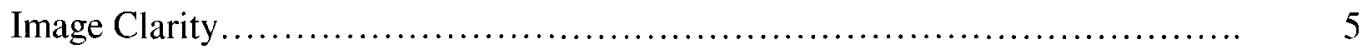

Advanced Imaging Modalities in Orthodontics............................. 8

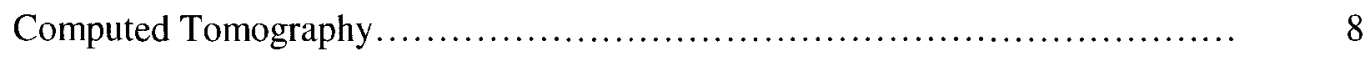

Fan Beam Acquisition............................................... $\quad 10$

Cone Beam Acquisition............................................. $\quad 10$

Cone Beam CT in Oral and Maxillofacial Imaging....................... 11

CBCT Advantages.............................................. 14

CBCT Applications................................................. $\quad 20$

Three Dimensional Cephalometrics.................................... 24

Conventional 3D CT Imaging Accuracy................................ 33

Potential of CBCT 3D Cephalometry................................... 37 
Overview........................................................ 39

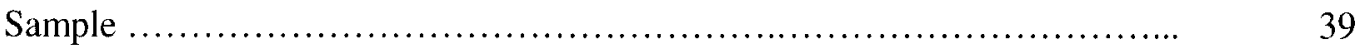

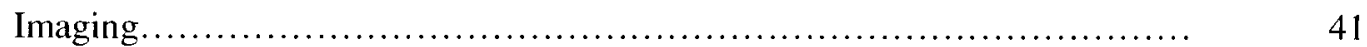

Lateral Cephalometric PSP Analysis................................... 46

CBCT Reconstruction and Analysis................................... 47

Measurement Analysis.......................................... 53

Data Collection..................................................... 56

Statistical Analysis............................................... 57

RESULTS........................................................ 58

Analysis of 3D Measurements....................................... 58

Measurement Reliability........................................... 58

Modality Accuracy........................................... $\quad 60$

Analysis of 2D Measurements ..................................... 65

Measurement Reliability......................................... 65

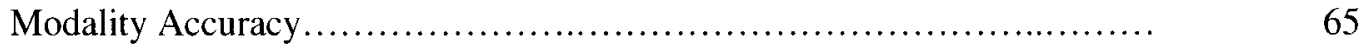

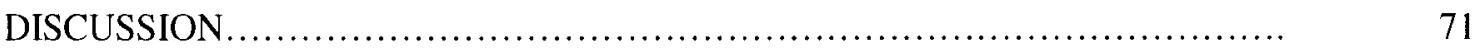

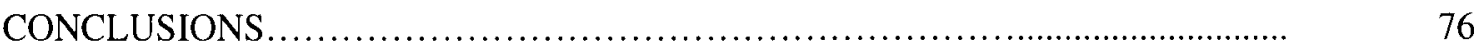

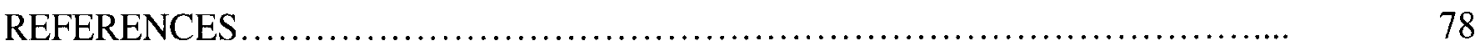

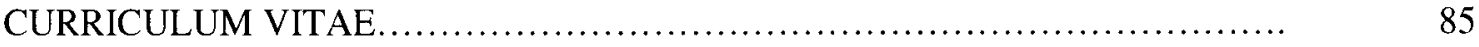




\section{LIST OF TABLES}

PAGE

1. Comparison of Maximum Resolution of Imaging Modalities..................... 7

2. Comparative Specifications of FDA-Approved CBCT Systems ............. 13

3. Radiation Exposures from CBCT and other Imaging Modalities ................ 16

4. Features of Imaging Plate and CBCT Digital Images ........................ 45

5. Definition of anthropometric topographic points Used as

Landmarks for the Measurements......................................... 53

6. Definition of Linear Planes used in the Cephalometric Analysis .................... 54

7. Average Measure intra-Class Correlation Coefficient for Triplicate Measurements on MidSagittal and Bilateral Linear Measurements by Multiple Observers on 23 skulls and for a Single Observer on CBCT 3D Reconstructions................................. 58

8. Comparison of Absolute and Percentage Mean Error for Mid-Sagittaland Bilateral Linear Measurements Between Dimensions of Planes on 23 Skulls and Measurements CBCT 3D

Reconstructions

9. Comparison of Absolute and Percentage Differences for Mid-Sagittal and Bilateral Linear Measurements Between Dimensions of Planes on 23 skulls and Measurements CBCT 3D Reconstructions.

10. Average Measure Intra-Class Correlation Coefficient for Multiple Measurements of Linear Dimensions by Multiple Observers on 23 Skulls and for a Single Observer on Photostimulable Storage Phosphor Cephalograms (PSP) and Simulated Cephalograms Generated from CBCT Volumetric Datasets (CBCT LC)....

11. Comparison of Absolute and Percentage Mean Error for Mid-Sagittal and Bilateral Linear Measurements Between Dimensions of Planes on 23 Skulls and Measurements Made on Photostimulable Storage Phosphor Cephalograms (PSP) and Simulated Cephalograms Generated from CBCT Volumetric Datasets (CBCTLC)......................................... 68

12. Comparison of Mean Linear Measurements ( \pm s.d.) Between Cephalometric Landmarks on Storage Phosphor and CBCT Derived Simulated Lateral Cephalometric Images of 23 Skulls 


\section{LIST OF FIGURES}

PAGE

1. X-ray Beam Projection Scheme Comparing Conventional or "Fan Beam"CT and Cone Beam

CT Geometry

2. Examples of Current Commercially Available CBCT Units for

Dento-Maxillofacial Radiology....

3. Comparison of Voxel Acquisition Features on Conventional "Fan Beam" CT

and "Cone Beam" CT......................................................... 17

4. Surface-Rendering Reconstruction of i-CAT CBCT Data Set ........................... 21

5. Application of maximum intensity projection algorithms to ray-sum projections .......... 27

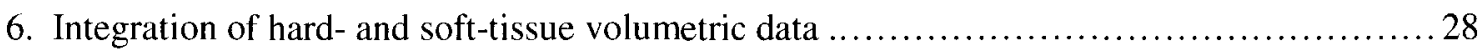

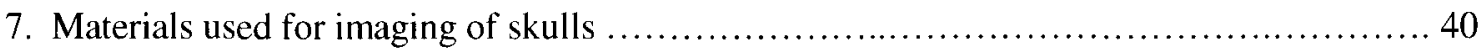

8. Skull Positioning for Lateral Cephalometric Radiograph............................. 4

9. Skull Positioning for Cone Beam Computed Tomography Scan .......................... 42

10. Scout images of a skull demonstrating initial position of specimen with excessive tilt and after

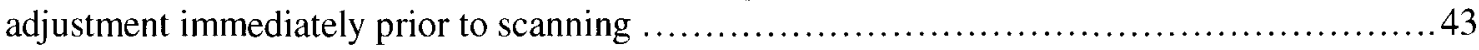

11. Example of Effect of Post Processing using PhotoShop on a Lateral Cephalometric Image

Before and After Image Equalization............................................... 44

12. Image Capture from Dolphin 3D Program Demonstrating the Segmentation

Screen.

13. Image capture from Dolphin 3D Program Demonstrating the "Build X-Rays" Screen for the Lateral Cephalometric Projections................................................48

14. PA 3D Volumetric Orientation ............................................. 49

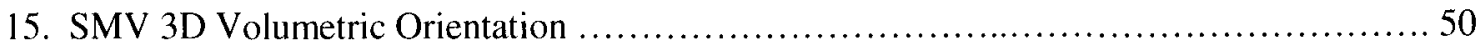

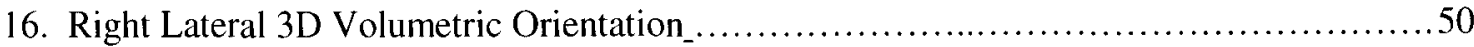


17. Superior 3D Volumetric Orientation 51

18. CBCT 3D Image Generated from Segmentation Demonstrating Identification of Landmarks and Linear Dimensions Measured in the Study......... 


\section{Chapter I}

\section{INTRODUCTION}

Radiographic imaging is an important diagnostic adjunct in the assessment of skeletal and dental relationships for the orthodontic patient. Historically, cephalometric analysis of the maxillofacial complex for orthodontic diagnosis and treatment planning has been determined from linear and angular measurements made on film or digital two dimensional (2D) cephalograms. Over the past decade, cone beam computed tomography (CBCT) specifically for imaging the maxillofacial region has been developed. CBCT is capable of providing submillimeter spatial resolution for images of the craniofacial complex with relatively short scanning times (10-70 sec.) and generally lower radiation dosages than ascribed to fan-beam or helical CT imaging methods.[1] Time and dose requirements for CBCT have been suggested to be a similar order of magnitude to other dental radiographic modalities.[2-4]

While CBCT images provide useful information for the orthodontist in regard to the position and location of impacted teeth and other pathologies, datasets can be used to generate both two dimensional (2D) planar projection and three dimensional (3D) surface or volume rendered images for use in orthodontic assessment and treatment planning. CBCT has a number of advantages compared to conventional CT imaging for cephalometric imaging including submillimeter resolution and reduced radiation exposure. Perhaps the most important clinical advantage is that CBCT volumetric datasets can be exported as DICOM files, imported into personal computers and third party software used to provide 3D reconstruction of the craniofacial skeleton. This possibility, and the increasing access of CBCT imaging in orthodontics, is a 
component of the paradigm that is directing imaging analysis from $2 \mathrm{D}$ cephalometry to $3 \mathrm{D}$ visualization of craniofacial morphology.[5] The availability of fast scan CBCT now provides multi-planar reformatted (MPR) imaging and the possibility of 3D image reconstruction of the maxillofacial complex with minimal distortion.

The linear accuracy of $\mathrm{CBCT}$ derived $2 \mathrm{D}$ and $3 \mathrm{D}$ reconstructions have not been previously reported for orthodontic assessment. Therefore this study was made to compare the accuracy of linear measurements made on 2D planar projections and 3D surface reconstructions generated using Dolphin 3D software (Chatsworth, CA) applied to CBCT DICOM datasets with direct measurements made on human skulls.

The aims of this study were to compare the:

1) reliability of linear measurements made from lateral cephalometric plain projection digital images and ray sum 2D simulated cephalometric projections derived from CBCT volumetric datasets using Dolphin 3D software (Chatsworth, CA) to direct measurements made on a sample of 25 human skulls.

2) accuracy of linear measurements made from lateral cephalometric plain projection digital images and ray sum 2D simulated cephalometric projections derived from CBCT volumetric datasets using Dolphin 3D software (Chatsworth, CA) to direct measurements made on a sample of 25 human skulls.

3) reliability of linear measurements made on CBCT derived 3D surface rendered volumetric images generated using Dolphin 3D software (Chatsworth, CA) to direct measurements made on a sample of 25 human skulls.

4) accuracy of linear measurements made on CBCT derived 3D surface rendered volumetric images generated using Dolphin 3D software (Chatsworth, CA) to direct measurements made on a sample of 25 human skulls. 


\section{The Limitations of Conventional Film Based Cephalometric Analysis}

Since 1931, 2D transmission X-ray images have been used to identify specific skull landmarks from which vertical and antero-posterior skeletal and dental dimensions are derived. These lateral skull radiographs, made under standard projection conditions, are currently the image format used in the analysis of both bony and soft tissue landmarks for orthodontic diagnostic purposes as well as for growth evaluation. Post-treatment cephalograms may also serve to evaluate orthodontic treatment outcome and success. Traditionally, cephalograms have been utilized for their cost and radiation efficiency as well as their ease of use. However, characteristics related to projection geometry such as inherent magnification, superimposition of bilateral anatomic structures and distortion as well as the nature of the detector system can diminish accuracy and reliability in evaluation of craniofacial structures and anomalies.

\section{Digital Cephalometrics}

Many conventional film based cephalostats are being replaced by digital systems. The advantages of digital cephalometric imaging versus conventional film based modalities include instantaneous imaging, lack of user and performance sensitive chemical developing processes, facilitated patient communication, ease of storage and retrieval, and the ability to enhance images for size or contrast.[6-8] Currently, three methods are available to produce digital images: digitization of film radiographs, solid state systems (charge-coupled device - CCD; complementary metal oxide semiconductor - CMOS; thin film transistor - TFT), and photostimulable phosphor systems (PSP).[6-10] Secondary capture through digitization of film radiographs can be achieved using a scanner with a radiograph/transparency adaptor. This method allows for digitization of all film radiographs, however, it is important to note that the quality of scanned images cannot exceed the quality of the original radiograph.[8] CCD detectors are sometimes incorrectly listed in the dental literature as direct digital imaging modalities, because the output is transferred via cables to a computer system and digitized by the frame grabber.[10] 
They are in fact usually indirect imaging devices as they employ a scintillator in most cases, similar to that used with indirect screen film. CCD is the more costly option for cephalometry in orthodontics. Photostimulable phosphor systems (PSP) are reusable and use an imaging plate that superficially resembles scintillating screens used for traditional extra-oral radiography.[8] These phosphor plates are illuminated by a solid state laser beam to release photoluminesence. The released light is photomultiplied and collected by a digital imaging chip and the signals are then analyzed by the image processor.[6-10]

Image quality in cephalometrics either analog or digital, is determined by two parameters: image accuracy and image quality

\section{Image Accuracy}

Cephalometric radiography is based on use of a standardized, reproducible head position in relation to the X-ray source and detector. Ear rods are used to prevent the head from rotating about the vertical, sagittal and transverse axes. A third reference, a nasal positioner, may be used to prevent the nose from rotating about the transverse axis. However, when the device is used to contact the external auditory meatus and soft tissues of the patient, the head can be incorrectly positioned sagittally, antero-posteriorly, or vertically, as the head can be slightly rotated within the head-holding device.

Due to these errors caused by different positioning of the head, cephalometric linear and angular measurements can vary depending on the different locations of anatomic structures against the central ray. Malkoc et al. found that horizontal linear and angular measurements between the horizontal planes on lateral cephalograms were subject to changes from $16.1 \%$ to $44.7 \%$ with a $14^{0}$ rotation of the head position. For PA cephalograms, they reported horizontal linear measurements, particularly mandibular length, were subject to a projection error of up to $34.9 \%$ with head rotation.[11] 
2D transmission cephalometric radiography is subject to inherent geometric differential magnification. All resulting images are magnified, because $\mathrm{X}$-rays do not radiate parallel to the whole part of the projected object. The ratio of magnification varies in the different planes, and hence the image is distorted. In cephalometric radiography, each landmark is not located at the same distance from the focal area of the anode. As a result, changes may be caused in the relationship of the landmarks to one and another on the cephalogram.[12,13]

\section{Image Clarity}

Clarity is the term used to describe the visibility of diagnostically important detail in an image. It is determined by two factors; radiographic contrast and image quality. Radiographic contrast is the ability to determine the difference in density between areas of the image. For both analog radiographic film and digital detectors contrast depends on radiation energy, subject contrast and scatter; however, a fourth element, detector contrast, is also a factor due to inherent dissimilarity between detection systems.

Image quality is defined as the ability to record each point in an object as a point on the detector. For film imaging it is partly determined by radiographic mottle (a feature of the film screen system and film graininess), sharpness and resolution. For digital detectors, seven essential characteristics should be considered: size of active area, signal-to-noise ratio, contrast resolution, spatial resolution, modulation transfer function, quantum efficiency and detective quantum efficiency.[8,15,16]

1. Active Area: No standard active areas have been specified for digital imaging systems comparable to the ISO/ANSI standards for the conventional X-ray film. For solid-state extra-oral systems, a narrower receptor is sometimes used for detecting the image and the image is formed via virtual movement. The plates used in storage phosphor systems can be cut to exactly replicate the size of their film counterparts and exposure is similar to cassette motion. 
2. Signal-to-Noise Ratio: For any imaging system, the useful signal must be compared with background noise which, in analog film, is comparable to the base density plus fog. The base plus fog density for conventional processed film is about $1 / 20$ of the signal density. Both newer CCD and PSP systems outperform film in signal-to-noise ratios (SNS) if base plus fog is considered to be equivalent to SNR. Newer CCD systems exhibit a SNR of approximately 50:1. No matter what the system, all SNRs improve with increased radiation dose.

3. Contrast Resolution: In imaging, the ability to separate and distinguish depends upon contrast between adjacent structures. Using current display monitors, working on the WINDOWS system, the maximum number of gray levels is 242 because the operating system in the past has been reported to use 14 shades and the total supported shades is 256 for an 8 -bit display. This is usually the maximum contrast resolution available.

4. Spatial Resolution: Resolutions comparable to those of conventional cephalometric radiographs are readily obtained using digital systems/detectors. Table 1 compares detector resolution for a number of currently available conventional film, CCD systems and PSP systems.[14]

5. Modulation Transfer Function: MTF is the ability of the detector to transfer the modulation of the input signal at a certain frequency to its output and deals with the display of contrast and object size. MTF is responsible for converting contrast values of different sized objects into contrast intensity levels within the image. Therefore, modulation transfer function (MTF) is a useful measure of true or effective resolution, because it accounts for the amount of contrast and blur over a range of spatial frequencies.[15] 
6. Quantum Efficiency: The average number of electrons photoelectrically emitted from a photocathode per incident photon of a given wavelength in a phototube. Quantum efficiency (QE) is a quantity defined for a photosensitive device such as photographic film or a charge-coupled device (CCD) as the percentage of photons hitting the photoreactive surface that will produce an electron-hole pair. It is an accurate measurement of the device's sensitivity. It is often measured over a range of different wavelengths to characterize a device's efficiency at each energy.

Photographic film typically has a QE of much less than 10\%, while CCDs can have a $\mathrm{QE}$ of well over $90 \%$ at some wavelengths.[16]

7. Detective Quantum Efficiency: Detective quantum efficiency (DQE) refers to the efficiency of a detector in converting incident x-ray energy into an image signal, and is calculated by comparing the signal-to-noise ratio at the detector output with that at the detector input as a function of spatial frequency. It is dependent upon radiation exposure, spatial frequency, MTF, and detector material as well as the quality of the radiation applied. High DQE levels indicate that less radiation is needed to achieve identical image quality, therefore, improved image quality can be obtained by increasing DQE and leaving radiation exposure constant. An ideal detector would have a DQE of 1, indicating that all radiation energy is absorbed and converted into image information. However, in clinical practice the DQE of digital detectors is limited to roughly 0.45 at 0.5 cycles $/ \mathrm{mm}$.[15]

Table 1. Comparison of maximum resolution of Imaging Modalities

\begin{tabular}{lcccc}
\hline & Analog Film (T-Mat G) & Storage Phosphor & \multicolumn{2}{c}{ CCD-Based } \\
\cline { 2 - 5 } $\begin{array}{l}\text { Maximum } \\
\text { Resolution }\end{array}$ & OP 100 & OP 100 DenOptix & $\begin{array}{c}\text { OP 100 } \\
\text { DigiPan }\end{array}$ & $\begin{array}{c}\text { Prototype OP } \\
\text { 100 D }\end{array}$ \\
\hline $\mathrm{lp} / \mathrm{mm}$ & $>5 ;<6$ & $>5 ;<6$ & $>4.47 ;$ & $>5 ;<6$ \\
& & & $<4.86$ & \\
\hline
\end{tabular}


Digital cephalometric images have been reported to be clinically and diagnostically acceptable for orthodontic treatment planning purposes; $[7-10]$ however, there is a need to further compare various radiographic modes of image capture for cephalometry such as conventional vs. digital radiographs and scanned conventional films vs. digital radiographs.[9]

\section{Advanced Imaging Modalities in Orthodontics}

Advanced technologies are those that acquire images using a digital receptor and that provide the possibility of multiple planar reformatting (MPR). In these modalities, multiple images become truly inter-relational in that direct comparisons in multiple planes can be made. Some advanced technologies that are available to image the maxillofacial complex include magnetic resonance imaging (MRI), fan-beam computerized tomography (CT), and Cone Beam Computed Tomography (CBCT). The basis of advanced imaging is the recording of transmitted, attenuated $\mathrm{x}$-rays of an object by a digital receptor to produce a digital image. Digital images are composed of pixels, or picture elements, arranged in a 2-dimensional rectangular grid. Each pixel has a specific size, color, intensity value, and location within an image and is the smallest element of the digitized image. In general, radiographic images use gray color with an intensity value between 8 bits ( 256 shades of gray) and 12 bits (4096 shades of gray). The number of pixels per given length of an image (pixels/mm), the number of gray levels per pixel (bits), and the management of the gray levels determine image resolution or the degree of sharpness of the image. A voxel is a three-dimensional stack of bitmapped images, (each voxel having a height, width, and thickness) and is the smallest element of a three-dimensional image.[18]

\section{Computed Tomography}

In addition to utilizing images that are digital, technological advancements now allow dentistry to create images of the maxillofacial region in 3-dimensions. The first 3D imaging technique used in dentistry was computerized tomography (CT). CT units can be divided into two 
groups based on the acquisition X-ray geometry: fan beam and cone beam (Figure 1). Essentially, the latter method for capturing an image differs from the traditional CT in that it does so by cone beam volumetric tomography. A three-dimensional X-ray beam passes through the object volume investigated. Simultaneously, the beam hits a two-dimensional extended detector and forms a true volumetric acquisition in a single scan (Figure 1).

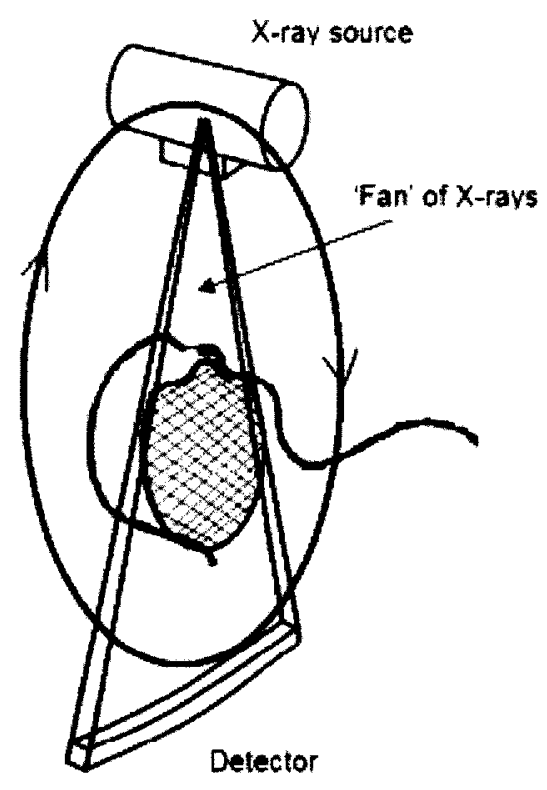

a.

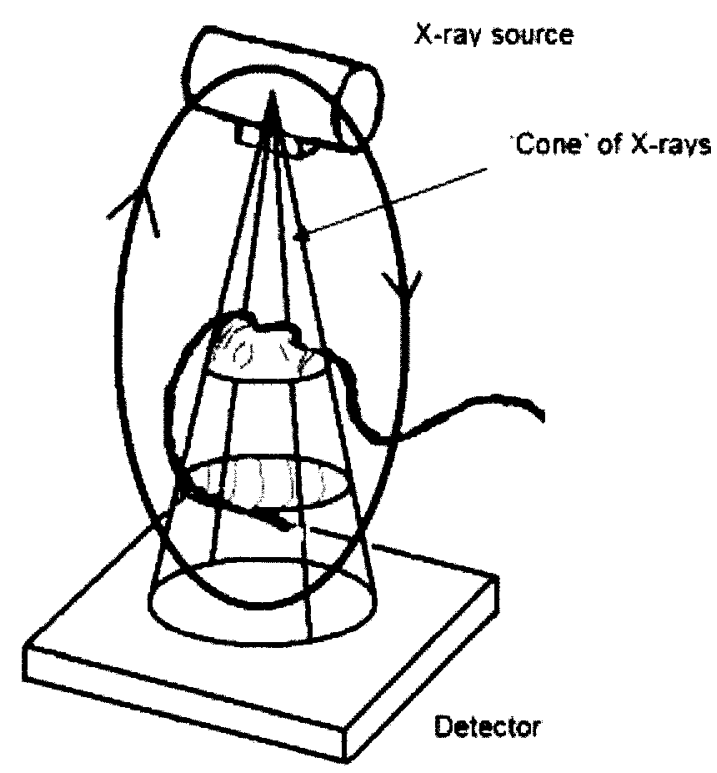

b.

Figure 1. X-ray beam projection scheme comparing conventional or "fan beam" CT (a.) and cone beam CT (b.) geometry (Images courtesy Predag Sukovic, Xoran Technologies, Ann Arbor, MI $\underline{\text { USA) }}$ 


\section{Fan beam acquisition}

CT scanners consist of an X-ray source and detector mounted on a rotating gantry (Figure la). During one rotation of the gantry, the detector detects the flux (I,) of x-rays that have passed through the patient. These integrals constitute so-called "raw data" that are then fed into an image reconstruction method that generates cross-sectional images whose pixel values correspond to linear attenuation coefficients. Such machines acquire image data through a thin, broad, fan shaped X-ray beam which is transmitted through the patient. These scanners use a large, arcshaped detector that acquires an entire projection without the need for translation. This rotateonly design, frequently referred to as "fan-beam", utilizes the power of the X-ray tube much more efficiently than the previous generations. Recent advances in CT include multi-row detectors and spiral scanning. Multi-row scanning allows for the acquisition of several cross-sectional slices at the same time, reducing scanning times. Today's state-of-the-art scanners have 64 rows of detectors. Spiral (helical) scanning incorporates a moving table with the rotating X-ray tube, with the net effect that the X-ray tube describes a helical path around the patient.

\section{Cone Beam Acquisition}

CBCT scanners often utilize a 2D flat panel detector (Figure 1b), which allows for a rotation of the gantry to generate a scan of the entire region of interest using a 180 degree or greater rotation (up to two 360 degree rotations), as compared to conventional CT scanners whose multiple "slices" must be stacked to obtain a complete image. In comparison with conventional fan-beam or spiral-scan geometries, cone-beam geometry has higher efficiency in X-ray use, inherent quickness in volumetric data acquisition, and potential for reducing the cost of CT. Conventional fan-beam scans are obtained by illuminating an object with a narrow, fan-shaped, beam of X-rays. The X-ray beam generated by the tube is focused to a fan-shaped beam by rejecting the photons outside the fan, resulting in a highly inefficient use of the X-ray photons. Further, the fan-beam approach requires reconstructing the object slice-by-slice and then stacking 
the slices to obtain a 3D representation of the object. Each individual slice requires a separate scan and separate $2 \mathrm{D}$ reconstruction. The cone beam technique, on the other hand, requires only a single scan to capture the entire object with a cone of X-rays. Thus, the time required to acquire a single cone-beam projection is the same as that required by a single fan-beam projection. However, since it takes several fan beam scans to complete the imaging of a single object, the acquisition time for the fan beam tends to be much longer than with the cone beam. Although it may be possible to reduce the acquisition time of the fan beam method by using a higher power $\mathrm{X}$-ray tube, this increases the cost and size of the scanner as well as the electric power consumption, thus making the design unsuitable for a compact scanner.

Although CBCT equipment has existed for over two decades, only recently has it become possible to develop clinical systems that are both inexpensive and small enough to be used in operating room, medical offices, emergency rooms, and intensive care. Four technological and application-specific factors have converged to make this possible. First, compact and high-quality flat-panel detector arrays were developed. Second, the computer power necessary for cone-beam image reconstruction has become widely available and is relatively inexpensive. Third, $\mathrm{x}$-ray tubes necessary for cone-beam scanning are orders-of-magnitude less expensive than those required for conventional CT. Fourth, by focusing on head/neck scanning only, one can eliminate the need for sub-second gantry rotation speeds that are needed for cardiac and thoracic imaging. This significantly reduces the complexity and cost of the gantry.

\section{CBCT in Oral and Maxillofacial Imaging}

Currently available CBCT units in the United States are the NewTom QR DVT 3G

(Quantitative Radiology s.r.l., Verona, Italy), CB MercuRay (Hitachi Medical Corp., Chiba-ken, Japan), i-CAT (Danaher/Imaging Sciences International, Hatfield, PA), Iluma, (Kodak Dental Imaging, Atlanta, GA/Imtec Imaging, Ardmore, OK, USA), Galileos, (Sirona Dental Systems, Charlotte NC), and 3D Accu-i-tomo - XYZ Slice View Tomograph, (J. Morita Mfg. 
Corp., Kyoto, Japan), Promax (Planmeca Oy, Helsinki, Finland). All but the two are capable of imaging the skull to include most anthropometric landmarks used in cephalometric analysis (Figure 2)(Table 2).

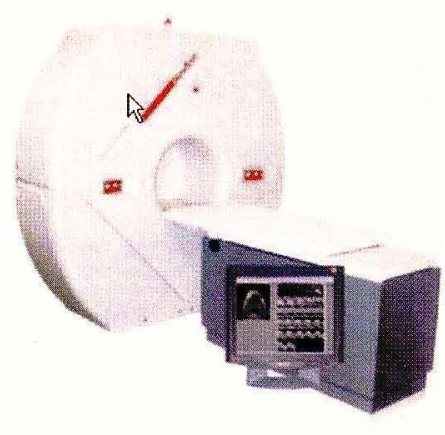

a.

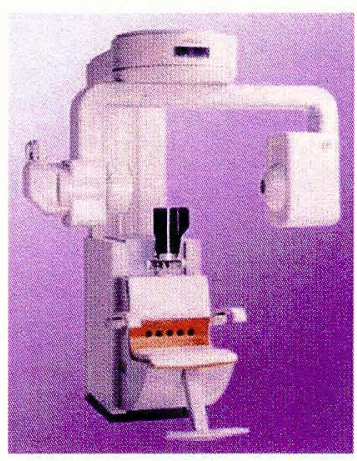

b.

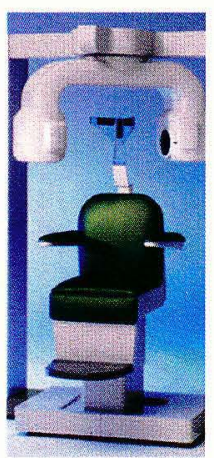

c.

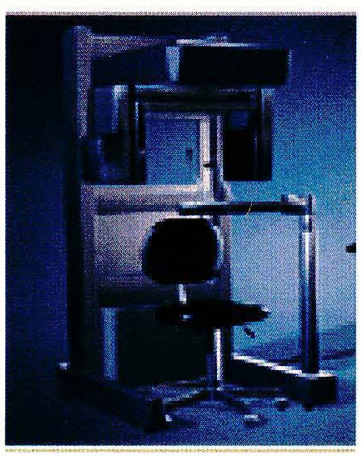

d.

Figure 2: Examples of current commercially available CBCT units for dento-maxillofacial radiology. a. Newtom 9000G (Quantitative Radiology, Verona, Italy) b. CB MercuRay (Hitachi, Medical Corp., Kashiwa-shi, Chiba-ken, Japan) c. 3D Accuitomo - XYZ Slice View Tomograph, (J. Morita Mfg. Corp., Kyoto, Japan) d. i-CAT (Danaher/Imaging Sciences International, Hatfield, PA) 
Table 2. Comparative Specifications of FDA-Approved CBCT Systems (Modified from: [19])

\begin{tabular}{|c|c|c|c|c|c|c|}
\hline Vendor & AFP-Dent-X & $\begin{array}{l}\text { J. Morita Mnfr. } \\
\text { Corp. }\end{array}$ & $\begin{array}{c}\text { Imaging Sciences } \\
\text { Intl. }\end{array}$ & $\begin{array}{c}\text { Hitachi Medical } \\
\text { Systems }\end{array}$ & Kodak Dental Systems & $\begin{array}{c}\text { Sirona Dental } \\
\text { Systems }\end{array}$ \\
\hline CBCT Name & NewTom $3 \mathrm{G}$ & 3D Accu-i-tomo & $\mathrm{iCAT}$ & CB MercuRay & $\begin{array}{l}\text { ILUMA Ultra Cone } \\
\text { Beam CT Scanner }\end{array}$ & Galileos \\
\hline Headquarters & Elmsford, NY & Kyoto, Japan & Hatfield, PA & Tokyo, Japan & Ardmore, $\mathrm{OK}$ & Charlotte, $\mathrm{NC}$ \\
\hline $\begin{array}{l}\text { Initial FDA/CDRH } \\
\text { Approval }\end{array}$ & March 2001 & May 2003 & October 2003 & October 2003 & November 2005 & July 2006 \\
\hline Grayscale & 12 Bit & $12 \mathrm{Bit}$ & 12 Bit & 12 Bit & 14 Bit & 12 Bit-sw 16 bit \\
\hline $\begin{array}{l}\text { Foot Print ( } \mathrm{H} \times \mathrm{W} \times \\
\text { D) (meters) }\end{array}$ & $2 \times 2 \times 0.74$ & $2.08 \times 1.62 \times 1.2$ & $1.83 \times 1.12 \times 1.49$ & $2.25 \times 1.96 \times 1.9$ & $1.06 \times 1.42 \times 2.15$ & $2 \times 1.60 \times 1.60$ \\
\hline Image Detector & $\begin{array}{c}\text { Image } \\
\text { intensifier/CCD }\end{array}$ & $\begin{array}{l}\text { Cesium iodide } \\
\text { Csl/amorphous } \\
\text { silicon flat panel }\end{array}$ & $\begin{array}{l}\text { Cesium iodide } \\
\text { Csl/amorphous } \\
\text { silicon flat panel }\end{array}$ & $\begin{array}{c}\text { Image } \\
\text { intensifier/CCD }\end{array}$ & $\begin{array}{c}127-\text { micron } \\
\text { amorphous silicon flat } \\
\text { panel }\end{array}$ & $\begin{array}{c}\text { Proprietary Siemens } \\
\text { Technology }\end{array}$ \\
\hline Rotation per scan & 1 & 1 & 1 or 2 & 1 & Single $360^{\circ}$ Rotation & $\begin{array}{l}210^{\circ} 200 \text { single } \\
\text { shots }\end{array}$ \\
\hline Patient Positioning & Supine & Seated & Seated & Seated & $\begin{array}{l}\text { Seated with rear-head } \\
\text { stabilization }\end{array}$ & Standing/sitting \\
\hline $\begin{array}{l}\text { Pre-Installed } \\
\text { Software }\end{array}$ & NewTom $3 G$ & i-Dixel & Xoran Cat & CBWorks & ILLUMINAVISION3D & SIDEXIS/GALAXIS \\
\hline Scan time (s) & $5.6-36$ & 17 & $10-4$ & 9.6 & $20-40$ & 14 \\
\hline $\mathrm{mA}$ & $15 \max$ & $1-10$ & $3-5$ & $2-15$ & $4-7$ & $5-7$ \\
\hline$K_{V}$ & $110 \max$ & $60-80$ & 120 & 120 & 120 & 85 \\
\hline Scan diameter $(\mathrm{cm})$ & 25 & $4-6$ & 17 & 25 & $17-19$ & 15 \\
\hline Scan height $(\mathrm{cm})$ & $15-30$ & $4-6$ & $6-27.4$ & $15-30$ & $10-19$ & 15 \\
\hline Slice width $(\mathrm{mm})$ & $0.1-0.5$ & $0.125-2.0$ & $0.2-0.4$ & $0.1-0.5$ & $0.0936-0.4$ & $\begin{array}{c}\text { Voxel size: } 150 / 300 \\
\text { microns }\end{array}$ \\
\hline
\end{tabular}


The cone-beamed technique uses a single scan in which the x-ray source and a reciprocating $\mathrm{x}$-ray detector are attached by a "U-" or C-arm and rotate around the patient's head acquiring multiple projection scan images. The field of view (FOV) or area of interest able to be covered is primarily dependent on the detector size (Image intensifier/CCD, CMOS or a:SiTFT field dimensions) and beam projection geometry. While the FOV can be varied by the application of zoomed image reconstruction (e.g. MercuRay [Hitachi, Medical Corp., Kashiwa-shi, Chiba-ken, Japan]) this is usually done at the loss of image resolution.

Data is obtained from a series of multiple single projection scan images as the x-ray source rotates around the patient's head. The number of projection scans comprising the data set is variable, depending on the system, and is referred to as the frame rate. With a higher the frame rate, more information is available to reconstruct the image: however, the signal-tonoise of individual MPR slices is also higher. The advantage of a higher frame rate is that it reduces metallic artifact, but this is usually accomplished with a longer scan time and therefore radiation dosage. A number of units have variable exposure cycles. For example, the i-CAT has a choice of 10 second, 20 second (standard) and 40 second scans. The number of basis images produced is roughly proportional to the exposure time reflecting a relatively constant frame rate.

\section{CBCT Advantages}

Because CBCT provides images of high contrasting structures well, it is extremely useful for evaluating osseous structures. Combined with the limitation of FOV, CBCT is therefore well suited towards the imaging of the craniofacial area. Currently, limitations exist in the application of this technology for soft tissue, $[23,24]$ but efforts are being directed towards the development of software algorithms to improve signal-to-noise and optimize available contrast.

The utilization of CBCT technology in clinical practice provides a number of 
potential advantages compared with conventional CT related to the beam limitation, scan time reduction, and image display. Specifically the advantages of CBCT are as follows [19]:

1) Variable $\mathrm{FOV}$. Collimation of the CBCT primary x-ray beam enables limitation of the $\mathrm{X}$-radiation to the area of interest. For most (but not all) CBCT systems an optimal FOV (field of view) can be selected for each patient based on suspected disease presentation and the region to be imaged. For example, radiographic investigation of the mandible can be performed by selection of an appropriate FOV. This functionality provides additional dose savings by limiting the irradiation field to fit the FOV, with a resulting exposure reduction to the patient.

2) Sub-millimeter resolution. Maxillofacial diagnostic CBCT units all use mega-pixel solid state devices for $\mathrm{x}$-ray detection providing a minimal voxel resolution of $<$ $0.25 \mathrm{~mm}$ isotropically, exceeding the specifications of commonly used multi-slice CT systems in terms of spatial resolution.

3) High speed scanning. Because CBCT acquires all projection images in a single rotation, scan time can be reduced enormously. In the fan-beam CT system, particularly in high resolution, each thin slice thickness can take up to several tens of seconds. However, various CBCT systems can scan an entire head in 10 seconds or less. While faster scanning times usually mean less number of projections from which to reconstruct the MPR images, motion artifact due to subject movement is reduced. Reconstruction times vary depending on FOV and scanning speed.

4) Dose reduction. Preliminary reports indicate that CBCT patient absorbed dose can be significantly reduced when compared to conventional CT used with manufacturer recommended sequences.[25] The Newtom 9000 system (Quantitative Radiology, Verona, Italy) also has an automatic exposure control device which selects the starting intensity of the x-ray beam, depending on the size of the patient, and modifies the anodic current according to the density of the transversed tissues (maximum value 
$15 \mathrm{~mA}$ ). This reduces the patient absorbed dose to approximately that of a film-based periapical survey of the dentition [26-28] or 1-7 times that of a single panoramic image (varying with the panoramic system used).[29, 30] Depending on bone density, a traditional CT exposes the patient to approximately 6-8 times that amount when evaluating either the maxilla or mandible [29] and 15 times the amount of CBCT exposure when imaging both the maxilla and mandible.[31] Table 3 compares radiation exposures from $\mathrm{CBCT}$ and other imaging modalities.

Table 3. Radiation Exposures from CBCT and other Imaging Modalities (Modified from: [19])

\begin{tabular}{|c|c|c|c|c|c|}
\hline $\begin{array}{l}\text { Machine \& } \\
\text { Technique }\end{array}$ & $\begin{array}{c}\text { Effective Dose } \\
(\mu S v) \text { using } \\
1990 \text { ICRP }\end{array}$ & $\begin{array}{c}\text { Dose in single } \\
\text { panoramic } \\
\text { multiples }\end{array}$ & $\begin{array}{c}\text { Dose in days } \\
\text { per capita } \\
\text { background }\end{array}$ & $\begin{array}{c}\text { Dose in \% } \\
\text { medical CT } \\
\text { equivalent }\end{array}$ & $\begin{array}{c}\text { Dose \% annual } \\
\text { per capita } \\
\text { background }\end{array}$ \\
\hline $\begin{array}{l}\text { NewTom 3G } \\
\text { full (12") FOV }\end{array}$ & 45 & 7 & 4 & 2.1 & 1.2 \\
\hline $\begin{array}{l}\text { NewTom } 3 \mathrm{G} \\
\text { w/ chin tilt \& } \\
\text { thyroid shield }\end{array}$ & 28 & 4 & 3 & 1.3 & 0.8 \\
\hline $\begin{array}{l}\text { CB MercuRay } \\
\text { full (12") FOV } \\
10 \mathrm{~mA}-100 \mathrm{kV}\end{array}$ & 477 & 74 & 48 & 22.7 & 13.2 \\
\hline $\begin{array}{l}\text { CB MercuRay } \\
\text { P (9") FOV }\end{array}$ & 289 & 45 & 29 & 13.8 & 8 \\
\hline $\begin{array}{l}\text { CB MercuRay } \\
\text { I (6") FOV } 125 \\
\text { (maxillary) }\end{array}$ & 169 & 26 & 17 & 12 & 4.7 \\
\hline $\begin{array}{l}\text { CB MercuRay } \\
\text { I (6") FOV w/ } \\
\text { chin tilt }\end{array}$ & 125 & 19 & 12 & 5.9 & 3.5 \\
\hline $\begin{array}{l}\text { iCAT full } \\
\text { (12") FOV }\end{array}$ & 135 & 21 & 13 & 6.4 & 3.7 \\
\hline $\begin{array}{l}\text { iCAT w/ chin } \\
\text { tilt \& thyroid } \\
\text { shield }\end{array}$ & 57 & 9 & 6 & 2.7 & 1.6 \\
\hline $\begin{array}{l}\text { Panoramic } \\
\text { (OrthoPhos } \\
\text { Plus DS) }\end{array}$ & 6 & 1 & 1 & 0.3 & 0.3 \\
\hline $\begin{array}{l}\text { CT maxilla \& } \\
\text { mandible }\end{array}$ & 2100 & 385 & 243 & 100 & 58.3 \\
\hline CT maxilla & 1400 & 164 & 103 & 100 & 38.9 \\
\hline Galileos & Pending & Pending & Pending & Pending & Pending \\
\hline
\end{tabular}


5) Voxel isotropy. The smallest element of a volumetric dataset is the voxel. Voxels have a dimension of thickness as well as the height and width of a 2-dimensional pixel.

Voxel representation and therefore resolution are dependent on lateral slice thickness, determined principally by the matrix size of the detector and longitudinal slice thickness (body axis), which in conventional CT is determined by slice pitch, a function of gantry motion. Therefore, conventional CT data is obtained anisotropically, where axial voxel dimensions are equal, but where coronal dimensions are greater and are determined by slice pitch, usually a $1 \mathrm{~mm}$ minimum (Figure 3a). Therefore, spatial resolution in the longitudinal slice (body axis direction) is poorer than that of lateral slice. On the other hand, the CBCT uses a 2D detector and the same high resolution is obtained in the longitudinal slice (body axis direction) and lateral slice (transverse direction). This voxel representation is known as isotropic (Figure 3b). Because of this characteristic, coronal multi-planar reformatting (MPR) of CBCT data has the same resolution as axial data.

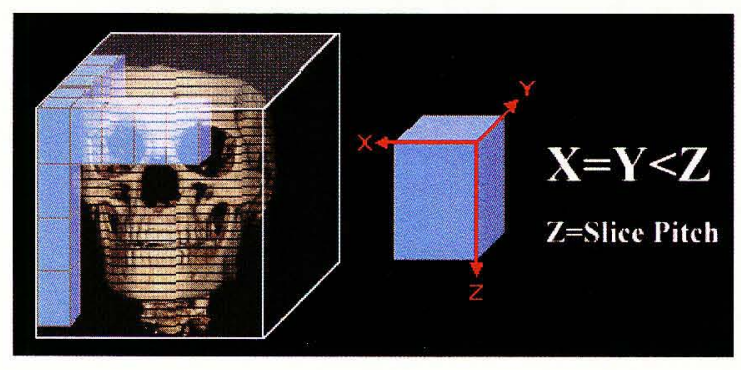

a. Anisotropic Voxel

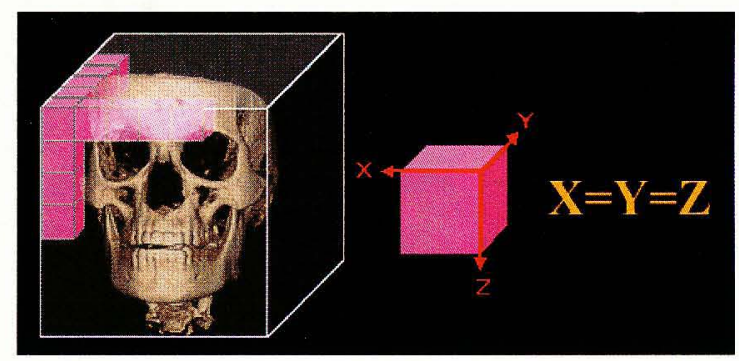

b. Isotropic Voxel

Figure 3: Comparison of voxel acquisition features on conventional "fan beam" CT (a.)_and "cone beam" CT (b.) 
6) Real time analysis and manipulation. Although conventional CT data is inherently digital, images are supplied to referring clinicians as fixed format, hard copies on film transparencies. CT image algorithms necessary to reformat the data require the computing power of workstations. While such data can be "converted" and imported into proprietary programs for use on personal computers (e.g. Simplant and Simplant CMF: Materialise, Ann Arbor, MI, USA; Procera: Nobel Biopharma, Sweden)) this process is expensive and requires an intermediary stage that potentially extends the diagnostic phase. Reconstruction of CBCT data is performed natively by a personal computer. In addition, availability of software to the user, not just the radiologist, is available either via direct purchase or innovative "per use" license from the various vendors (e.g. Danaher/Imaging Sciences International). Further, because the original data is isotropic, it can theoretically be re-orientated such that the patient's anatomic features are re-aligned. At least one manufacturer has incorporated this capability into both their acquisition and viewer software (Imaging Sciences International). Finally, the availability of cursor-driven measurement algorithms provides the clinician with an interactive capability for real-time dimensional assessment.

7) Display modes unique to maxillofacial imaging. CBCT software can reconstruct the projection data to provide as many as 512 coronal, sagittal and axial MPR frames. Common to all standard viewing layouts are usually preset options providing display of coronal, sagittal and axial MPR frames. Basic manipulations include zoom or magnification, window/level, the capability to add annotation and measurement algorithms. Some proprietary software is capable of advanced imaging processing functions including:

a. Oblique MPR such as linear oblique MRP (useful for TMJ assessment) or curved oblique MPR providing a "panoramic" image.

b. Cross-sectional imaging provides sequential multi-slice images usually 
perpendicular to the "panoramic" MPR, useful in implant site assessment or lateral oblique MPR which has application in the assessment of the TMJ.

c. Variable slice thickness adjustments for oblique MPR images provide the clinician with the possibility of producing undistorted plain radiograph projection-like images. One example is the creation of a cephalometric plane projection, either sagitally or coronally. This is developed by increasing the slice thickness of a mid sagittal MPR plane to the width of the head (130-150mm) to produce an image composed of the summed voxels, an image which has been referred to as "Ray Sum". This image can be exported and analyzed using third party proprietary cephalometric analysis software. This functionality may potentially reduce the need for additional radiographic exposure. Oblique MPR images along the curve of the dental arch with slice thickness comparable to the in-focus image layer of panoramic radiographs $(25-35 \mathrm{~mm})$ can also be individually created to provide a "panoramic" radiograph customized for each patient. However, unlike conventional panoramic radiographs, these MPR images are undistorted and are free from projection artifacts.

d. Maximum intensity projection (MIP). This is a three dimensional volume rendering technique which is used to visualize high-intensity structures within volumetric data. At each pixel, the highest data value encountered along a corresponding viewing ray is depicted. In combination with oblique MPR and selection of wide slice thickness, this technique is capable of providing 3D surface images. This is particularly useful in cephalometric radiography.

e. Surface and volume rendering algorithms are available with some software which provides three-dimensional reconstruction and presentation of data that can be interactively adjusted.

f. Previously unavailable for viewer use, numerous image enhancement algorithms 
are now able to optimize image presentation. While the diagnostic efficacy of the application of these algorithms is yet to be studied, preliminary investigations indicate that sharpening and edge filters show the greatest potential in refining anatomic structures for interpretation.

8) Variable acquisition modes. Many, but not all, units are capable of variable scanning fields of view (FOV) from large FOV capable of imaging the entire craniofacial complex (currently up to $13.2 \mathrm{~cm}$ with i-CATand $19 \mathrm{~cm}$ with CB MercuRay to limited FOV for specific diagnostic tasks. The Iluma at the time of this research was limited to one full FOV.

\section{CBCT Applications}

The advent of CBCT technology has paved the way for the development of relatively small and inexpensive CT scanners dedicated for use in dento-maxillofacial imaging. Manufacturers' web sites provide numerous examples illustrating the value of $\mathrm{CBCT}$ in evaluating the position of impacted teeth, supernumerary teeth, maxillary sinus position (in reference to maxillary molars), mandibular canals, and lingual nerves. Maxillofacial applications of CBCT imaging have also been reported for oral and maxillofacial surgery, [34-38] implantology, [39-42] and craniofacial assessment in orthodontics.[43-48] A number of researchers have reported high dimensional accuracy of maxillofacial CBCT in measurement of facial structures.[42,49] Other examples of this modality's uses include surgical assessment of pathology, and preoperative/postoperative assessment of craniofacial fractures.[24,28,33] 


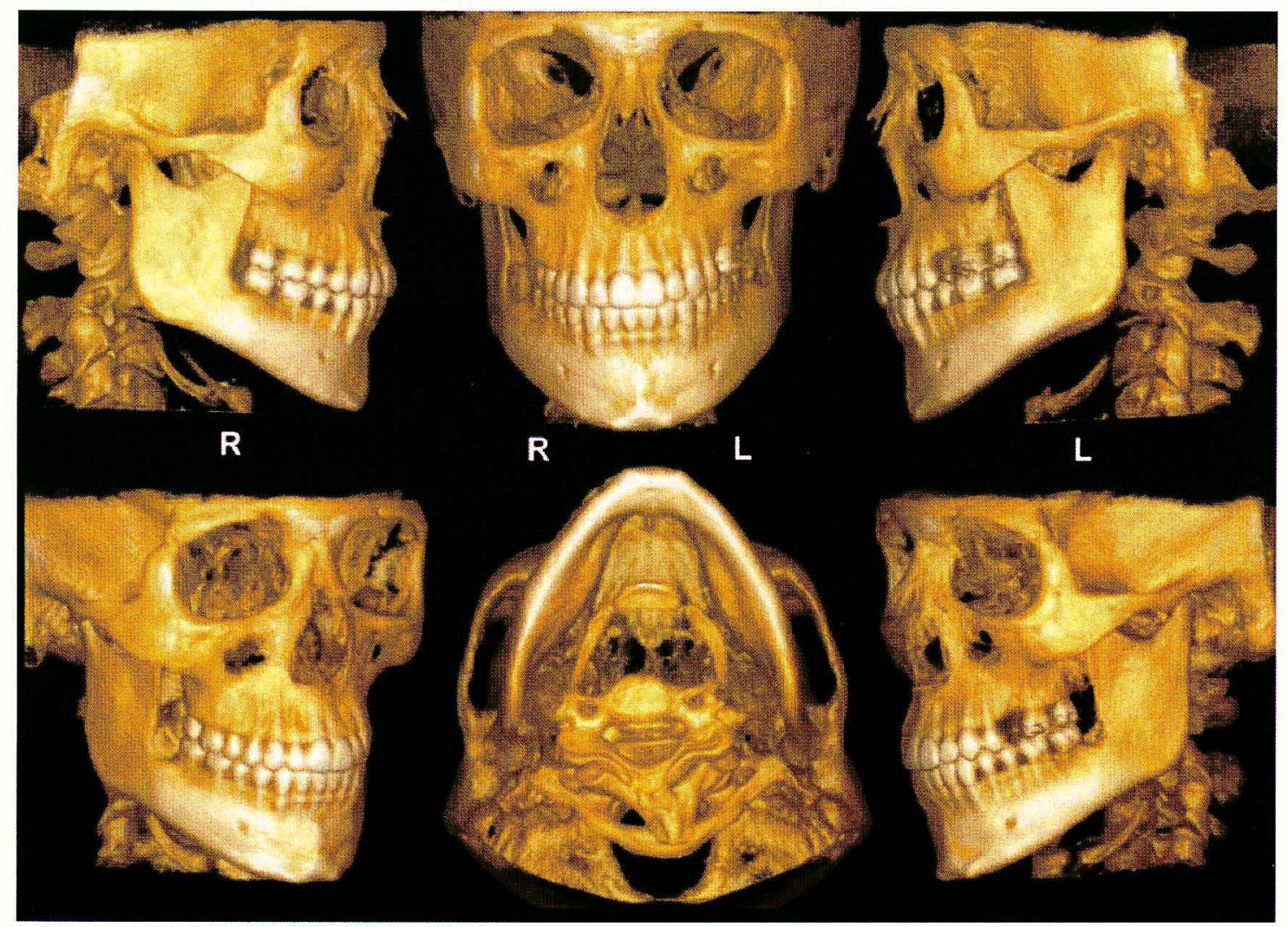

Figure 4. Surface-rendering reconstruction of i-CAT CBCT data set (3DVR, Allovision,

Geenville, SC) produces interactive volumetric image that can be manipulated to display bony surfaces of maxillofacial complex from various standard orientations.

\section{Applications in Orthodontics}

In orthodontics CBCT imaging has current and potential applications in the diagnosis, assessment and analysis of patients with maxillofacial orthodontic and orthopedic anomalies.

In diagnosis, $\mathrm{CBCT}$ provides numerous display modalities that can assist the assessement of numerous dental conditions of concern in orthodontics including impacted and supernumerary teeth. The exact position of impacted teeth and their relationships to adjacent roots or other anatomical structures (eg, the mandibular canal) can be comprehended, so that surgical exposure and subsequent movement can be planned. Some of the most significant potential gains from the introduction of CBCT in orthodontics are the ability of integration of information. Instead of 
looking at individual diagnostic records—the panoramic radiograph, the cephalogram and its concurrent analysis, the dental models and the patient photographs - a single volume that contains all of this information is now available allowing for a unique appreciation of the intercorrelations between all planes and structures. Image integration, particularly three dimensional imaging, may help to overcome a number of inherent deficiencies in orthodontic treatment planning by providing adequate visualization of anatomical structures.[51,53] These include assessment of:

1) Temporomandibular joint condition prior to treatment particularly if related to condylar trauma and structural development during growth

2) Osseous structural conditions in the sagittal, vertical and transverse plane

3) Alveolar bone width of available bone for buccolingual movement of teeth (i.e. arch expansion or labial movement of incisors) and evaluation of fenestrations and dehiscence on the buccal and lingual surfaces.

4) Tooth inclination and torque: $3 \mathrm{D}$ evaluation of the axial inclination of teeth might provide information to supplement that obtained from models.

5) Root resorption: Current CT machines could have too low resolution to detect early stages of root resorption due to orthodontic movement, but advances in technology might permit this in the future.

6) Soft tissue relationships: Lip length is currently measured on lateral radiographs, but mouth width is not. Three-dimensional data could provide information on the relationship of the corners of the mouth to the underlying dentition. Also, cheek thickness and cheek prominence are soft tissue variables that could be investigated in relation to dental arch width and facial esthetics.

7) Tongue size and posture: Volume measurements of the tongue could provide a more objective assessment of size, to aid in the diagnosis of open bites and arch-width discrepancies. 
8) Airway assessment: Volume measurements of the airway could assess patency, especially in patients who are suspected of mouth breathing, adenoid hypertrophy, or sleep apnea. Nasal morphology and turbinates can be clearly seen in CT scans.

9) Patients requiring surgery and those with syndromes and clefts: Surgical planning for such patients can benefit from 3D imaging. 3D data are especially helpful in patients with asymmetry, where true dimensions can be measured, without the problems of magnification or distortion, from which our customary 2D projections suffer. In patients with clefts, bone and soft-tissue defects can be understood much better. There is an increasing desire in orthodontics to integrate the images of all functional elements, both hard and soft tissue, in the assessment of patients with maxillofacial anomalies. Currently, this is performed using a combination of photographic and radiographic images and study models. Due to the fact that orthodontics involves assessment of hard tissue and soft tissue interactions, such as the effects of tooth movement on esthetics and on functional elements such as occlusion and TMJ, it is highly desirable to have one imaging modality that provides images of all existing elements therefore leading to a better assessment of the interactions present.

Traditionally, conventional cephalometric projections such as the lateral cephalogram, posterior anterior, and submentovertex were used individually or in combination to provide two dimensional representations of structures in three planes of space. There was no single imaging technique readily available to the orthodontist that provided accurate representation of all osseous aspects of the TMJ complex and associated structures until the recent commercialization of CBCT. Hilgers et al. studied CBCT multi-planar reformatted projections for TMJ examination to compare the accuracy of linear measurements of the TMJ and related structures with similar measurements made using conventional cephalograms and with the anatomic truth. Using a digital caliper, the investigator measured linear dimensions between 11 anatomic sites to assess the anatomic truth for 25 dry human skulls. All skulls were imaged using i-CAT CBCT and digital cephalograms (PSP) were made in all three orthogonal planes (lateral cephalometric, 
posterior anterior, and submentovertex). Linear measurements were made on seven custom CBCT reconstructions and the digital cephalograms. Results showed that all CBCT measurements were accurate; however, three of five lateral cephalometric (LC) measurements, four of five posterior anterior (PA) measurements, and four of six submentovertex (SMV) measurements varied significantly from the truth. Intra-observer $\mathrm{CBCT}$ measurements were highly reliable compared to the anatomic truth, and significantly more reliable than measurements made from LC, PA, an SMV images. The authors conclude that custom oblique MPR reconstructions using CBCT provides accurate and reliable linear measurements of mandibular and TMJ dimensions.[54]

\section{Three Dimensional Cephalometrics}

Since cephalometric radiology was developed, numerous analyses have been proposed to facilitate communication between practitioners and to describe how individual patients vary from norms derived from other studies. None the less, current cephalometric analyses are two dimensional diagnostic renderings derived from a three dimensional structure. Cephalometric measurements made on 2D radiographs are subject to projection, landmark-identification, and measurement errors.[56-58] The major source of cephalometric error is landmark-identification, which is influenced by many factors such as the quality of the radiographic image, the precision of landmark definition, the reproducibility of the landmark location, the operator, and the registration procedure. Although some cephalometric landmarks are located in the midsagittal plane, many are located at different depth fields leading to increased distortion errors.[56-58] In addition, in lateral cephalometry, it is difficult to determine the difference between right and left sides for superimposition of images, and the sides have different enlargement ratios. It is also difficult to detect deformities in the midfacial area and reading films is difficult due to the superimposition of cranial structures.[59] Despite the potential errors innate to this technique, 
cephalometric radiographs are still widely used and, in many cases are essential in the diagnosis and treatment of the patient.

To compensate for the drawbacks of 2D measurements, many techniques have been developed. These techniques include the orientator, [60] the coplanar stereometric system, [61] the multiplane cephalometric analysis, [62] the basilar multiplane cephalometric analysis, [63] and the bilanar cephalometric stereoradiography[64].

Since the mid 1970s, 3D analyses and related procedures in orthodontics have been attempted through several different approaches.[56] There have been three dimensional cephalometrics proposed that use a combination of lateral and frontal cephalograms. These methods rely on the identification of the same point on both radiographs and the implementation of geometry to calculate the point three dimensionally. These approaches, however, are not truly three dimensional and have obvious limitations in that the accuracy depends on a correct correspondence between the landmark locations on the two radiographs, and points not visible on both radiographs cannot be used.[51] Advances in the use of 3D imaging software have permitted important changes in the perception of 3D craniofacial structures.[56] CBCT produces a lower radiation dose than spiral $\mathrm{CT}$ and is comparable to conventional radiographs. Because of its volumetric data, CBCT allows secondary reconstructions, such as sagittal, coronal, and para-axial cuts and 3D reconstructions of various craniofacial structures.[34,43,56] Unlike the traditional cephalometric radiograph, the $\mathrm{CBCT}$ produces images that are anatomically true $(1: 1$ in size $) 3 \mathrm{D}$ representations, from which slices can be displayed from any angle in any part of the skull and provided digitally on paper or film. Other reasons for the implementation of 3D cephalometry include:[59]

1) actual measurements can be obtained

2) a spatial image of the craniofacial structures can be produced

3) the 3D image can be rotated easily by changing the rotational axis

4) the inner structures can be observed by removing the outer surfaces 
5) various anatomical areas can be observed independently by changing the density

According to Hajeer there are numerous benefits of 3D imaging in orthodontics

including: pre- and post-orthodontic assessment of dentoskeletal relationships and facial esthetics, auditing orthodontic outcomes with regard to soft and hard tissues, 3D treatment planning and 3D soft and hard tissue prediction. 3D orthodontics also offers efficiency in archiving 3D facial, skeletal and dental records for treatment planning, research and medico-legal purposes.[55] Some authors indicate that three dimensional CBCT images may be useful in the assessment of growth and development.[18,20,35-37,50]

However, many practitioners are accustomed to working with traditional two dimensional cephalograms and may be hesitant to turn to $3 \mathrm{D}$, however, $2 \mathrm{D}$ conventional measurements do not have to be abandoned when moving to $3 \mathrm{D}$ implementation. Three dimensional data can be rendered as a $2 \mathrm{D}$ projection resembling a radiograph allowing traditional analyses to be completed, and customary cephalometric points can also be digitized in $3 \mathrm{D}$ on the volumetric rendering itself.[51] Halazonetis believes that the push at implementation of 3D imaging in cephalometrics will lead to an introduction of new landmarks and new analyses which also incorporate advances from related fields, such as geometric morphometrics.[51]

Several CBCT systems permit reconstructions that are comparable with traditional cephalometric projections. Recently, Farman and Scarfe reported a methodology for generating simulated lateral cephalometric images from CBCT using "ray-sum" multiplanar reformatted (MPR) volume reformation.[65] The authors describe a methodology in which existing CBCT image data sets acquired using a 20 -second exposure cycle were used to create two dimensional projection images. The three methods of acquisition involved 1) Scout method: exporting the lateral scout radiograph taken initially to confirm the patient's position, which only provided a lateral cephalogram, 2) Basis image method: selecting the individual lateral and anteroposterior basis images with the least anatomic discrepancies between the right and left sides corresponding to lateral and posteroanterior cephalometric projections and 3) Ray-sum method: manipulation of 
the volumetric data set allowed for the development of cephalometric images in all three orthogonal planes. The ray-sum method includes two dimensional cephalometric reconstructions that were developed by increasing the slice thickness of each plane, hence providing an image composed of the summed voxels, or a ray-sum image. The authors indicate that the major difference between the scout or basis image method, or conventional cephalometric images, and the ray-sum method, is that ray sum image projections are orthogonal and have equal magnification between the beam's entrance and exit sides of the patient. The authors were able to produce slices equal to the dimension of the chosen voxel resolution, thus removing anatomic superimposition of landmarks and allowing for more precise definition of bony landmarks. The authors suggest that the use of 3D surface rendering techniques such as volume rendering (Figure 4) and maximum intensity profile algorithms (Figure 5) will redefine orthodontic treatment planning due to the ability to view $3 \mathrm{D}$ volumes of the maxillofacial complex from any plane.

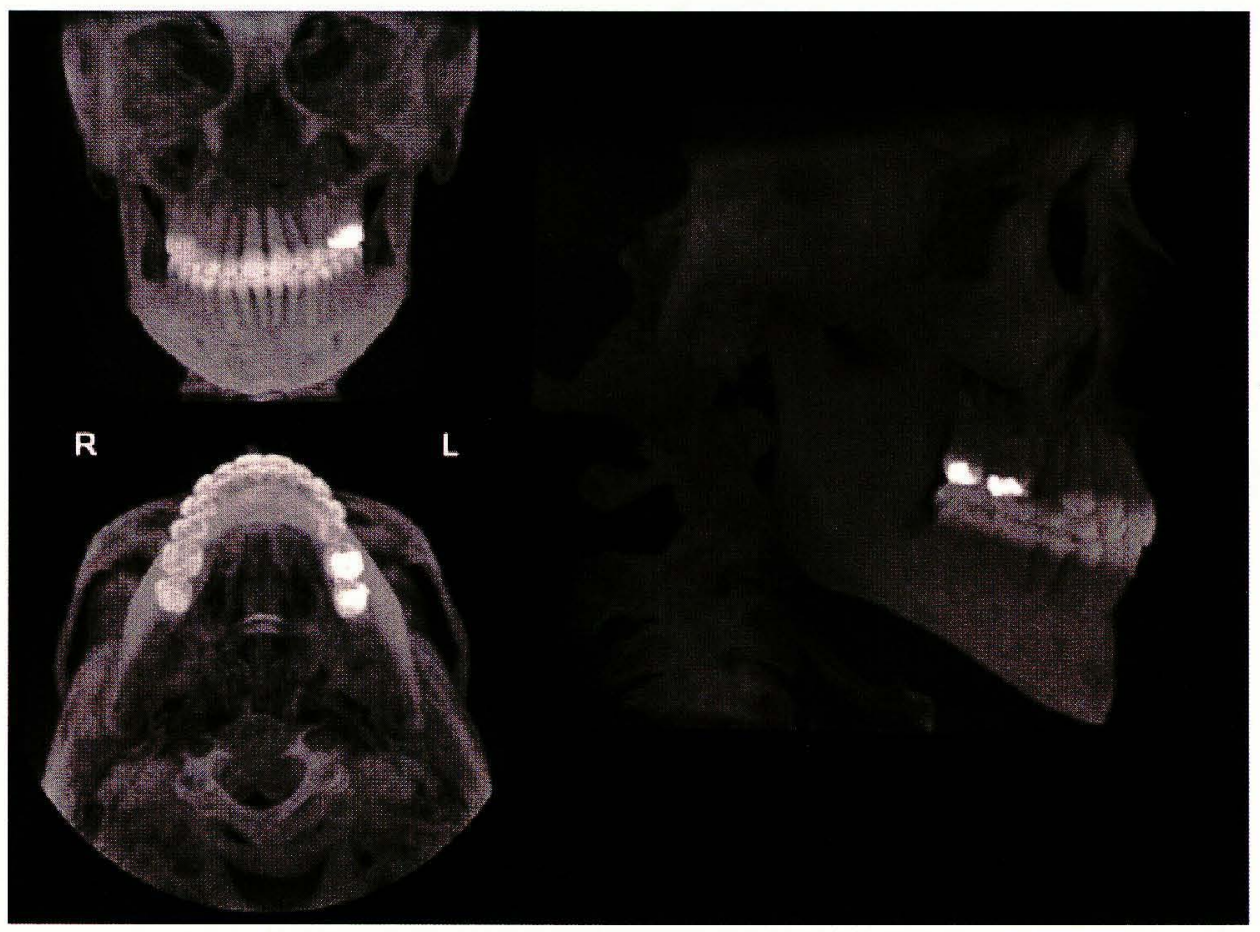

Figure 5. Application of maximum intensity projection algorithms to ray-sum projections show relationships of numerous elements (eg, angulation of tooth roots in alveolar bone) 
because of their transparent nature. Ray-sum projections provide surface representation of CBCT volumetric data as posteroanterior, submentovertex, and lateral skull images.[65]
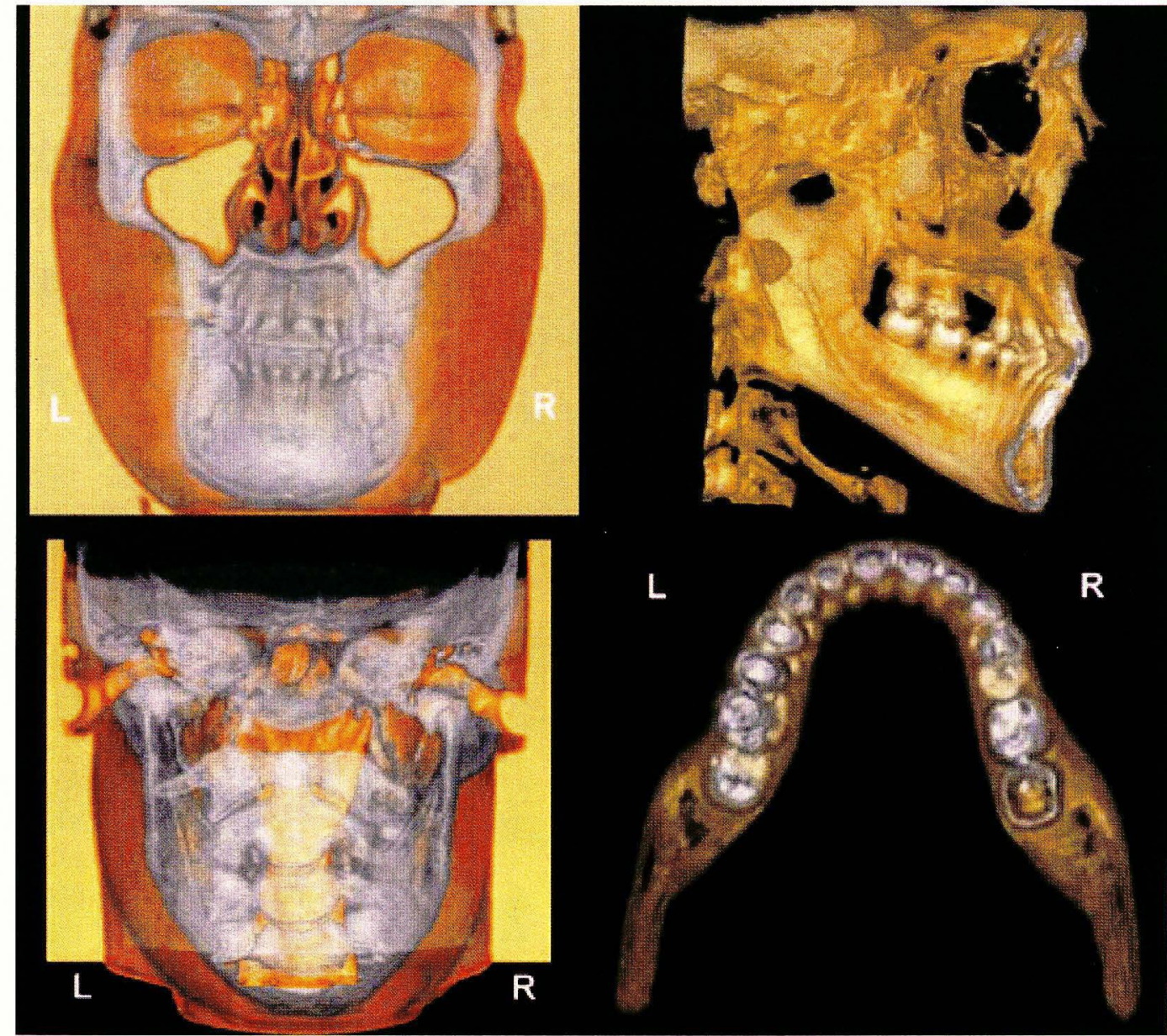

Figure 6: Integration of hard- and soft-tissue volumetric data are achieved through surfaceand volume-rendering techniques. Visualization of dental occlusion from different perspectives can be achieved via production of surface images of selected maxillofacial structures.[65]

In a recent study, Moshiri et al. showed that data from full field scanners can be used to generate simulated cephalometric images.[66] This observational cross-sectional in vitro study was conducted to compare the accuracy of linear measurements made on planar images from photostimulable phosphor based cephalograms and two dimensional (2D) simulated lateral 
cephalograms derived from full field cone beam computed tomography (CBCT) with direct measurements made on human skulls. The investigator measured the linear dimensions between 15 anatomical landmarks on 23 dentate dry human skulls using a digital caliper to provide nine orthodontic linear measurements (S-N, Ba-N, M-N, ANS-N, ANS-PNS, Pog-Go, Go-M, Po-Or and Go-Co). The skulls were stabilized and imaged with CBCT with a single $360^{\circ}, 20 \mathrm{~s}, 0.4 \mathrm{~mm}$ voxel resolution scan. Three 2D simulated cephalometric projections were created: 1) Scout (S), 2) "ray-sum" reconstructed (RS) and 3) basis projection single frame (F) images. Conventional lateral cephalograms (LC) were acquired using a Quint Sectograph and a storage phosphor imaging plate system. TIFF Images were imported into a cephalometric analysis program (Dolphin Imaging Cephalometric and Tracing Software, Chatsworth, CA, USA) and a single observer computed the linear measurements between landmarks and compared them to the anatomic truth. The results showed that the ICC for LC was significantly less than for skull and all CBCT derived modalities. Statistical differences between modalities were found for all measurements except Po-Or $(p=0.27)$. For S-N, Ba-N, ANS-PNS and N-M, values for lateral cephalogram measurements were significantly different from actual dry skull dimensions, whereas CBCT values did not differ from the dry skull measurements. All modalities provided significantly different measurements for Pog-Go and Go-M. For ANS-N and Go-Co all CBCT measurements were significantly less than lateral cephalogram measurements. In addition for GoCo, measurements from scout images were significantly different from actual dimensions. The study concluded that for most measurements in the sagittal plane, simulated 2D lateral cephalometric projections from $\mathrm{CBCT}$ are more accurate than lateral cephalogram images. The authors also add that while cephalometric images generated from single CBCT basis projections provide added accuracy in cephalometric analysis, there was no additional advantage in using ray sum images generated from the CBCT volumetric dataset.

Adams et al. conducted a study to evaluate and compare traditional 2D cephalometric analysis to a 3-D imaging system with regard to accuracy in recording the anatomical truth as 
defined by physical measurements taken using a calibrated caliper.[67] The study used nine dried human skulls to locate thirteen skeletal landmarks both by traditional $2 \mathrm{D}$ cephalometry as well as the three dimensional approach. The high average intra-class correlation $(0.995)$, variance $(.054$ $\mathrm{mm}^{2}$ ), and standard deviation ( $\mathrm{SD} \pm 0.237 \mathrm{~mm}$ ) as averaged over 76 measurements derived from precision calipers, using the predetermined 13 skeletal landmarks, established these physical measurements as the gold standard for comparison of the two radiographic methods. The measurements from the 2D model indicated higher variability, with a larger mean standard deviation $(6.94 \mathrm{~mm})$ compared with the $3 \mathrm{D}$ measures $(0.54 \mathrm{~mm})$. The $2 \mathrm{D}$ analysis lacked precision as compared with the $3 \mathrm{D}$ analysis (points clustered within $0.5 \mathrm{~mm}$ ). As compared to the gold standard, the ranges between the two systems demonstrated a much larger magnitude of potential error inherent in the 2D system. According to the study, when comparing the actual distance of anatomical distances as measured on a human skull to the measurements derived from a $2 \mathrm{D}$ or $3 \mathrm{D}$ model, the $3 \mathrm{D}$ method is more accurate and precise than the $2 \mathrm{D}$. According to the authors, "Evaluating distances in 3D space with a 2D image grossly exaggerates the true measure and offers a distorted view of craniofacial growth."

Chidiac et al. compared measurements from human skulls and their images from lateral and PA cephalometric radiographs and CT scanograms on thirteen adult skulls. They were unable to reveal any statistically significant differences between mean angular values on cephalometric radiographs and CT views. For sagittal distances, the highest correlation was between the direct measure of condylion-to-pogonion and its radiographic image $(r=0.73)$. Correlations between radiographic and skull transverse measures were higher $(0.46<r<0.80)$ than the corresponding skull vs. CT measures $(0.06<\mathrm{r}<0.38)$. CT and CR images are $2 \mathrm{D}$ slices and projections, respectively, of $3 \mathrm{D}$ structures. They found that radiographic images have a distortion (approximately $8 \%$ ) that brings Co-Pg closer to its anatomic distance, inadvertently contributing to better clinical planning, particularly in orthognathic surgery. The pattern of distortion of PA images was in opposite directions for CR and CT views. They concluded that cephalograms and 
CT scanograms are close in depicting angular relations of structures, but they differ in the accuracy of imaging linear measurements, because the location and size of an object within the imaged 3D structure varies with both records.[68]

Most recently, Chan et al. compared eight measurements [(sagittal (Sella-Nasion, ANSPNS), transverse (biorbital, bicoronoidal, and palatal width) and vertical (upper, lower, and posterior facial height)] between 12 commonly used craniometric landmarks made directly on five dry skulls to traditional cephalometry and CBCT (Hitachi CB MercuRay system) using three fields of view (6", 9", and 12"). Intraoperator analysis for skull, CBCT and cephalometric measurements showed good correlation ( $r>0.93$ ). Both cephalometric and all CBCT measurements showed high correlation $(r>0.96)$ and no statistical significant difference when compared to skull measurements. The average absolute difference between cephalometric and skull measurements was $3.34 \pm 4.55 \mathrm{~mm}$. Comparing skull to CBCT measurements, 6", 9", and 12 " FOV images showed differences of $0.53 \pm 0.46 \mathrm{~mm}, 0.48 \pm 0.44 \mathrm{~mm}$, and $0.46 \pm 0.45 \mathrm{~mm}$ respectively. They concluded that $\mathrm{CBCT}$ measurements showed reliability and more linear measurement accuracy than cephalometry and that CBCT linear measurement accuracy improved as voxel size decreased.[69]

Although recent studies have shown that $\mathrm{CBCT}$ derived images are accurate in regard to linear cephalometric measurements, $[66,67]$ the current challenge for clinicians is to understand and interpret 3D imaging, because there is currently no specific way to analyze these 3D images, and interpretation limitations still exist.[56] Lagravere et al. proposed a reference landmark for use in three dimensional cephalometric analysis with 3-dimensional volumetric images.[56] CBCT scans were obtained on 10 patients, all using the same imaging protocol of having the patient lie down with the Frankfort horizontal plane perpendicular to the floor. Images were converted into DICOM format and then rendered into volumetric images using AMIRA software. The investigators used the sagittal, axial, and coronal slices and the 3D image reconstruction for landmark positioning. A point located equidistant to the points in the centers of each foramen 
spinosum (ELSA) was established as the reference point $(x=0, y=0, z=0$ coordinates).

Traditionally used cephalometric landmarks were located on the volumetric images and coordinates of the different landmarks were determined with respect to that reference.

Coordinates of ELSA were registered in a datasheet in the form of $\mathrm{x}, \mathrm{y}$, and $\mathrm{z}$ dimensions for the 10 subjects measured at three independent times. Present statistical tests do not consider 3D data values, therefore in order to find the intraexaminer reliability, it was necessary to convert all $3 \mathrm{D}$ values $(x, y$, and $z$ ) to a sole value using the Delta $E$ formula obtained from the Commission Internationale de I'Eclairage L*a*b* color systems (Vienna, Austria). This system was applied because both use similar Cartesian coordinate systems. The intraexaminer reliability was determined to be kappa $=0.998$. Other cephalometric landmarks were then located in different parts of the images where linear and angular measurements could be determined. ELSA as an $\mathrm{x}=$ $0, y=0, z=0$ reference point in $3 D$ images was used because the location of the foramina spinosum was shown to have a low identification error in both the vertical and horizontal planes. The reason in choosing this landmark was twofold: 1) it is a small circle when viewed axially and is easy to locate by using the condyle and the glenoid fossa as guides, and 2) published literature has demonstrated that most of the cranial base growth (>85\%) occurs in a child's first 5 years with only minor changes after that age. The authors state that although $3 \mathrm{D}$ imaging is a new type of auxiliary examination in orthodontics, no validated method of describing change exists. Most clinicians analyze these images by visually identifying the structures seen without exact measurements or other quantitative analysis. The authors conclude that because ELSA has high intrareliability that it is an adequate reference point for 3D cephalometric analysis.

Although three-dimensional imaging provides volumetric images that can be compared to reality in a 1 to 1 ratio, there is no validated method to describing change with this modality, because most clinicians simply analyze the images with no exact measurements or quantitative analysis.[70] By establishing a precise and reliable instrument for analyzing images produced by 3-D technology, clinicians may have new possibilities for determining changes produced by 
certain types of orthodontic treatment. In a subsequent study, Lagravere et al. propose certain landmarks and planes to standardize 3D cephalometric image orientation.[70] CBCT scans were obtained on 10 adolescents free from craniofacial anomalies. Images were converted into DICOM format and then rendered into volumetric images using AMIRA software. The investigators used the sagittal, axial, and coronal slices as well as the 3D reconstruction of the images for landmark positioning. To determine orientation planes, the reference point ELSA from the previous study was located, then points located at the superior-lateral border of the external auditory meatus (SLEAM) bilaterally and on the mid-dorsum of foramen magnum (MDFM) were located. Coordinates (in $\mathrm{mm}$ ) were established for these three points with respect to ELSA and intrareliability values were determined by using the intraclass correlation coefficient for all four points. The axial-horizontal plane ( $\mathrm{x}-\mathrm{y}$ plane) was then determined by using both superior external auditory meatus and ELSA; the sagittal-vertical plane (z-y plane) was formed by ELSA and mid-dorsum foramen magnum perpendicular to the $x-y$ plane. Because all points are located on structures that are not significantly affected by growth after 5 years of age these planes are adequate for standardizing the orientation of 3D images and eliminating the possibility of different results when using other landmarks or structures that might be influenced by growth or treatment. With these planes, the effect of the patient's head position during image acquisition for analysis would be eliminated. The authors conclude that ELSA, rSLEAM, ISLEAM, and MDFM have high intrareliability when locating them with 3D images. The $x-y$ and $z-y$ planes formed by the respective points are an adequate way to standardize the orientation of $3 \mathrm{D}$ images.

\section{Conventional 3D CT Imaging Accuracy}

The clinical applicability of 3D CT has been evaluated in many studies, and a number of authors have investigated the accuracy of reconstruction software using conventional fan beam derived data sets.[71-73] Recent studies have indicated that there is a high degree of accuracy of 
3D reconstructions.[74-76] with differences between measurements and actual dimensions being $2 \mathrm{~mm}$ to $3 \mathrm{~mm} \cdot[77,78]$

The accuracy of craniometric measurements in 3D surface rendering technique has previously been reported,[75] and recently a new 3D CT volume rendering protocol in vitro and in vivo was established regarding the mental foramen, testing the accuracy and precision of the system.[79] However, there had previously been no report concerning the validation of the soft tissue and the corresponding bone craniometric measurements using specific computer system tools in association with a 3D-CT volume rendering technique. Therefore, Cavalcanti et al.[74] investigated the precision and accuracy of anthropometric measurements using $3 \mathrm{D}$ conventional (spiral) CT volume rendering by imaging 13 cadaver heads and compared the dimensional accuracy of 10 linear measurements on $2 \mathrm{D}$ and $3 \mathrm{D}$ reconstructed images performed by two radiologists with those obtained using a spatial digitizer. They used craniofacial measurements including Al-Al (Nasal breadth), G-Op (Skull length), N-Me (Facial height), N-Ns (Nasal height), Po-Al (Camper's plane), Po-G (Distance between Po and G), Po-Me (Distance between Po and M), Po-N (Distance between Po and N), Po-Ns (Distance between Po and Ns), and ZyZy. They found no statistically significant differences between interobserver and intraobserver measurements or between imaging and physical measurements in both $3 \mathrm{D}-\mathrm{CT}$ protocols. The standard error was found to be between $0.45 \%$ and $1.44 \%$ for all the measurements in both protocols, indicating a high level of precision. Furthermore, there was no statistically significant difference between imaging and physical measurements $(P \geq 0.01)$. The error between the mean actual and mean 3D-based linear measurements was $0.83 \%$ for bone and $1.78 \%$ for soft tissue measurements, demonstrating high accuracy of both 3D-CT protocols. The authors concluded that the new methodology allowed for a qualitatively high $3 \mathrm{D}$ resolution in both bone and soft tissue parameters. They also express that the anthropometric measurements in 3D-CT were considered to be accurate and precise for craniofacial applications. 
Recently, Swennen et al. developed a new voxel-based 3D cephalometry method.[80] From a single computed tomography data set, virtual lateral and frontal cephalograms are computed and linked with both hard and soft tissue 3D surface representations, allowing the setup of a precise and reproducible $3 \mathrm{D}$ cephalometric reference system[81,82] and reliable and accurate definition of 3D cephalometric hard and soft tissue landmarks[83,84]. Voxel based 3D cephalometry was developed and validated by using spiral multi-slice CT (MS-CT) data.[85] Statistical analysis showed that MS-CT 3D cephalometry is highly accurate and reliable with intraobserver measurement errors as low as $0.88,0.76$, and $0.84 \mathrm{~mm}$ for horizontal, vertical, and transverse orthogonal measurements, respectively. Interobserver measurement error was also low: $0.78,0.86$, and $1.26 \mathrm{~mm}$ for horizontal, vertical, and transverse orthogonal measurements respectively. Squared correlation coefficients showed high intraobserver and interobserver reliability.[86,82] The authors state that MS-CT cephalometry is a powerful craniofacial measurement tool with several advantages:[80]

1) truly volumetric 3D depiction of hard and soft tissues of the skull

2) real size (1:1 scale) and real time $3 \mathrm{D}$ cephalometric analysis

3) no superimposition of anatomic structures

4) high accuracy and reliability

5) the setup of a biological meaningful 3D cephalometric reference system for crosssectional and longitudinal analysis of craniofacial changes.

6) MS-CT Cephalometry is a major improvement over conventional 2D cephalometry, however, some drawbacks do exist:[80]

7) horizontal positioning of the patient during record taking falsifies the position of the soft tissue facial mask

8) lack of a detailed occlusion due to artifacts

9) limited access for the routine craniofacial patient because of higher cost

10) higher radiation exposure than other craniofacial x-ray acquisition systems 
Most recently Park et al.[59] have described organized, methodological approaches to cephalometric analysis of 3D CT images. Axial images of 30 subjects were taken using CT Hispeed Advantage (GE Medical System, Milwaukee) and reconstructed into 3D models using Vworks 4.0 (Cybermed, Seoul, Korea). Horizontal, midsagittal, coronal, maxillary, midmaxillary, mandibular, and mid-mandibular planes were all established. 19 Landmarks were first designated on the 3D surface model, and their positions were verified in multiple planar reformat mode, then the Vworks 4.0 and Vsurgery (Cybermed) programs were used to measure the 3D models. The following measurements were determined:

1) Zygoma: facial index, midface angle, and $\mathrm{Bc}$ point

2) Maxilla: canting, rotation, divergence, A-point, and PNS point

3) Mandible: canting, rotation, divergence, body length, ramal height, gonial angle, chin prominence, internal ramal inclination, external ramal inclination, lateral ramal inclination, B-point, Pog point, Me point, and mandibular facial width

4) Facial convexity (indicates the protrusive state of $\mathrm{Bc}, \mathrm{A}, \mathrm{B}$, and $\mathrm{Pog}$ to the coronal plane)

The results show that cephalometric measurements of the subjects were comparable with the normal Korean averages ( $\mathrm{t}$ test, $p \leq .01$ ) and no statistically significant differences were found. All landmarks were reproducible, and there was no significant intraexaminer error between the 2 sessions $(p \geq .01)$. The authors do suggest that there are some limitations when using conventional 3D CT as a diagnostic tool. Relatively large errors in the vertical position (z-coordinate) compared with the anteroposterior ( $\mathrm{y}$-coordinate) and transverse ( $\mathrm{x}$-coordinate) positions were found. The authors state that these errors can be overcome if thin slices are used during the reconstruction. The authors also express that high cost and radiation dose of conventional CT are major disadvantages, and can be improved upon by using cone beam CT, which offers a dose similar to the range of a conventional dental radiographic examination ( 40 to $50 \mu \mathrm{Sv}$ ). In addition, in some craniofacial deformities, Orbitale or Porion are deviated, therefore, points in the 
horizontal plane should not be used as the reference plane. This limitation can also be overcome by using $\mathrm{CBCT}$, in that $\mathrm{CBCT}$ can take an image in the natural head position, and the horizontal reference plane can be parallel to the floor, which is not influenced by Porion and Orbitale. The authors conclude that valuable information can be obtained from a 3D CT reconstruction, and that good treatment results can be obtained with a more precise diagnosis, and the continuous development of 3D analysis will provide more accurate data on a patient.[59]

\section{Potential of CBCT 3D Cephalometry}

The application of CBCT technology has allowed the development of a new generation of commercial volumetric dentofacial imaging acquisition systems.[59] CBCT scanners allow image acquisition of a large part of the craniofacial complex with only a $360^{\circ}$ rotational sequence, and with dedicated $\mathrm{CB}$ reconstruction algorithms a CT data volume is obtained. [86] These scanners focus mainly on bony imaging, leading to a significant decrease in radiation dose. Interesting advantages of CBCT 3D cephalometry for the future include:[80]

1. Reduced radiation exposure

2. Natural shape of the soft tissue facial mask because of the vertical scanning procedure (iCAT, CB MercuRay)

3. Reduced artifacts at the level of the occlusion

4. Increased access for the routine dentofacial patient because of in-office imaging (sufficiently compact to be installed in orthodontic and oral surgery outpatient clinics and private practices)

\section{Reduced cost}

Current limitations of CBCT 3D cephalometry include the scanning volume and positional dependency of the image value of a structure in the field of view of the scanner.[80] The NewTom 3G, i-CAT, and CB MercuRay CBCT scanners all have a scanned volume that is sufficient enough for the setup of the anatomic Cartesian 3D cephalometric reference system and 
$3 \mathrm{D}$ cephalometric hard and soft tissue analyses that do not involve the calavarium or complete ears. However, the 3D Accu-i-tomo and NewTom 9000 systems are not suitable for 3D cephalometry methods due to scanning volumes that are too small.[80] In CBCT systems, the image value of an organ is dependant upon the position in the image volume. Hence, $x$-ray attenuation of $\mathrm{CBCT}$ acquisition systems currently produces different $\mathrm{HU}$ values or radiographic densities for similar bony and soft tissue structures in different areas of the scanned volume. An example of this would be that dense bone has a specific image value at the level of menton, but the same bone has a significantly different image value at the level of the cranial base.[80] Vannier states that when new developments in the synthesis and optimization of CBCT reconstruction algorithms allow the full exploitation of the potential of area detectors in CBCT, that CBCT will provide even more important benefits in craniofacial imaging.[44] Therefore it is suggested that improvements in both $\mathrm{CB}$ reconstruction algorithms and post-processing will solve or reduce this problem soon.[80]

In conclusion, $\mathrm{CBCT}$ derived $3 \mathrm{D}$ cephalometry has a number of potential advantages for cephalometric imaging including sub-millimeter resolution, reduced radiation exposure, and inclusion of soft tissue profile. Perhaps the most important clinical advantage is that CBCT volumetric data can be exported as DICOM files and imported into personal computer based software to provide 3D reconstruction of the craniofacial skeleton. This possibility and the increasing access of CBCT imaging in orthodontics is a component of the paradigm that is directing imaging analysis from $2 \mathrm{D}$ cephalometry to $3 \mathrm{D}$ visualization of craniofacial morphology.[5] The availability of fast scan CBCT now provides an alternate imaging modality capable of providing a 3D representation of the maxillofacial complex with minimal distortion using multi-planar reformatted (MPR) images. 


\section{CHAPTER III \\ METHODS AND MATERIALS}

\section{Overview}

This investigation was designed as an observational ex vivo comparison of linear cephalometric dimensions measured on a sample of 23 skulls to measurements obtained from three modalities 1) digital 2D lateral cephalograms, 2) CBCT derived simulated lateral cephalometric images generated using Dolphin 3D software (Chatsworth, CA) and, 3) Shaded surface 3D reconstructions generated using Dolphin 3D software. This study did not require approval by the Institutional Human Remains Committee, University of Louisville, Louisville KY. The skulls were imaged using CBCT and extraoral lateral cephalometric skull projections. CBCT volumetric data sets were oriented to represent standard head positioning and simulated lateral cephalograms generated using Dolphin 3D software. Twenty cephalometric dimensions were measured on the skulls with a vernier caliper and compared to magnification corrected measurements obtained from displayed images for each of the three modalities. A single rater (PI) performed the measurements on three independent occasions for each modality and the mean measurements and standard deviations compared with ANOVA with post hoc analyses.

\section{Sample}

Twenty three intact dentate human skulls $(n=23)$ were obtained through the Department of Anatomical Sciences and Neurobiology at the University of Louisville. No demographic data was available on the available human remains so therefore the sample was 
not identified by age, gender or ethnic group. The skulls were selected upon the basis of the following criteria: presence of a full permanent dentition and a reproducible, stable occlusion. A stable mandibular relation to the maxilla was achieved for each skull. Careful consideration was taken to assure that proper positioning of the condyle within the glenoid fossa was achieved and reproducible upon imaging and acquisition of measurements. Occlusal interdigitation was also considered in achieving proper mandibular and maxillary alignment. No skulls presented any damage or abnormalities that would interfere with the cephalometric dimensions of interest. All of the skulls were inspected and deemed eligible for providing measurements in the study by two independent observers, Dr. William C. Scarfe and Dr. Mazyar Moshiri.

To provide soft-tissue equivalent attenuation, two latex balloons filled with water were placed in the cranial vault prior to imaging. To separate the mandibular condyle from the temporal fossa, a $1.5 \mathrm{~mm}$ thick Styrofoam wedge was placed in the joint space between the glenoid fossa and the condylar head. For all images, the teeth were placed in centric occlusion (maximum intercuspation) and the jaws were held closed by bilateral metal springs. A custom plastic head holder, with a polyvinyl chloride pipe extension for placing into the foramen magnum, was constructed to support the skulls during imaging (Figure 7). 


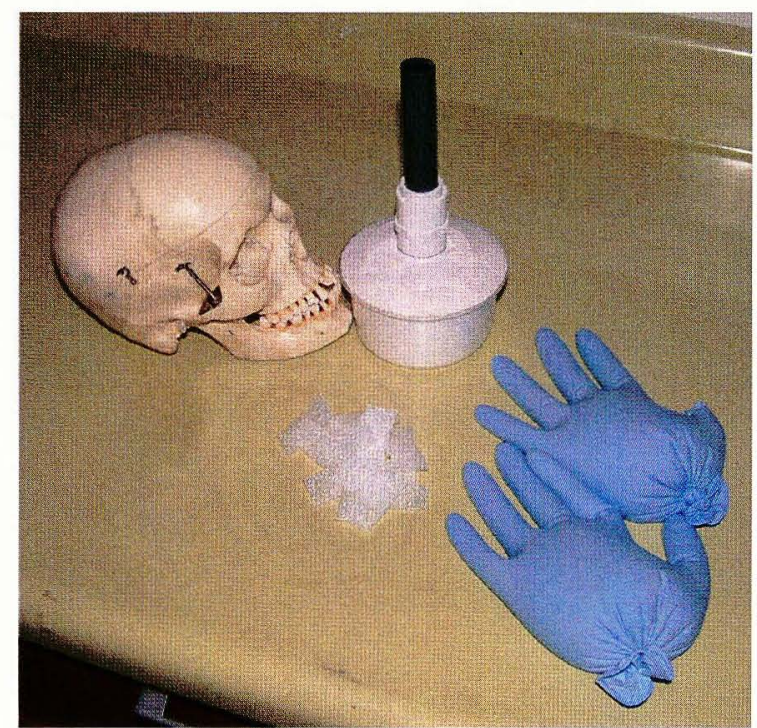

Figure 7. Materials used for imaging of skulls: gloves filled with water, skull holder and foam wedges, and skull.

\section{Imaging}

Two modalities were used to image the 23 skull specimens:

1. Lateral Cephalometric Radiography. Extraoral lateral cephalometric projection radiography was performed using a Quint Sectograph (Model QS 10-1627W; Denar Corporation) using a 10:1 parallel grid. This device maintains a source-to-mid-sagittal distance of $5 \mathrm{ft}$. Exposure settings were at 78 $\mathrm{kVp}, 200 \mathrm{~mA}$, and $2 / 15 \mathrm{~s}$. These were determined by subjective evaluation of image quality of multiple images over a range of exposures taken on a skull with a $1 \mathrm{~cm}$ thick Perspex attenuation material over the exit beam. Skulls were positioned in the cephalostat in standard lateral cephalometric position and stabilizing by two ear pieces inserted into the external auditory meati of the skull and oriented such that the Frankfort plane was parallel to the floor. The skull was oriented such that the sagittal plane was parallel to the X-ray beam with the facial bones of the left side of the skull of the specimen closest to the 
imaging detector. The central ray of the beam was directed at the external auditory meati.

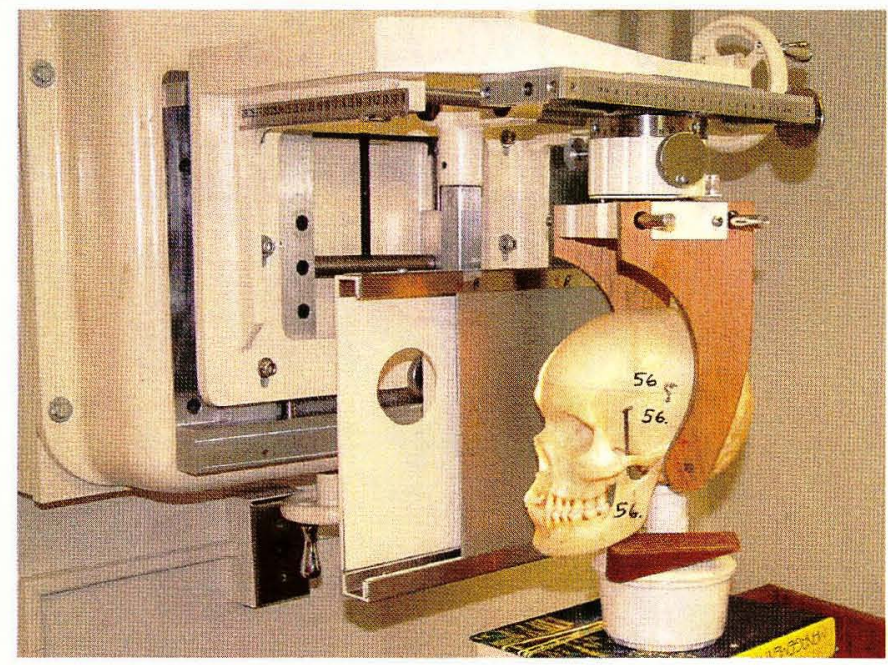

Figure 8. Skull positioning for lateral cephalometric radiograph

2. Cone beam computed tomography $(C B C T)$. CBCT images were acquired of the entire skull using the i-CAT ${ }^{\mathrm{TM}}$ CBCT unit (Imaging Sciences International, Hatfield, PA, USA). The device was operated at $1-3 \mathrm{~mA}$ and $120 \mathrm{kV}$ using a high frequency, constant potential, fixed anode with a nominal focal spot size of $0.5 \mathrm{~mm}$. Each skull was positioned into the device supported by the constructed plastic head holder. The hard tissue chin of each skull was inserted into the chin holder and vertical and horizontal laser lights on the device used to position the head. The head was oriented such that the mid-sagittal was perpendicular to the floor and the horizontal laser reference was along an imaginary line at the intersection of the posterior maxillary teeth and alveolar ridge (Figure 9). 


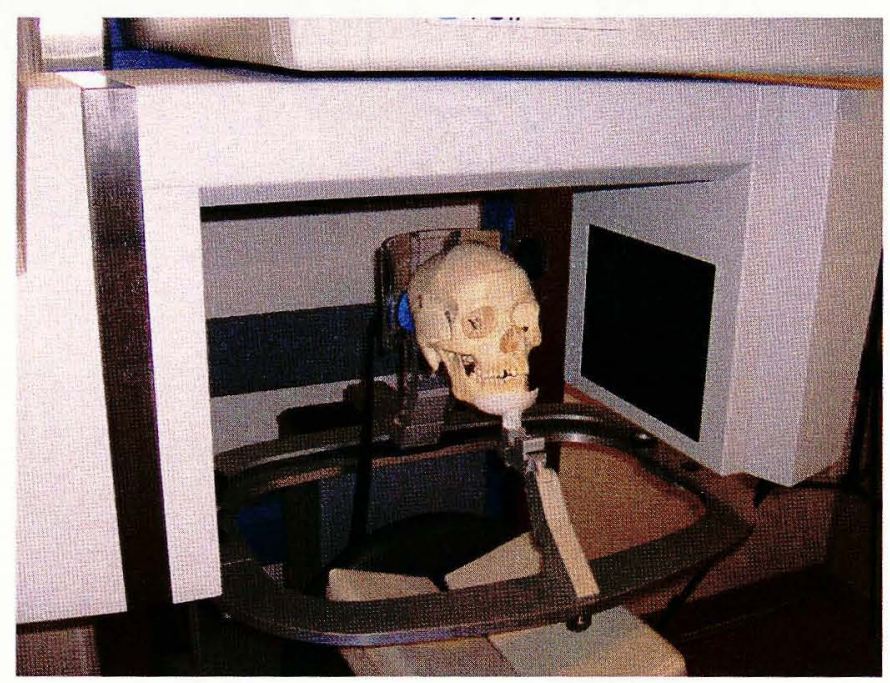

Figure 9. Skull positioning for cone beam computed tomography scan

Lateral scout radiographs were then taken and small adjustments made to the skull orientation such that discrepancies between bilateral structures (e.g. posterior and inferior border of the mandibular ramus, zygomatic arch) were less $5 \mathrm{~mm}$ (Figure 10).

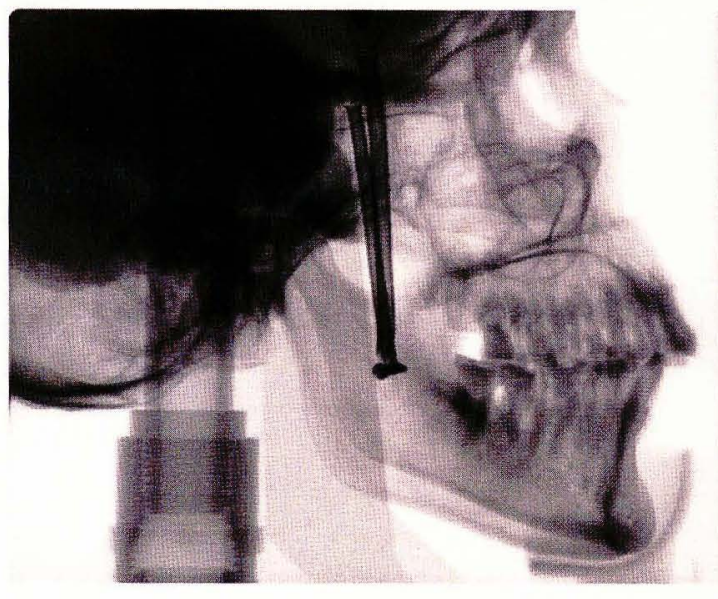

a.

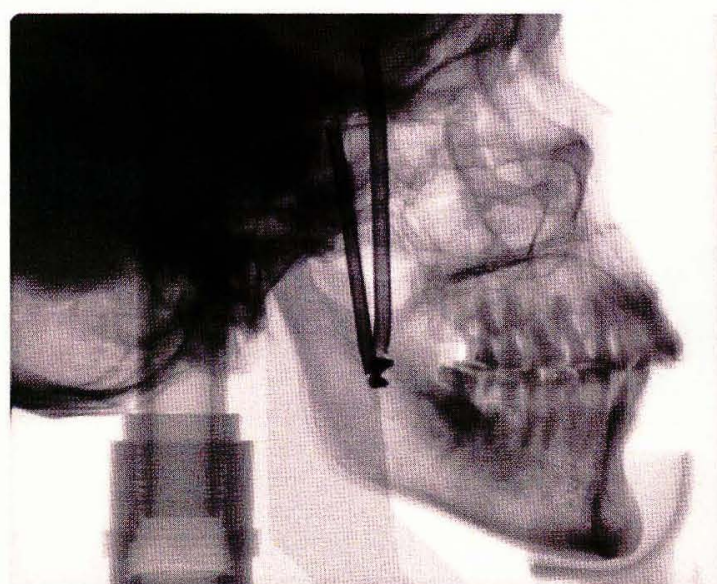

b.

Figure 10. Scout images of a skull demonstrating initial position of specimen with excessive tilt

(a) and after adjustment immediately prior to scanning (b) 
This positioned the skull for imaging such that the minimal amount of distortion occurred and that analysis with the proprietary software could be facilitated. A single $360^{\circ}$ rotation, 20 s. scan, comprising 306 basis projections was then made for each skull with a "Full" field of view $(17.0 \mathrm{~cm}$ (diameter) $\mathrm{x}$ $13.2 \mathrm{~cm}$ (height)) collimation using XoranCat acquisition software (Xoran Technologies, Ann Arbor, MI, version 1.7.7). Exposure parameters were controlled by automatic exposure control.

Primary reconstruction of the data was performed immediately after acquisition. Data sets were stored as DICOM and imported into Dolphin 3D Imaging for orientation and construction of PA cephalogram.

\section{Pre-Processing of PSP Images}

Extra-oral cephalometric images were acquired using an extra-oral photostimulable storage phosphor 8" x 10" imaging plate and scanned at 300dpi and 16-bit TIFF using the DenOptix Imaging system (Gendex/Kavo, Lake Zurich, IL, USA). The proprietary software used was VixWin 2000 (Version 1.2) digital imaging software (Gendex/Kavo, Lake Zurich, IL, USA). Images were exported from VixWin as lossless 16-bit TIF format without image enhancement. For display and analysis extraoral images were imported into a commercial photographic imaging software (Adobe Photoshop V7.0, 2002; Adobe, San Jose, CA) and images equalized prior to measurement (Figure 11). This was performed to standardize post processing and image display rather than use the proprietary VixWin software equalization algorithm. Equalization redistributes the brightness values of pixels so that they more evenly represented over the entire range of brightness levels. After detecting the brightest and darkest values in the composite image, they are remapped such that the brightest value 
represents white and the darkest represents black. Brightness is then equalized by distributing the intermediate pixel values evenly through the gray scale.

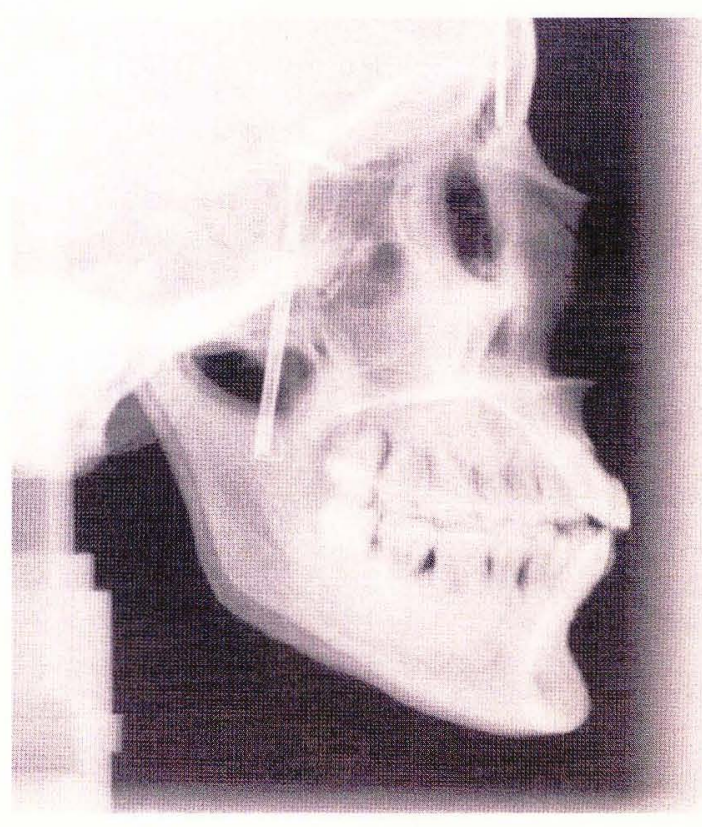

a.

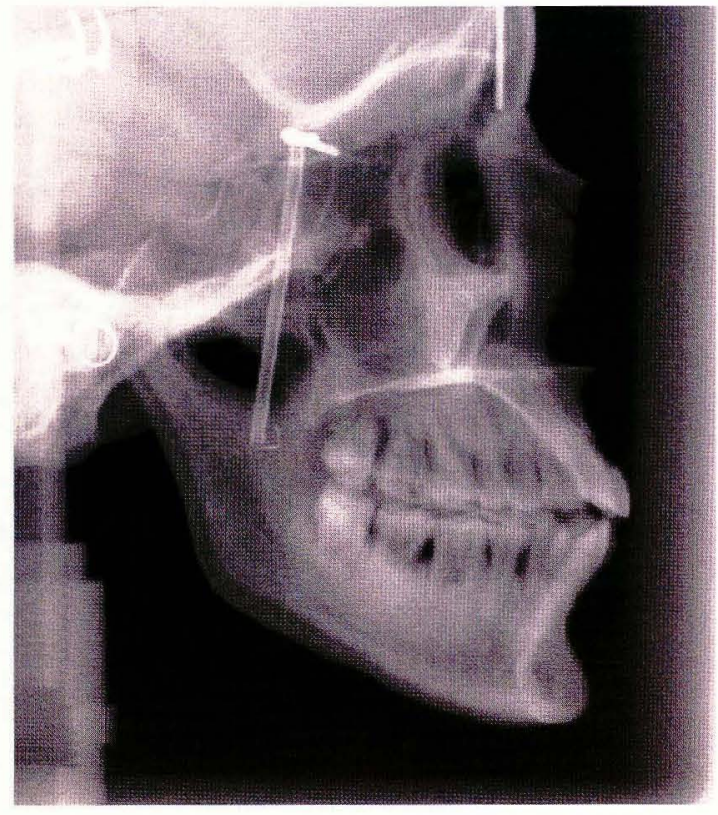

b.

Figure 11 Example of effect of post processing using PhotoShop on a lateral cephalometric image (a.) before and (b.) after image equalization.

CBCT images were acquired with a mega pixel (1024 x 1024) flat-panel hydrogenated amorphous silicon detector with cesium iodide scintillator and secondary reconstructed images reformatted from 306 projections for $20 \mathrm{sec}$ scans each providing a pixel matrix size of $0.4 \mathrm{~mm}$.

\section{Use of Dolphin Imaging Program for Analysis}

The Dolphin Imaging Cephalometric and Tracing Software (Chatsworth, CA) was used exclusively to analyze both the lateral cephalometric digital and CBCT data. 


\section{Lateral Cephalometric PSP Analysis}

Equalized lateral cephalometric images were imported into the dolphin program. Because of the differences in image dimensions and dpi, calibration of each image was necessary. Therefore a 100-mm radiographic film calibration ruler (Model PN 130-0168, Dolphin Imaging Cephalometric and Tracing Software, Chatsworth, CA USA) was placed in the mid-sagittal plane of the skull perpendicular to the radiographic beam. This image was used to calculate the image-casting magnification factor for PSP images and calibrate distances measured in the cephalometric analysis program. The calculated calibration magnification factors and resulting dpi used within the software program are shown in Table 4.

Table 4. Features of imaging plate and CBCT digital images

\begin{tabular}{|c|c|c|c|c|c|c|c|}
\hline \multirow{2}{*}{$\begin{array}{l}\text { Image } \\
\text { Modality }\end{array}$} & \multirow[b]{2}{*}{ Type } & \multicolumn{2}{|c|}{$\begin{array}{c}\text { Image Dimensions } \\
\text { (Width } \times \text { Height) }\end{array}$} & \multicolumn{2}{|c|}{ Image } & \multirow[b]{2}{*}{$\begin{array}{c}\text { Calibration } \\
\text { Factor }\end{array}$} & \multirow[b]{2}{*}{$\begin{array}{c}\text { Final } \\
\text { dpi }\end{array}$} \\
\hline & & $\begin{array}{c}\text { Matrix } \\
\text { Size } \\
\text { (Pixels) }\end{array}$ & $\begin{array}{c}\text { Physical } \\
\text { Size } \\
\text { (inches) }\end{array}$ & $\begin{array}{l}\text { File } \\
\text { size } \\
(k B)\end{array}$ & $d p i$ & & \\
\hline $\begin{array}{l}\text { Projection } \\
\text { radiograph }\end{array}$ & $\begin{array}{l}\text { Lateral } \\
\text { Cephalometric }\end{array}$ & $\begin{array}{c}2847 x \\
2386\end{array}$ & $\begin{array}{l}9.5 x \\
7.96\end{array}$ & 6,804 & 300 & $9.92 \%$ & 327 \\
\hline
\end{tabular}

Images were coded and the PI viewed all images on a 20.1-inch flat panel color active matrix TFT (FlexScan L888, Eizo Nanao Technologies Inc., Cypress, CA) screen with a resolution of $1600 \times 1200$ at $85 \mathrm{~Hz}$ and a $0.255 \mathrm{~mm}$ dot pitch, operated at 24 bit. A custom analysis within the program was developed that directed the observer to identify specific anatomic landmarks on the images (Table 5). Landmarks were identified by using a cursordriven pointer. The resultant analysis provided specific linear measurements (Table 6) which were exported as text data. Some anatomic landmarks required identification of bilateral structures that are inherently difficult to view on conventional cephalometric images. For these points the observer was instructed to attempt to differentiate between left and right 
features and construct a point midway between them. If the feature could not be differentiated, both right and left condyle landmarks were considered coincident. Although theoretically this would lead to differential magnification of left- and right-sided condylar images compared with the mid-sagittal correction factor, the minimal influence on absolute dimension in relation to the size of the feature and the summation of these distances should average the effect.

\section{CBCT Reconstruction and Analysis}

The CBCT data was exported from the XoranCat software in DICOM multi-file format and imported into Dolphin 3D (Pre-release V.2.3, Dolphin Imaging, Chatsworth, CA) on the same computer. All constructions and measurements were performed on a 20.1 -inch flat panel color active matrix TFT (FlexScan L888, Eizo Nanao Technologies Inc., Cypress, CA) screen with a resolution of $1600 \times 1200$ at $85 \mathrm{~Hz}$ and a $0.255 \mathrm{~mm}$ dot pitch, operated at 24 bit. Two reconstructions were performed of the volumetric dataset:

1) Reconstruction of a planar lateral cephalometric projection from CBCT dataset using Dolphin 3D software

2) Reconstruction of three-dimensional volumetric renderings from CBCT dataset using Dolphin 3D software

For both reconstructions, first the $3 \mathrm{D}$ surface rendering was generated by manually adjusting the threshold of visible pixel levels. This was the method used for segmentation (Fig. 12). 


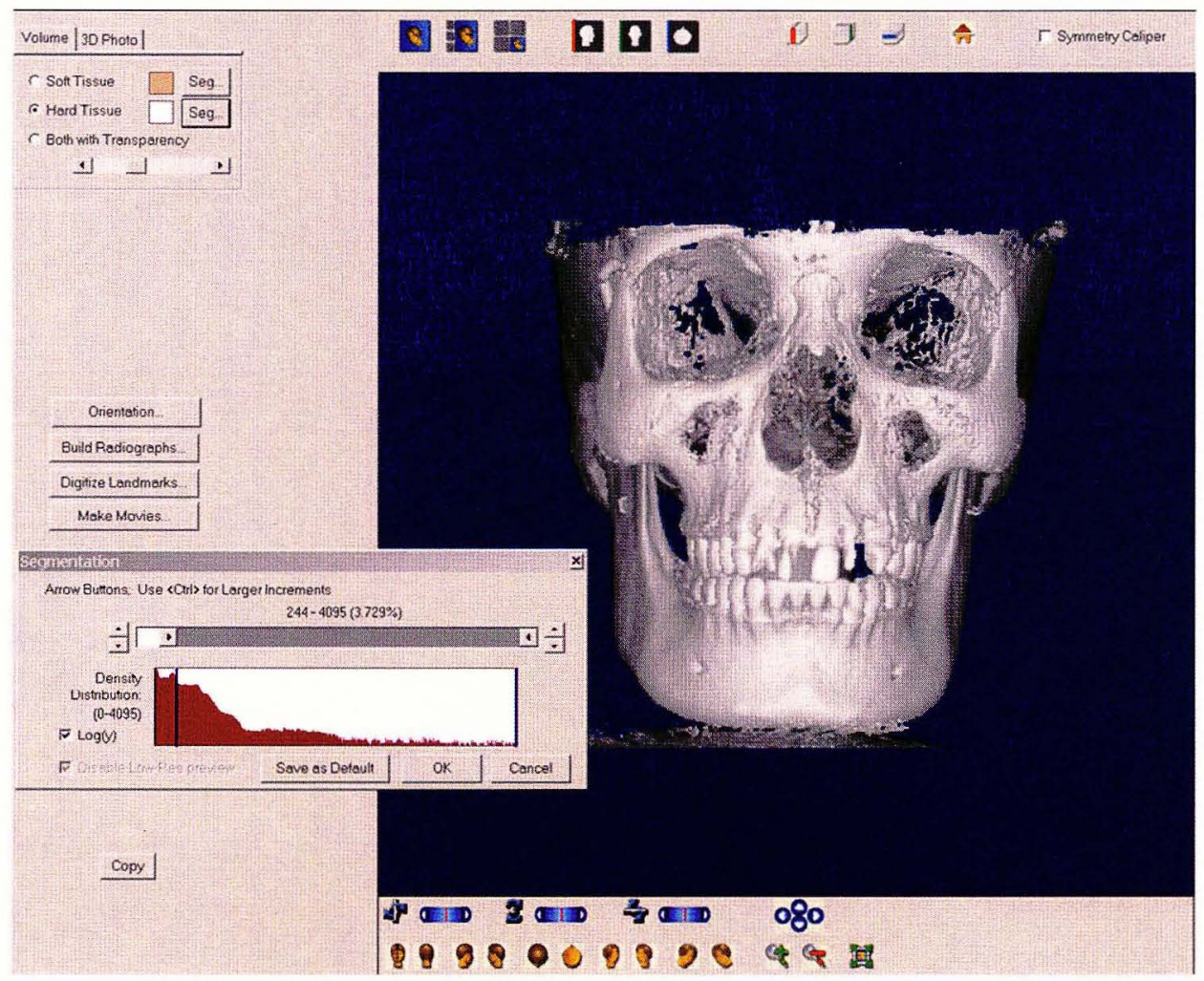

Figure 12 Image capture from Dolphin 3D program demonstrating the segmentation

screen. The hard tissue volume segmentation is selected (upper left) and using the

$\underline{\text { segmentation cursor (lower left) the displayed gray level of the voxels is dynamically altered }}$

to provide the most realistic appearance of the skull with minimal loss of cortical bone due to

$\underline{\text { thin structures and minimal superimposition of artifacts and soft tissue. }}$

Reconstruction of a planar lateral cephalometric projection

For the reconstruction of the planar cephalometric images, the "Build Radiographs" icon was selected and the Dolphin 3D program constructed 2-dimensional lateral cephalometric renderings from the acquired data set. These images were copied and subsequently imported into a cephalometric analysis program (Dolphin Imaging Cephalometric and Tracing Software, Chatsworth, CA) and images were then analyzed using the same methodology as described above for the two-dimensional digital lateral 
cephalometric images. Current versions of Dolphin 3D generate 7 variations of images (Dolphin 1, Dolphin 2, Dolphin 3, Ray-Sum, Emboss, MIP and Trace Filter) which are automatically copied into the Dolphin Imaging system. The pre-release version used in this study did not incorporate these features and therefore only one image was available for export (referred to as "Dolphin 3). Dolphin 3 is a modified Ray-Sum image with optimized gamma, sharpness, contrast and brightness

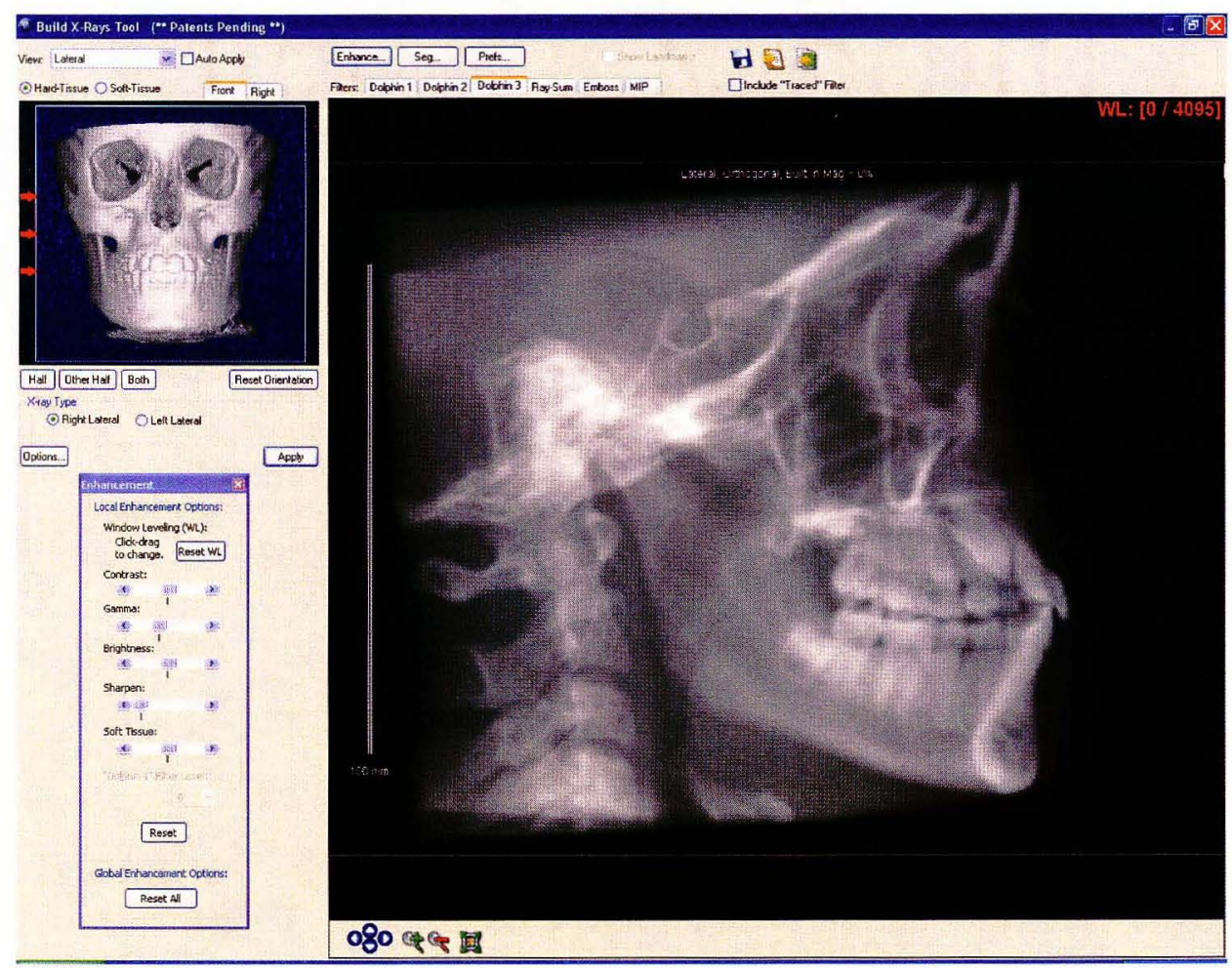

Figure 13 Image capture from Dolphin 3D program demonstrating the "Build X-

Rays" screen for the lateral cephalometric projections. The hard tissue volume segmented is displayed (upper left) and using the arrow cursor (left) the direction of the reconstruction (either left or right) and volume to be included in the reconstruction (determined by manually changing the position of the left or right white limits or performed semi-automated by selection of the lateral margins) are determined. The resultant image is shown and exported to Dolphin Imaging. 
Reconstruction of a 3D Shaded Surface Volumetric Renderings

For the three-dimensional volumetric renderings, after segmentation of the image, the cephalometric landmarks were located and marked on the surface rendered volumetric image. The Dolphin 3D software allowed 3D CBCT measurements from different views using rotation and translation of the rendered image. Landmarks were identified by using a cursordriven pointer. This was performed by a sequence of pre-set volumetric orientations (Figure 14-17).

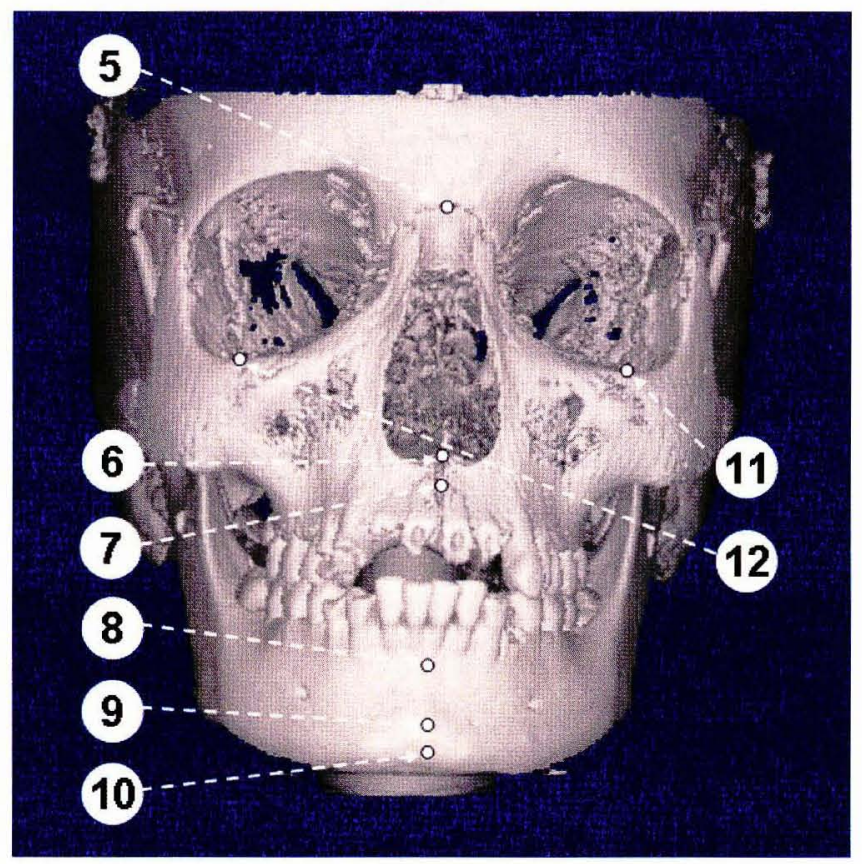

Figure 14. PA 3D Volumetric Orientation allowed identification of $\mathrm{Na}$, A point, ANS, $\mathrm{B}$ point, Gn, Pog and Or bilaterally located. (5=Nasion ; $6=\mathrm{ANS}, 7=\mathrm{A}$ point , $8=\mathrm{B}$ point, 9=Pogonion , 10=Gnathion , 11=left Orbitale , 12=right Orbitale) 


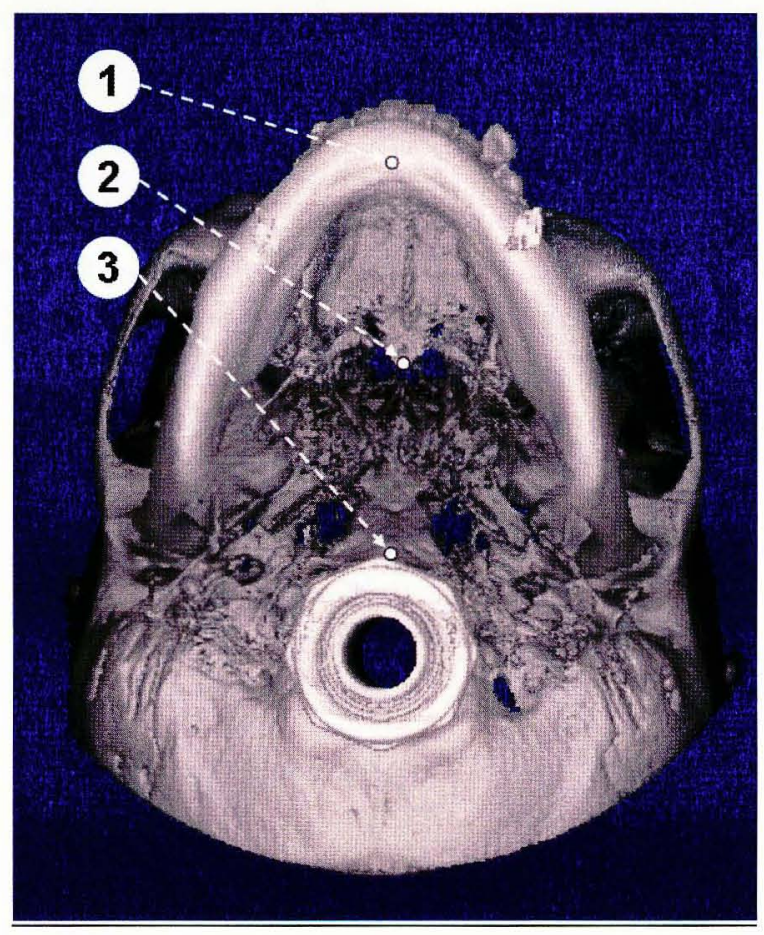

Figure 15. SMV 3D Volumetric Orientation allowed identification of Me, PNS and Ba. (1=Menton, 2=PNS, 3=Basion)

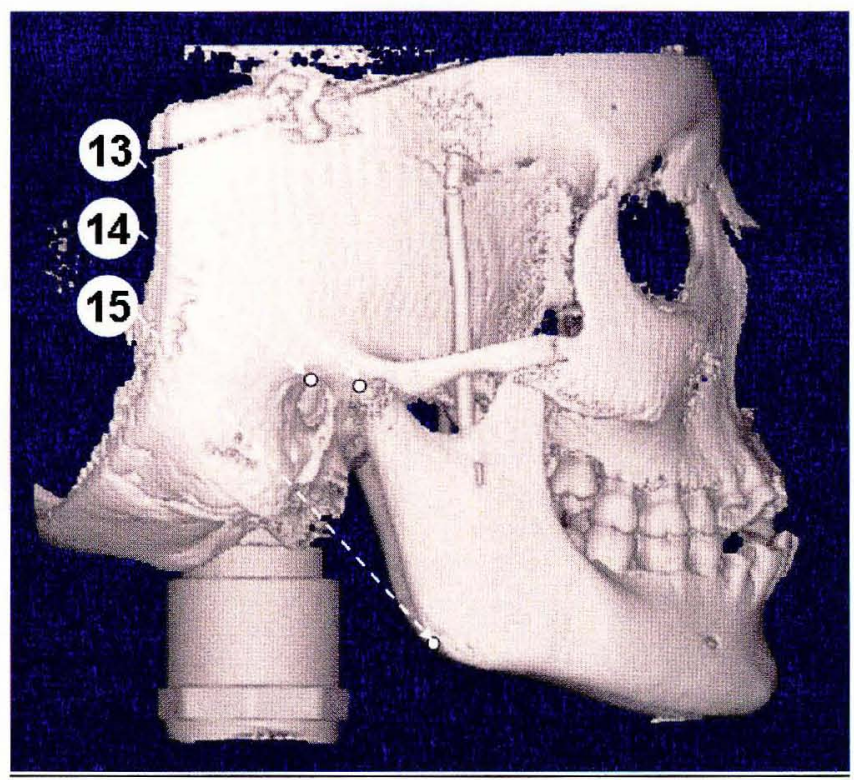

Figure 16. Left and Right Lateral ((Only Right shown) 3D Volumetric Orientation allowed identification of Co, Po and, Go. (13= Condylion, 14= Porion, 15= Gonion) 


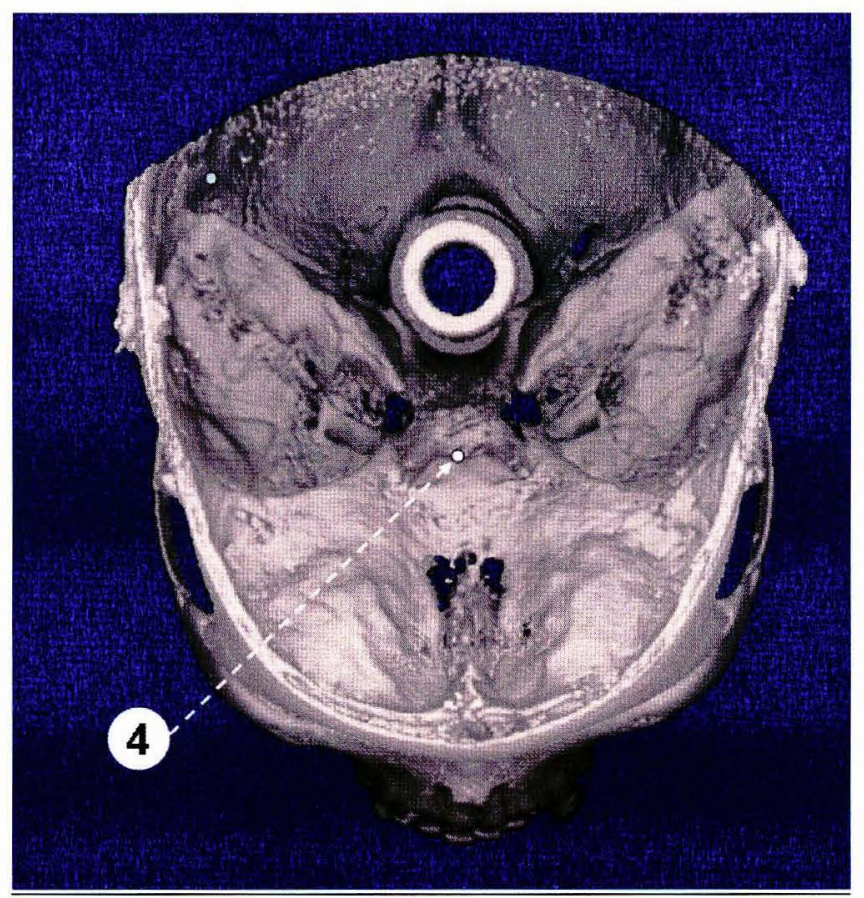

Figure 17. Superior 3D Volumetric Orientation allowed identification of cranial fossa and S. $\underline{(4=\text { Sella })}$

Because Sella is a spatial landmark, for the purposes of this study, Sella was assumed to be on the anterior of the clivus, midway between the anterior clinoid processes. As the volume rendering was reoriented, the positions of the previously positioned landmarks were verified and, if necessary, relocated.

Finally measurements between specific landmarks were made. For the pre-release software version used, points and planes were unnamed. Therefore it was necessary to select points to identify a linear plane. This was performed in a specific sequence such that linear measurement 1 corresponded to $\mathrm{Na}-\mathrm{A}$, linear measurement 2 corresponded to $\mathrm{Na}-\mathrm{B}$ and so forth. In this way the resulting analysis provided specific linear measurements (Figure 18) which could be exported as text data. This procedure was repeated three times by the first author. 


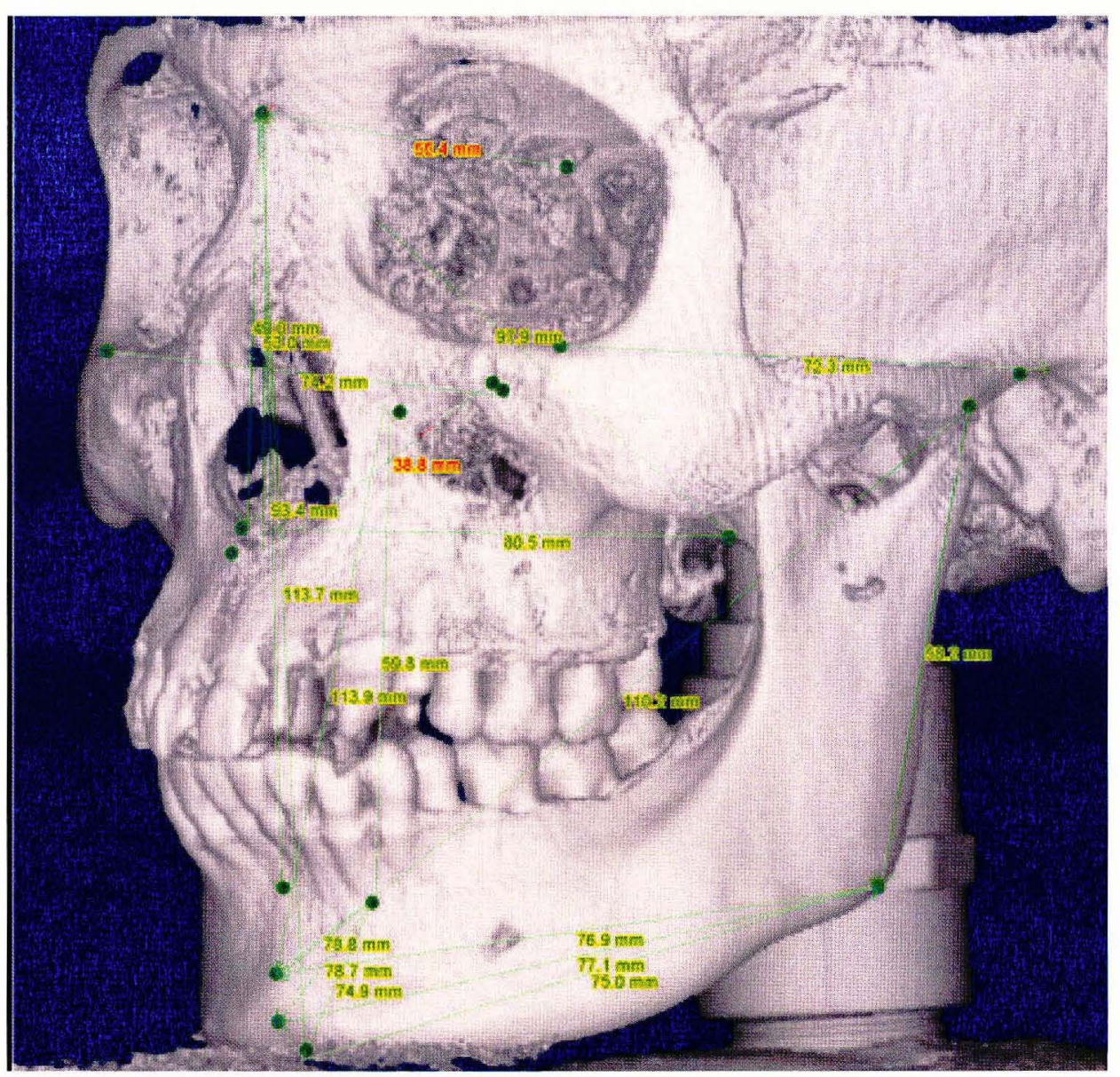

Figure 18. CBCT 3D image generated from segmentation demonstrating identification of landmarks and linear dimensions measured in the study.

\section{Measurement Analysis}

On each skull, fourteen conventional craniometric anatomic landmarks were identified on using an indelible marker (Table 5). Operational definitions of these landmarks were developed considering the vagaries of established definitions and in regard to minimizing location subjectivity. 
Table 5. Definition of anthropometric topographic points Used as Landmarks for the

Measurements

\begin{tabular}{|c|c|}
\hline Landmark (abbreviation) & Definition \\
\hline Sella $(S)$ & $\begin{array}{l}\text { Midpoint of rim between the anterior clinoid process in the median } \\
\text { plane }\end{array}$ \\
\hline Nasion $(\mathrm{Na})$ & $\begin{array}{l}\text { Mid-sagittal point at the junction of the frontal and nasal bones at } \\
\text { the naso-frontal suture }\end{array}$ \\
\hline Basion (Ba) & $\begin{array}{l}\text { Most inferior point on the anterior margin of foramen magnum, at } \\
\text { the base of the clivus }\end{array}$ \\
\hline $\begin{array}{l}\text { Anterior Nasal Spine } \\
\text { (ANS) }\end{array}$ & $\begin{array}{l}\text { Most anterior limit of the of the floor of the nose, at the } \\
\text { tip of the anterior nasal spine }\end{array}$ \\
\hline $\begin{array}{l}\text { Posterior Nasal Spine } \\
\text { (PNS) }\end{array}$ & $\begin{array}{l}\text { Point along palate immediately inferior to the pterygomaxillary } \\
\text { fossa }\end{array}$ \\
\hline A point (A) & $\begin{array}{l}\text { Signifies the apical base, the juncture of maxillary basal bone with } \\
\text { alveolar bone. The most posterior point between the innermost } \\
\text { curvature of the anterior nasal spine and the crest of the labial } \\
\text { alveolar plate }\end{array}$ \\
\hline B point (B) & $\begin{array}{l}\text { Signifies the apical base, the juncture of mandibular basal bone } \\
\text { with alveolar bone. The most posterior point between pogonion and } \\
\text { the crest of the labial plate }\end{array}$ \\
\hline Menton (Me) & $\begin{array}{l}\text { Most inferior point along the curvature of the chin in the mid- } \\
\text { sagittal plane }\end{array}$ \\
\hline Gnathion $(\mathrm{Gn})$ & $\begin{array}{l}\text { Most anterior inferior point along the curvature of the chin in the } \\
\text { mid-sagittal plane }\end{array}$ \\
\hline Pogonion (Pog) & $\begin{array}{l}\text { Most anterior point along the curvature of the chin in the mid- } \\
\text { sagittal plane }\end{array}$ \\
\hline Gonion* (Go) & $\begin{array}{l}\text { Point along the angle of the mandible, midway between the lower } \\
\text { border of the mandible and posterior ascending ramus }\end{array}$ \\
\hline Porion* (Po) & $\begin{array}{l}\text { Most superior point of the anatomic external auditory meatus } \\
\text { (anatomic Porion) }\end{array}$ \\
\hline Condylion* $(\mathrm{Co})$ & $\begin{array}{l}\text { Most posterior superior point of the mid-planed contour of the } \\
\text { mandibular condyle }\end{array}$ \\
\hline Orbitale* (Or) & Most inferior point on infraorbital rim \\
\hline
\end{tabular}

* Bilateral landmark

Twenty linear measurements characterizing the horizontal and vertical dimensions of the maxillofacial skeleton were then developed from a consideration of the operational definitions and with regard to sagittal assessments provided by conventional extraoral lateral 
cephalometric plane projection imaging (Table 6). To establish the true distances between the selected anatomic points, measurements were made by two research associates three times independently using an electronic digital caliper (27-500-90, GAC, Bohemia, NY). The mean of the measurements was designated as the anatomic truth.

Table 6. Definition of Linear Planes used in the Cephalometric Analysis

\begin{tabular}{|c|c|c|}
\hline Abbreviation & Name & Definition \\
\hline \multicolumn{3}{|c|}{ Mid-sagittal Planes } \\
\hline $\mathrm{S}-\mathrm{Na}$ & Sella-Nasion & $\begin{array}{l}\text { A line connecting Sella and Nasion used to represent } \\
\text { the cranial base in the midsagittal plane }\end{array}$ \\
\hline $\mathrm{Na}-\mathrm{Ba}$ & Nasion-Basion & $\begin{array}{l}\text { A line connecting Nasion and Basion used to } \\
\text { represent the cranial base in the Ricketts Analysis }\end{array}$ \\
\hline ANS-PNS & $\begin{array}{l}\text { Anterior Nasal Spine- } \\
\text { Posterior Nasal Spine }\end{array}$ & $\begin{array}{l}\text { A line connecting ANS and PNS. Used to represent } \\
\text { the palatal plane or angle of the maxilla }\end{array}$ \\
\hline $\mathrm{Na}-\mathrm{A}$ & Nasion-A point & $\begin{array}{l}\text { A line connecting Nasion and A Point. A sagittal } \\
\text { reference line for the maxilla's anterior-posterior } \\
\text { position in the Steiner Analysis }\end{array}$ \\
\hline $\mathrm{Na}-\mathrm{B}$ & Nasion-B point & $\begin{array}{l}\text { A line connecting Nasion and B Point. Represents } \\
\text { the anterior-posterior position of the mandible in the } \\
\text { Steiner Analysis }\end{array}$ \\
\hline $\mathrm{Na}-\mathrm{Me}$ & Nasion-Menton & $\begin{array}{l}\text { A line connecting Nasion and Menton. Represents } \\
\text { total anterior face height. }\end{array}$ \\
\hline $\mathrm{Na}-\mathrm{ANS}$ & $\begin{array}{l}\text { Nasion-Anterior } \\
\text { Nasal Spine }\end{array}$ & $\begin{array}{l}\text { A line connecting Nasion and ANS. Represents } \\
\text { upper facial Height }\end{array}$ \\
\hline Ba-ANS & $\begin{array}{l}\text { Basion-Anterior } \\
\text { Nasal Spine. }\end{array}$ & A line connecting Basion and Anterior Nasal Spine \\
\hline \multicolumn{3}{|c|}{ Bilateral Planes } \\
\hline Pog-Go & Pogonion-Gonion & $\begin{array}{l}\text { A line connecting Pogonion and Gonion. Represents } \\
\text { mandibular body length }\end{array}$ \\
\hline Pog-Co & Pogonion-Condylion & $\begin{array}{l}\text { A line connecting Pogonion and Condylion. } \\
\text { Represents mandibular unit length }\end{array}$ \\
\hline Go-Me & Gonion-Menton & $\begin{array}{l}\text { A line connecting Gonion and Menton. Represents } \\
\text { the mandibular plane }\end{array}$ \\
\hline Go-Co & Gonion-Condylion & $\begin{array}{l}\text { A line connecting Gonion and Condylion. Represents } \\
\text { posterior facial height }\end{array}$ \\
\hline Go-Gn & Gonion-Gnathion & $\begin{array}{l}\text { A line connecting Gonion and Gnathion. Used to } \\
\text { represent the mandibular plane in the Steiner } \\
\text { Analysis }\end{array}$ \\
\hline
\end{tabular}


Measurements on digital extraoral images were performed by the author on three separate occasions for each skull in the Dolphin Cephalometric and Tracing Software program (Chatsworth, CA).

A custom lateral cephalometric analysis template was designed within the Dolphin imaging program measuring the linear dimensions of interest to this study. Using the custom analysis the PI identified the selected cephalometric landmarks on each lateral cephalometric cephalogram three times and linear distances were calculated by the measurement algorithm implemented by the Dolphin software.

The same steps were repeated for the simulated lateral cephalometric images constructed from the CBCT volumetric data sets; however no equalization was necessary for these images. One set of measurements was taken for each skull at the $20 \mathrm{~s}$ scanning interval. The monitor used was a 17". (Proview, California) flat panel TFT color monitor with a screen resolution of $1280 \times 1024$, a $0.23 \mathrm{~mm}$ dot pitch set at an image quality of 32-bit.

While the measurement algorithm of the CBCT software is calibrated with respect to voxel dimensions and provides a true 1:1 image ratio, direct measurements from the digital extraoral projections suffer from differential magnification.

\section{Data Collection}

All measurements from the Dolphin custom cephalometric analysis were exported with the "data" export function into a text document. The text documents were entered, rearranged and data subsequently exported into a Microsoft Excel 2003 (Microsoft, Redmond, WA, USA) database. Mean \pm standard deviation of three independent replicates of the 20 measurements were calculated for each skull sample and for the three modalities (digital photostimulable storage phosphor lateral cephalometric (PSP), simulated lateral cephalometric generated from the CBCT volumetric dataset (CBCT LC) and, the 3D shaded surface volumetric rendering (CBCT 3D). The data files were then coded for use with the 
Statistical Package for the Social Sciences software (SPSS, Version 12.0, SPSS, Inc., Chicago, IL, USA) which was used to conduct the analyses.

\section{Statistical Analyses}

Because of the inherent difference sin comparing 2D dimensions to $3 \mathrm{D}$ measurements, for the purposes of the study, data was analyzed accordingly.

The first analysis (3D Analysis) comprised comparisons of the anatomic measurements from the skulls to those derived from 3D volumetric renderings (Anatomic measurement vs. CBCT 3D). The second analysis (2D Analysis) comprised comparisons of the anatomic measurements from the skulls to those derived from $2 \mathrm{D}$ representations (Anatomic measurement vs. CBCT LC vs. PSP)

The Statistical Package for the Social Sciences version 12.0 software (SPSS, Chicago, Il, USA) was used for data analysis. To determine intra-observer reliability, the average measures intraclass correlation coefficient (ICC) was determined for repeat measurements. In addition, absolute and percentage mean error; standard deviations and 95\% confidence levels were calculated. Absolute and percentage linear means of triplicate measurements between specified anatomic landmarks were calculated and standard deviations and $95 \%$ confidence levels calculated. For the 3D Analysis, the digital measurements of the skulls were taken as ground truth and compared with the PSP lateral cephalograms as well as the 3D CBCT measurements with a two tail paired Student's $t$ test at an $\grave{a}$ priori level of significance of $P \leq .05$. For the 2D Analysis, the digital measurements of the skulls were taken as ground truth and bilateral measurements were pooled to provide a mean. This skull dimension was compared with measurements from the PSP lateral cephalograms as well as the simulated lateral cephalometric from CBCT with a one way ANOVA using Scheffé post hoc analysis. The à priori level of significance for both analyses Was $P \leq .05$. 


\section{CHAPTER IV}

\section{RESULTS AND CONCLUSIONS}

Because of the inherent difference in the measurements obtained from the modalities investigated, the analysis of data was performed in two sections.

1. The first analysis (3D Analysis) comprised comparisons of the anatomic measurements from the skulls to those derived from 3D volumetric renderings (Anatomic measurement vs. CBCT 3D).

2. The second analysis (2D Analysis) comprised comparisons of the anatomic measurements from the skulls to those derived from 2D representations (Anatomic measurement vs. CBCT LC vs. PSP)

For each analysis intra-observer reliability and modality accuracy were calculated and compared to anatomic dimensions obtained from the skull.

\section{Analysis of 3D Measurements}

\section{Measurement Reliability}

Table 7 shows the average measure ICC of triplicate skull measurements made by multiple raters compared to triplicate linear measurements made by the first author for each linear dimension for 3D CBCT. The mean skull ICC (0.996 \pm 0.007 ; range; 0.981 to 0.991$)$ was significantly higher than the mean ICC for $3 \mathrm{D} \mathrm{CBCT}(0.976 \pm 0.016$; range; 0.941 to 0.993$)$ $(\mathrm{t}=5.468, P<.001)$ 
Table 7. Average measure intra-class correlation coefficient for triplicate measurements for midsagittal and bilateral linear measurements by multiple observers on 23 skulls and for a single observer on CBCT $3 \mathrm{D}$ reconstructions.

\begin{tabular}{|c|c|c|c|c|c|c|c|}
\hline \multirow[b]{4}{*}{ Plane } & \multirow[b]{4}{*}{ Location } & \multicolumn{6}{|c|}{ Modality } \\
\hline & & \multicolumn{3}{|c|}{ Skull } & \multicolumn{3}{|c|}{ CBCT $3 D$ Reconstructions } \\
\hline & & \multirow[b]{2}{*}{ Mean } & \multicolumn{2}{|c|}{$C L$} & \multirow[b]{2}{*}{ Mean } & \multicolumn{2}{|c|}{$C L$} \\
\hline & & & Lower & Upper & & Lower & Upper \\
\hline S-N & Mid-sagittal & 0.998 & 0.996 & 0.999 & 0.941 & 0.882 & 0.973 \\
\hline $\mathrm{Ba}-\mathrm{Na}$ & Mid-sagittal & 0.996 & 0.994 & 0.998 & 0.993 & 0.987 & 0.997 \\
\hline ANS-PNS & Mid-sagittal & 0.994 & 0.989 & 0.997 & 0.954 & 0.907 & 0.979 \\
\hline $\mathrm{Na}-\mathrm{A}$ & Mid-sagittal & 0.999 & 0.997 & 0.999 & 0.964 & 0.928 & 0.983 \\
\hline $\mathrm{Na}-\mathrm{B}$ & Mid-sagittal & 0.996 & 0.994 & 0.998 & 0.964 & 0.927 & 0.983 \\
\hline $\mathrm{Na}-\mathrm{Me}$ & Mid-sagittal & 0.997 & 0.995 & 0.999 & 0.994 & 0.988 & 0.997 \\
\hline Na-ANS & Mid-sagittal & 0.997 & 0.995 & 0.999 & 0.958 & 0.917 & 0.981 \\
\hline Ba-ANS & Mid-sagittal & 0.990 & 0.981 & 0.996 & 0.979 & 0.957 & 0.990 \\
\hline \multirow[t]{2}{*}{ Pog-Go } & Right & 0.999 & 0.999 & 0.999 & 0.987 & 0.974 & 0.994 \\
\hline & Left & 0.999 & 0.999 & 0.999 & 0.990 & 0.980 & 0.995 \\
\hline \multirow[t]{2}{*}{ Pog-Co } & Right & 0.999 & 0.999 & 0.999 & 0.952 & 0.904 & 0.978 \\
\hline & Left & 0.969 & 0.998 & 0.999 & 0.972 & 0944 & 0.987 \\
\hline \multirow[t]{2}{*}{ Go-Me } & Right & 0.999 & 0.999 & 0.999 & 0.982 & 0.964 & 0.992 \\
\hline & Left & 0.999 & 0.999 & 0.999 & 0.987 & 0.974 & 0.994 \\
\hline \multirow[t]{2}{*}{ Go-Co } & Right & 0.999 & 0.998 & 0.999 & 0.990 & 0.981 & 0.996 \\
\hline & Left & 0.999 & 0.999 & 0.999 & 0.983 & 0.966 & 0.992 \\
\hline \multirow[t]{2}{*}{ Go-Gn } & Right & 0.997 & 0.993 & 0.999 & 0.965 & 0.931 & 0.984 \\
\hline & Left & 0.995 & 0.990 & 0.998 & 0.986 & 0.972 & 0.994 \\
\hline \multirow[t]{2}{*}{ Po-Or } & Right & 0.996 & 0.994 & 0.998 & 0.980 & 0.96 & 0.991 \\
\hline & Left & 0.996 & 0.992 & 0.998 & 0.987 & 0.974 & 0.994 \\
\hline
\end{tabular}

$\mathrm{CL}=95 \%$ confidence interval

Table 8 shows the absolute and mean percentage intrarater measurement error for 3D CBCT and skull measurements. Mean percentage measurement error for 3D CBCT $(2.31 \pm$ $2.11 \%$; Range; $1.07 \pm 0.72 \%$ to $3.86 \pm 1.85 \%$ ) was significantly higher than repeated 
measurements to directly determine anatomic skull dimensions $(0.63 \pm 0.51 \%$; Range; $0.29 \pm$ $0.13 \%$ to $1.18 \pm 0.58 \%)(\mathrm{t}=16.6, P<.001)$. For all measurements except $\mathrm{Ba}-\mathrm{Na}, 3 \mathrm{D}$ CBCT mean absolute and percentage error was significantly higher than direct skull repeated measurements.

\section{Modality Accuracy}

Table 9 provides comparison of mean linear measurements obtained from 3D CBCT reconstructions and actual skull dimensions. 3D CBCT measurements were significantly different to actual skull measurements for 13 of the 20 parameters; seven of the eight mid-sagittal measurements (all except $\mathrm{Na}-\mathrm{A})$ and six of the 12 bilateral measurements (Pog-Go $\mathrm{Go}_{\text {right }}$, Go-Me, Go-Gn $\mathrm{left}_{\text {, }}$ and Po-Or). The greatest mean difference of $3.32 \mathrm{~mm}(3.56 \%)$ was found with BaANS. In eight of 20 measurements (40\%), an average difference of less than $1 \mathrm{~mm}$, three of which were significantly different from actual measurements was found. In six measurements (30\%) a mean difference of between $1 \mathrm{~mm}$ and $1.5 \mathrm{~mm}$ was found, and for five skulls the CBCT measurements were significantly different from actual measurements made directly on the anatomic specimens. In four measurements $(20 \%)$ an average difference of between $1.5 \mathrm{~mm}$ and $2 \mathrm{~mm}$ was found, all of which were significantly different from the assumed anatomic truth. Finally for two measurements $(10 \%)$ a mean difference greater than $2 \mathrm{~mm}$ was found, one of which was significantly different from the mean direct skull measurements. In all comparisons, except Na-B and Go-Gn bilaterally, 3D CBCT measurements were less than skull measurements. The mean percentage difference between the mean "actual" and mean 3D-based linear measurements was $-1.13 \%$ (s.d. $\pm 1.47 \%$ ) and ranged from -0.27 for $\mathrm{Na}-\mathrm{A}$ to $-3.44 \%$ for ANSPNS. 
Table 8. Comparison of absolute and percentage mean error for mid-sagittal and bilateral linear measurements between dimensions of planes on 23 skulls and measurements CBCT 3D reconstructions.

\begin{tabular}{|c|c|c|c|c|c|c|c|c|c|c|c|}
\hline \multirow[b]{3}{*}{ Plane } & \multirow[b]{3}{*}{ Location } & \multicolumn{4}{|c|}{ Skull } & \multicolumn{4}{|c|}{ CBCT $3 D$ Reconstructions } & & \\
\hline & & \multicolumn{2}{|c|}{ Absolute Error (mm) } & \multicolumn{2}{|c|}{ Percentage Error (\%) } & \multicolumn{2}{|c|}{ Absolute Error } & \multicolumn{2}{|c|}{ Percentage Error } & \multicolumn{2}{|c|}{ Significance } \\
\hline & & Mean \pm s.d. & $C L$ & Mean \pm s.d. & $C L$ & Mean \pm s.d. & $C L$ & Mean \pm s.d. & $C L$ & $t$ & $p$ \\
\hline S-N & MS & $0.41 \pm 0.2$ & 0.09 & $0.7 \pm 0.34$ & 0.15 & $1.82 \pm 0.86$ & 0.37 & $3.86 \pm 1.85$ & 0.80 & 7.61 & $<0.001$ \\
\hline $\mathrm{Ba}-\mathrm{Na}$ & MS & $0.69 \pm 0.35$ & 0.15 & $0.7 \pm 0.36$ & 0.15 & $0.85 \pm 0.60$ & 0.26 & $1.07 \pm 0.72$ & 0.31 & 1.1 & 0.280 \\
\hline $\begin{array}{l}\text { ANS- } \\
\text { PNS }\end{array}$ & MS & $0.55 \pm 0.25$ & 0.11 & $1.18 \pm 0.58$ & 0.25 & $1.30 \pm 1.46$ & 0.63 & $3.55 \pm 4.00$ & 1.73 & 2.43 & 0.019 \\
\hline $\mathrm{Na}-\mathrm{A}$ & MS & $0.33 \pm 0.16$ & 0.07 & $0.64 \pm 0.31$ & 0.13 & $1.44 \pm 1.08$ & 0.47 & $3.52 \pm 2.62$ & 1.13 & 4.90 & $<0.001$ \\
\hline $\mathrm{Na}-\mathrm{B}$ & MS & $0.33 \pm 0.18$ & 0.08 & $0.38 \pm 0.20$ & 0.09 & $1.41 \pm 2.02$ & 0.87 & $1.96 \pm 2.76$ & 1.19 & 2.53 & 0.015 \\
\hline $\mathrm{Na}-\mathrm{Me}$ & MS & $0.49 \pm 0.64$ & 0.28 & $0.45 \pm 0.54$ & 0.23 & $1.05 \pm 0.55$ & 0.24 & $1.22 \pm 0.65$ & 0.28 & 3.16 & $<0.01$ \\
\hline Na-ANS & MS & $0.32 \pm 0.17$ & 0.08 & $0.7 \pm 0.36$ & 0.16 & $1.16 \pm 0.86$ & 0.37 & $3.2 \pm 2.45$ & 1.06 & 4.54 & $<0.001$ \\
\hline Ba-ANS & MS & $1.07 \pm 0.93$ & 0.40 & $1.16 \pm 0.99$ & 0.43 & $2.11 \pm 2.12$ & 0.91 & $2.98 \pm 3.13$ & 1.35 & 2.15 & 0.040 \\
\hline \multirow[t]{2}{*}{ Pog-Go } & $\mathrm{Rt}$ & $0.29 \pm 0.10$ & 0.05 & $0.35 \pm 0.13$ & 0.06 & $1.24 \pm 1.12$ & 0.48 & $1.88 \pm 1.77$ & 0.76 & 4.04 & $<0.001$ \\
\hline & $\mathrm{Lt}$ & $0.3 \pm 0.11$ & 0.05 & $0.36 \pm 0.13$ & 0.06 & $1.21 \pm 0.80$ & 0.34 & $1.83 \pm 1.14$ & 0.49 & 5.40 & $<0.001$ \\
\hline \multirow[t]{2}{*}{ Pog-Co } & $\mathrm{Rt}$ & $0.33 \pm 0.15$ & 0.06 & $0.29 \pm 0.13$ & 0.06 & $2.27 \pm 1.80$ & 0.78 & $2.49 \pm 2.05$ & 0.89 & 5.16 & $<0.001$ \\
\hline & $\mathrm{Lt}$ & $0.35 \pm 0.24$ & 0.10 & $0.31 \pm 0.21$ & 0.09 & $1.61 \pm 1.65$ & 0.72 & $1.77 \pm 1.91$ & 0.83 & 3.60 & $<0.001$ \\
\hline \multirow[t]{2}{*}{ Go-Me } & Rt & $0.31 \pm 0.15$ & 0.06 & $0.38 \pm 0.19$ & 0.08 & $1.33 \pm 0.86$ & 0.37 & $2.12 \pm 1.31$ & 0.56 & 5.66 & $<0.001$ \\
\hline & $\mathrm{Lt}$ & $0.40 \pm 0.59$ & 0.25 & $0.51 \pm 0.75$ & 0.33 & $1.11 \pm 0.90$ & 0.39 & $1.77 \pm 1.38$ & 0.60 & 3.17 & $<0.01$ \\
\hline
\end{tabular}


Table 8 (Continued). Comparison of absolute and percentage mean error for mid-sagittal and bilateral linear measurements between dimensions of planes on 23 skulls and measurements CBCT 3D reconstructions.

\begin{tabular}{|c|c|c|c|c|c|c|c|c|c|c|c|}
\hline \multirow[b]{3}{*}{ Plane } & \multirow[b]{3}{*}{ Location } & \multicolumn{4}{|c|}{ Skull } & \multicolumn{4}{|c|}{ CBCT $3 D$ Reconstructions } & & \\
\hline & & \multicolumn{2}{|c|}{ Absolute Error $(\mathrm{mm})$} & \multicolumn{2}{|c|}{ Percentage Error (\%) } & \multicolumn{2}{|c|}{ Absolute Error } & \multicolumn{2}{|c|}{ Percentage Error } & \multicolumn{2}{|c|}{ Significance } \\
\hline & & Mean \pm s.d. & $C L$ & Mean $\pm s . d$. & $C L$ & Mean $\pm s . d$ & $C L$ & Mean \pm s.d. & $C L$ & $t$ & $p$ \\
\hline \multirow[t]{2}{*}{ Go-Co } & Rt & $0.37 \pm 0.18$ & 0.08 & $0.65 \pm 0.30$ & 0.13 & $0.97 \pm 0.71$ & 0.31 & $2.13 \pm 1.50$ & 0.65 & 3.91 & $<0.001$ \\
\hline & $\mathrm{Lt}$ & $0.30 \pm 0.12$ & 0.05 & $0.54 \pm 0.23$ & 0.1 & $1.12 \pm 0.97$ & 0.42 & $2.45 \pm 2.03$ & 0.78 & 4.04 & $<0.001$ \\
\hline \multirow[t]{2}{*}{ Go-Gn } & Rt & $0.69 \pm 0.51$ & 0.22 & $0.88 \pm 0.68$ & 0.29 & $1.56 \pm 1.24$ & 0.54 & $2.44 \pm 1.98$ & 0.86 & 3.08 & $<0.01$ \\
\hline & $\mathrm{Lt}$ & $0.71 \pm 0.66$ & 0.29 & $0.88 \pm 0.78$ & 0.34 & $1.43 \pm 0.77$ & 0.33 & $2.22 \pm 1.28$ & 0.55 & 3.36 & $<0.01$ \\
\hline \multirow[t]{2}{*}{ Po-Or } & Right & $0.56 \pm 0.23$ & 0.10 & $0.7 \pm 0.28$ & 0.12 & $1.22 \pm 0.90$ & 0.39 & $1.96 \pm 1.45$ & 0.63 & 3.41 & $<0.01$ \\
\hline & Left & $0.58 \pm 0.18$ & 0.08 & $0.74 \pm 0.23$ & 0.10 & $1.10 \pm 0.68$ & 0.29 & $1.80 \pm 1.13$ & 0.49 & 3.54 & $<0.001$ \\
\hline
\end{tabular}

* MS=Mid-sagittal; $\mathrm{Rt}=$ right, $\mathrm{Lt}=$ left $\quad \mathrm{CL}=95 \%$ Confidence Interval 
Table 9. Comparison of Absolute and Percentage differences for mid-sagittal and bilateral linear measurements between dimensions of planes on 23 skulls and measurements CBCT 3D reconstructions.

\begin{tabular}{|c|c|c|c|c|c|c|c|c|c|}
\hline \multirow[b]{3}{*}{ Plane } & \multirow[b]{3}{*}{ Location } & \multirow[b]{3}{*}{ Skull } & \multirow{3}{*}{$\begin{array}{c}\text { CBCT } 3 D \\
\text { Reconstructions }\end{array}$} & \multicolumn{4}{|c|}{ Difference } & & \\
\hline & & & & \multicolumn{2}{|c|}{ Absolute } & \multicolumn{2}{|c|}{ Percentage } & \multicolumn{2}{|c|}{ Significance } \\
\hline & & & & Mean & $C L$ & Mean & $C L$ & $t$ & $p$ \\
\hline S-N & MS & $59.31 \pm 3.75$ & $58.56 \pm 3.67$ & -0.75 & $(-1.25$ to -0.24$)$ & -1.26 & $(-2.11$ to -0.4$)$ & -3.059 & 0.006 \\
\hline $\mathrm{Ba}-\mathrm{Na}$ & MS & $98.81 \pm 4.99$ & $97.18 \pm 4.92$ & -1.63 & $(-2.02$ to -1.25$)$ & -1.65 & $(-2.04$ to -1.27$)$ & -8.72 & $<0.001$ \\
\hline ANS-PNS & MS & $47.70 \pm 3.25$ & $46.06 \pm 3.29$ & -1.64 & $(-2.32$ to -0.95$)$ & -3.44 & $(-4.86$ to -1.99$)$ & -4.94 & $<0.001$ \\
\hline $\mathrm{Na}-\mathrm{A}$ & MS & $51.00 \pm 3.36$ & $50.86 \pm 3.23$ & -0.14 & $(-0.63$ to 0.34$)$ & -0.27 & $(-1.24$ to 0.67$)$ & -0.61 & 0.546 \\
\hline $\mathrm{Na}-\mathrm{B}$ & MS & $88.64 \pm 5.71$ & $89.75 \pm 6.07$ & 1.11 & $(0.59$ to 1.62$)$ & 1.25 & (0.67 to 1.83$)$ & 4.5 & $<0.001$ \\
\hline $\mathrm{Na}-\mathrm{Me}$ & MS & $108.58 \pm 7.06$ & $107.77 \pm 7.03$ & -0.81 & $(-1.26$ to -0.36$)$ & -0.75 & $(-1.16$ to -0.33$)$ & -3.77 & 0.001 \\
\hline Na-ANS & MS & $46.41 \pm 2.86$ & $45.58 \pm 2.85$ & -0.83 & $(-1.10$ to -0.55$)$ & -1.79 & $(-2.37$ to -1.19$)$ & -6.17 & $<0.001$ \\
\hline Ba-ANS & MS & $93.17 \pm 6.31$ & $89.85 \pm 7.40$ & -3.32 & $(-4.96$ to -1.68$)$ & -3.56 & $(-5.32$ to -1.8$)$ & -4.19 & $<0.001$ \\
\hline \multirow[t]{2}{*}{ Pog-Go } & Rt & $83.33 \pm 5.83$ & $81.86 \pm 5.65$ & -1.48 & $(-2.08$ to -0.87$)$ & -1.78 & $(-2.50$ to -1.04$)$ & -5.09 & $<0.001$ \\
\hline & $\mathrm{Lt}$ & $84.20 \pm 9.76$ & $81.78 \pm 5.71$ & -2.42 & $(-5.31$ to 0.47$)$ & -2.87 & $(-6.31$ to 0.56$)$ & -1.73 & 0.097 \\
\hline \multirow[t]{2}{*}{ Pog-Co } & Rt & $114.77 \pm 5.39$ & $114.20 \pm 4.84$ & -0.57 & $(-1.32$ to 0.17$)$ & -0.50 & $(-1.15$ to 0.15$)$ & -1.59 & 0.127 \\
\hline & Lt & $114.63 \pm 5.44$ & $113.88 \pm 5.02$ & -0.75 & $(-1.67$ to 0.16$)$ & -0.65 & $(-1.46$ to 0.14$)$ & -1.69 & 0.104 \\
\hline \multirow[t]{2}{*}{ Go-Me } & Rt & $79.89 \pm 5.59$ & $78.16 \pm 5.19$ & -1.73 & $(-2.35$ to -1.12$)$ & -2.17 & $(-2.94$ to -1.4$)$ & -5.83 & $<0.001$ \\
\hline & Lt & $79.31 \pm 5.93$ & $78.21 \pm 5.29$ & -1.09 & $(-1.64$ to -0.55$)$ & -1.37 & $(-2.07$ to -0.69$)$ & -4.14 & $<0.001$ \\
\hline
\end{tabular}


Table 9 (Continued). Comparison of Absolute and Percentage differences for mid-sagittal and bilateral linear measurements between dimensions of planes on 23 skulls and measurements CBCT $3 \mathrm{D}$ reconstructions.

\begin{tabular}{|c|c|c|c|c|c|c|c|c|c|}
\hline \multirow[b]{3}{*}{ Plane } & \multirow[b]{3}{*}{ Location } & \multirow[b]{3}{*}{ Skull } & \multirow{3}{*}{$\begin{array}{c}C B C T 3 D \\
\text { Reconstructions }\end{array}$} & \multicolumn{4}{|c|}{ Difference } & \multirow{2}{*}{\multicolumn{2}{|c|}{ Significance }} \\
\hline & & & & \multicolumn{2}{|c|}{ Absolute } & \multicolumn{2}{|c|}{ Percentage } & & \\
\hline & & & & Mean & $C L$ & Mean & $C L$ & $t$ & $p$ \\
\hline \multirow[t]{2}{*}{ Go-Co } & Rt & $56.38 \pm 4.97$ & $56.22 \pm 4.71$ & -0.16 & $(-0.74$ to 0.43$)$ & -0.28 & $(-1.31$ to 0.76$)$ & -0.547 & 0.590 \\
\hline & $\mathrm{Lt}$ & $56.54 \pm 5.04$ & $56.00 \pm 4.21$ & -0.53 & $(-1.07$ to 0.002$)$ & -0.94 & $(-1.89$ to 0.0$)$ & -2.067 & 0.051 \\
\hline \multirow[t]{2}{*}{ Go-Gn } & Rt & $79.85 \pm 6.52$ & $81.18 \pm 6.02$ & 1.33 & $(-0.064$ to 2.72$)$ & 1.67 & $(-0.08$ to 3.41$)$ & 1.98 & 0.061 \\
\hline & $\mathrm{Lt}$ & $79.78 \pm 6.20$ & $81.04 \pm 5.92$ & 1.27 & (0.38 to 2.16$)$ & 1.59 & $(0.48$ to 2.71$)$ & 2.95 & 0.007 \\
\hline \multirow[t]{2}{*}{ Po-Or } & Right & $78.97 \pm 4.79$ & $77.59 \pm 4.43$ & -1.38 & $(-2.06$ to -0.69$)$ & -1.75 & $(-2.61$ to -0.87$)$ & -4.16 & $<0.001$ \\
\hline & Left & $78.00 \pm 4.82$ & $76.33 \pm 4.83$ & -1.67 & $(-2.41$ to -0.93$)$ & -2.14 & $(-3.09$ to -1.19$)$ & -4.68 & $<0.001$ \\
\hline
\end{tabular}




\section{Analysis of 2D Measurements}

\section{Measurement Reliability}

Table 10 shows the average measure ICC of triplicate skull measurements made by multiple raters compared to triplicate linear measurements made by the first author for each linear dimension for PSP and CBCT LC. The one-way ANOVA identified a significant difference $(\mathrm{F}=3.29 ; \mathrm{p}=.048)$, however post hoc analysis was unable to identify differences between PSP $(0.973 \pm 0.052 ;$ range; 0.942 to 1.0$)$, skull $(0.997 \pm 0.003 ;$ range; 0.996 to 0.998$)$, or CBCT LC $(0.999 \pm 0.001$; range; 0.998 to 0.999$)$ ICC.

Table 11 shows the absolute and mean percentage intrarater measurement error for PSP, CBCT LC and skull measurements. One-way ANOVA analysis demonstrated differences between modalities with absolute $(\mathrm{F}=13.71, \mathrm{p}<.001)$ and percentage error measurements $(\mathrm{F}=12.52, \mathrm{p}<.001)$. Mean absolute measurement error for skull dimensions $(.49 \pm .22 \mathrm{~mm}$; Range; $.362-.612)$ were significantly lower than PSP (.93 $\pm .44 \mathrm{~mm}$; Range; .68 to 1.18$)$ or CBCT LC $(1.19 \pm .39 \mathrm{~mm}$; Range; .97 to 1.41$)$. Mean percentage measurement error for skull dimensions $(.66 \pm .27 \%$; Range; $.50 \%-.82 \%)$ were significantly lower than PSP $(1.39 \pm .77 \%$; Range; $.94 \%-$ $1.83 \%)$ or CBCT LC (1.75 $\pm .60 \%$; Range; $1.4 \%-2.09 \%)$. For all measurements, except Po-Or, CBCT LC mean absolute and percentage error was significantly higher than direct skull repeated measurements.

\section{Modality Accuracy}

Table 12 provides a comparison of mean linear measurements obtained from PSP, CBCT LC and actual skull dimensions. Overall no differences between modalities were found ( $\mathrm{F}=.098$, $\mathrm{p}=.91$ ). However for all of the bilateral structures, except Go-Co, skull dimensions were significantly less than either PSP or CBCT LC measurements. This difference varied from $4.7 \%$ (Po-Or) to $17 \%$ (Go-Me). No differences were found between measurements obtained from PSP or CBCT cephalometric images for all bilateral structures. 
For all mid-sagittal measurements, except Ba-Na, no differences between modalities were found. For Ba-NA PSP measurements were significantly larger than skull or CBCT LC dimensions by $4.5 \%$. 
Table 10. Average measure intra-class correlation coefficient for multiple measurements of linear dimensions by multiple observers on 23 skulls and for a single observer on photostimulable storage phosphor cephalograms (PSP) and simulated cephalograms generated from CBCT volumetric datasets (CBCT LC).

\begin{tabular}{|c|c|c|c|c|c|c|c|c|c|}
\hline \multirow[b]{5}{*}{ Plane } & \multicolumn{9}{|c|}{ Modality } \\
\hline & & & & \multicolumn{6}{|c|}{ Lateral Cephalometric images } \\
\hline & \multicolumn{3}{|c|}{ Skull } & \multicolumn{3}{|c|}{$P S P$} & \multicolumn{3}{|c|}{$C B C T L C$} \\
\hline & \multirow{2}{*}{$\frac{\text { Mean }}{\text { Mean }}$} & \multicolumn{2}{|c|}{$C L$} & \multirow{2}{*}{$\frac{\text { Mean }}{\text { Mean }}$} & \multicolumn{2}{|c|}{$C L$} & \multirow{2}{*}{$\frac{\text { Mean }}{\text { Mean }}$} & \multicolumn{2}{|c|}{$C L$} \\
\hline & & Lower & Upper & & Lower & Upper & & Lower & Upper \\
\hline $\mathrm{S}-\mathrm{N}$ & 0.998 & 0.996 & 0.999 & 0.794 & 0.588 & 0.906 & 0.997 & 0.995 & 0.999 \\
\hline $\mathrm{Ba}-\mathrm{Na}$ & 0.996 & 0.994 & 0.998 & 0.994 & 0.988 & 0.997 & 0.999 & 0.998 & 0.999 \\
\hline ANS-PNS & 0.994 & 0.990 & 0.997 & 0.972 & 0.944 & 0.987 & 0.999 & 0.999 & 0.999 \\
\hline $\mathrm{Na}-\mathrm{A}$ & 0.999 & 0.997 & 0.999 & 0.986 & 0.972 & 0.994 & 0.999 & 0.999 & 0.999 \\
\hline $\mathrm{Na}-\mathrm{B}$ & 0.996 & 0.994 & 0.998 & 0.997 & 0.994 & 0.999 & 0.999 & 0.998 & 0.999 \\
\hline $\mathrm{Na}-\mathrm{Me}$ & 0.997 & 0.995 & 0.999 & 0.999 & 0.999 & 0.999 & 0.999 & 0.999 & 0.999 \\
\hline Na-ANS & 0.997 & 0.995 & 0.999 & 0.993 & 0.986 & 0.997 & 0.997 & 0.995 & 0.999 \\
\hline Ba-ANS & 0.990 & 0.981 & 0.996 & 0.998 & 0.996 & 0.999 & 0.998 & 0.998 & 0.999 \\
\hline Pog-Go (Lt.) & 0.999 & 0.999 & 0.999 & 0.985 & 0.970 & 0.993 & 0.999 & 0.998 & 0.999 \\
\hline Pog-Go (Rt.) & 0.999 & 0.999 & 0.999 & --- & --- & --- & --- & --- & -- \\
\hline Pog-Co (Lt.) & 0.999 & 0.999 & 0.999 & 0.987 & 0.974 & 0.994 & 0.999 & 0.999 & 0.999 \\
\hline Pog-Co (Rt.) & 0.999 & 0.999 & 0.999 & --- & --- & --- & --- & --- & --- \\
\hline
\end{tabular}


Table 10 (Continued). Average measure intra-class correlation coefficient for multiple measurements of linear dimensions by multiple observers on 23 skulls and for a single observer on photostimulable storage phosphor cephalograms (PSP) and simulated cephalograms generated from CBCT volumetric datasets (CBCT LC).

\begin{tabular}{|c|c|c|c|c|c|c|c|c|c|}
\hline \multirow[b]{5}{*}{ Plane } & \multicolumn{9}{|c|}{ Modality } \\
\hline & & & & \multicolumn{6}{|c|}{ Lateral Cephalometric images } \\
\hline & \multicolumn{3}{|c|}{ Skull } & \multicolumn{3}{|c|}{$P S P$} & \multicolumn{3}{|c|}{$C B C T L C$} \\
\hline & \multirow{2}{*}{$\frac{\text { Mean }}{\text { Mean }}$} & \multicolumn{2}{|c|}{$C L$} & \multirow{2}{*}{$\frac{\text { Mean }}{\text { Mean }}$} & \multicolumn{2}{|c|}{$C L$} & \multirow{2}{*}{$\frac{\text { Mean }}{\text { Mean }}$} & \multicolumn{2}{|c|}{$C L$} \\
\hline & & Lower & Upper & & Lower & Upper & & Lower & Upper \\
\hline Go-Me (Lt.) & 0.997 & 0.995 & 0.999 & 0.979 & 0.959 & 0.991 & 0.999 & 0.999 & 0.999 \\
\hline Go-Me (Rt.) & 0.999 & 0.999 & 0.999 & --- & --- & -- & & & --- \\
\hline Go-Co (Lt.) & 0.999 & 0.999 & 0.999 & 0.977 & 0.953 & 0.989 & 0.999 & 0.999 & 0.999 \\
\hline Go-Co (Rt0.) & 0.999 & 0.999 & 0.999 & --- & --- & -- & --- & --- & --- \\
\hline Go-Gn (Lt.) & 0.995 & 0.990 & 0.998 & 0.982 & 0.963 & 0.992 & 0.999 & 0.998 & 0.999 \\
\hline Go-Gn (Rt.) & 0.997 & 0.993 & 0.999 & --- & --- & --- & --- & --- & --- \\
\hline \multirow[t]{2}{*}{ Po-Or } & 0.998 & 0.997 & 0.999 & 0.972 & 0.944 & 0.987 & 0.999 & 0.998 & 0.999 \\
\hline & 0.998 & 0.996 & 0.998 & --- & --- & --. & --. & --- & --- \\
\hline
\end{tabular}

$\mathrm{CL}=95 \%$ Confidence Limit 
Table 11. Comparison of absolute and percentage mean error for mid-sagittal and bilateral linear measurements between dimensions of planes on 23 skulls and measurements made on photostimulable storage phosphor cephalograms (PSP) and simulated cephalograms generated from CBCT volumetric datasets (CBCT LC).

\begin{tabular}{lccccccccc}
\hline & & \multicolumn{2}{c}{ Skull } & \multicolumn{2}{c}{ PSP } & \multicolumn{2}{c}{ CBCT LC } & \multicolumn{2}{c}{ Significance } \\
\cline { 3 - 9 } Plane & Location & Absolute & Percentage & Absolute & Percentage & Absolute & Percentage & $\boldsymbol{F}$ & $\boldsymbol{p}$ \\
\hline S-N & MS & $0.42 \pm 0.20$ & $0.70 \pm 0.34$ & $0.85 \pm 2.12$ & $1.45 \pm 3.65$ & $1.91 \pm 1.86$ & $2.49 \pm 3.40$ & 3.16 & 0.049 \\
Ba-Na & MS & $0.69 \pm 0.35$ & $0.71 \pm 0.36$ & $0.61 \pm 0.75$ & $0.60 \pm 0.75$ & $1.25 \pm 0.72$ & $1.94 \pm 1.63$ & 6.95 & 0.002 \\
ANS-PNS & MS & $0.55 \pm 0.25$ & $1.18 \pm 0.58$ & $0.93 \pm 0.65$ & $1.98 \pm 1.41$ & $0.89 \pm 0.47$ & $1.29 \pm 0.82$ & 4.11 & 0.021 \\
Na-A & MS & $0.33 \pm 0.16$ & $0.64 \pm 0.31$ & $0.64 \pm 0.35$ & $1.25 \pm 0.66$ & $0.97 \pm 0.82$ & $1.60 \pm 1.48$ & 8.63 & 0.000 \\
Na-B & MS & $0.34 \pm 0.18$ & $0.38 \pm 0.20$ & $0.64 \pm 0.36$ & $0.71 \pm 0.39$ & $1.01 \pm 0.57$ & $1.45 \pm 0.97$ & 15.77 & 0.000 \\
Na-Me & MS & $0.49 \pm 0.64$ & $0.45 \pm 0.55$ & $0.35 \pm 0.23$ & $0.32 \pm 0.20$ & $1.12 \pm 0.69$ & $1.5 \pm 0.82$ & 12.38 & 0.000 \\
Na-ANS & MS & $0.33 \pm 0.17$ & $0.70 \pm 0.36$ & $0.41 \pm 0.23$ & $0.90 \pm 0.50$ & $2.10 \pm 1.93$ & $3.43 \pm 3.76$ & 18.04 & 0.000 \\
Ba-ANS & MS & $1.07 \pm 0.93$ & $1.16 \pm 0.99$ & $0.51 \pm 0.42$ & $0.54 \pm 0.44$ & $1.37 \pm 0.78$ & $1.96 \pm 1.35$ & 7.91 & 0.001 \\
Pog-Go & Ave. Lt/Rt & $0.30 \pm 0.07$ & $0.35 \pm 0.08$ & $1.37 \pm 1.01$ & $1.97 \pm 1.51$ & $1.01 \pm 0.88$ & $1.67 \pm 1.81$ & 11.52 & 0.000 \\
Pog-Co & Ave. Lt/Rt & $0.34 \pm 0.14$ & $0.30 \pm 0.12$ & $0.99 \pm 0.90$ & $0.93 \pm 0.79$ & $1.09 \pm 0.74$ & $1.52 \pm 0.99$ & 8.42 & 0.001 \\
Go-Me & Ave. Lt/Rt & $0.35 \pm 0.29$ & $0.45 \pm 0.38$ & $1.40 \pm 1.14$ & $2.18 \pm 1.88$ & $0.88 \pm 0.74$ & $1.17 \pm 0.94$ & 9.90 & 0.000 \\
Go-Co & Ave. Lt/Rt & $0.34 \pm 0.10$ & $0.60 \pm 0.18$ & $1.52 \pm 0.10$ & $2.81 \pm 1.90$ & $0.71 \pm 0.57$ & $1.04 \pm 0.93$ & 19.03 & 0.000 \\
Go-Gn & Ave. Lt/Rt & $0.70 \pm 0.37$ & $0.88 \pm 0.45$ & $1.72 \pm 1.14$ & $2.33 \pm 1.62$ & $1.18 \pm 0.67$ & $1.72 \pm 0.94$ & 9.31 & 0.000 \\
Po-Or & Ave. Lt/Rt & $0.57 \pm 0.13$ & $0.72 \pm 0.15$ & $1.09 \pm 0.85$ & $1.44 \pm 1.07$ & $1.15 \pm 1.48$ & $1.65 \pm 2.42$ & 2.41 & 0.098 \\
\hline *MS=Mid-sagittal; Rt=right, Lt=left & & & & & & & &
\end{tabular}

* MS=Mid-sagittal; Rt=right, Lt=left 
Table 12. Comparison of Mean Linear measurements ( \pm s.d.) between cephalometric landmarks on Storage Phosphor and CBCT Derived Simulated Lateral Cephalometric Images of 23 Skulls.

\begin{tabular}{|c|c|c|c|c|c|c|}
\hline \multirow[b]{2}{*}{ Plane } & \multirow[b]{2}{*}{ Location } & \multirow[b]{2}{*}{ Skull } & \multicolumn{2}{|c|}{ Lateral Cephalometric } & \multicolumn{2}{|c|}{ Significance } \\
\hline & & & Storage phosphor & Simulated from $C B C T$ & $F$ & $p$ \\
\hline S-N & MS & $59.31 \pm 3.75$ & $59.76 \pm 2.41$ & $58.60 \pm 3.65$ & 0.71 & 0.5 \\
\hline $\mathrm{Ba}-\mathrm{Na}^{\mathrm{a}}$ & MS & $98.81 \pm 4.99$ & $103.30 \pm 5.63$ & $100.33 \pm 5.02$ & 4.4 & .016 \\
\hline ANS-PNS & MS & $47.70 \pm 3.25$ & $46.87 \pm 2.94$ & $46.98 \pm 2.87$ & 0.5 & 0.61 \\
\hline $\mathrm{Na}-\mathrm{A}$ & MS & $51.00 \pm 3.36$ & $50.87 \pm 2.78$ & $50.66 \pm 2.59$ & 0.08 & 0.93 \\
\hline $\mathrm{Na}-\mathrm{B}$ & MS & $88.64 \pm 5.71$ & $89.64 \pm 5.83$ & $88.82 \pm 5.95$ & 0.19 & 0.83 \\
\hline $\mathrm{Na}-\mathrm{Me}$ & MS & $108.58 \pm 7.06$ & $109.38 \pm 6.98$ & $107.96 \pm 6.64$ & 0.24 & 0.79 \\
\hline Na-ANS & MS & $46.41 \pm 2.86$ & $46.25 \pm 2.58$ & $45.94 \pm 2.49$ & 0.19 & 0.83 \\
\hline Ba-ANS & MS & $93.17 \pm 6.31$ & $96.11 \pm 6.48$ & $94.80 \pm 5.98$ & 1.23 & 0.29 \\
\hline $\mathrm{Pog}-\mathrm{Go}^{\mathrm{b}}$ & Bilat & $83.76 \pm 7.46$ & $70.83 \pm 5.77$ & $71.44 \pm 6.48$ & 28.08 & $<0.001$ \\
\hline $\mathrm{Pog}-\mathrm{Co}^{\mathrm{b}}$ & Bilat & $114.7 \pm 5.35$ & $105.40 \pm 5.25$ & $105.76 \pm 5.92$ & 21.02 & $<0.001$ \\
\hline $\mathrm{Go}^{\mathrm{Me}} \mathrm{b}^{\mathrm{b}}$ & Bilat & $79.6 \pm 5.72$ & $65.46 \pm 5.27$ & $65.16 \pm 6.06$ & 48.39 & $<0.001$ \\
\hline Go-Co & Bilat & $56.46 \pm 4.93$ & $55.06 \pm 5.02$ & $55.72 \pm 4.68$ & 0.47 & 0.63 \\
\hline Go-Gn ${ }^{b}$ & Bilat & $79.81 \pm 6.24$ & $74.37 \pm 5.92$ & $75.12 \pm 6.65$ & 5.09 & 0.009 \\
\hline Po-Or ${ }^{b}$ & Bilat & $78.49 \pm 4.73$ & $75.02 \pm 3.71$ & $74.31 \pm 4.04$ & 6.57 & 0.003 \\
\hline
\end{tabular}

${ }^{\mathrm{a}}$ Significant difference between Truth and the PSP lateral cephalometic $(\mathrm{p}=.018) .{ }^{\mathrm{b}}$ Significant difference between truth and lateral cephalometrics from both methods (both $p<.0001$ ) 


\section{CHAPTER V}

\section{DISCUSSION}

No single imaging technique has been readily available that provides an accurate, easily interpreted representation of all osseous aspects of the craniofacial region in one exposure. Previously, a plain lateral cephalogram in combination with a panoramic radiograph and occasionally a posterior anterior or submentovertex projection has been used for standard imaging analysis in orthodontics. The introduction of maxillofacial cone beam imaging equipment provides clinicians with an opportunity to generate $2 \mathrm{D}$ simulated projections and 3D volumetric renderings easily using relatively inexpensive third party personal computer based software. The rapidly emerging availability of this technology will undoubtedly expand the use and application of 3D imaging, particularly in the field of orthodontics. The aim of this study was to compare linear dimensions between common cephalometric landmarks on a sample of skulls to both 3D measurements and 2D measurements obtained from reconstructed CBCT images and planar PSP lateral cephalometric radiographs.

For $2 \mathrm{D}$ analysis we found that for most mid-sagittal measurements, simulated lateral cephalometric images produced from reconstructed CBCT volumetric dataset were similar to those from PSP images. In addition we found these measurements to be accurate, except for Ba$\mathrm{Na}$ from PSP, which overestimated this dimension. For bilateral measurements, simulated CBCT LC measurements were similar to those obtained from PSP however, as expected because of projection geometry, both modalities were less accurate, underestimating dimensions by between $4.7 \%$ to $17 \%$. Our results compare well to those of Chan et al.[69] who also found no statistically 
significant difference between skull, traditional frontal cephalometric and CBCT measurements. Our results also compare favorably with previous work done by Chidiac et al.[68] who were unable to reveal any statistically significant differences between mean angular values on cephalometric radiographs and $\mathrm{CT}$ views.

For 3D measurements we found that for two-thirds of dimensions, CBCT measurements were statistically significantly different from actual measurements. However analyzing the absolute and percentage differences, this statistical significance probably does not translate into clinical relevance. Statistical differences most likely resulted from small standard deviations within the measurements. In addition, the greater intraobserver variability demonstrated by the 3D CBCT measurements may have also contributed. These results are very similar in magnitude to those of Cavalcanti et al. [74] However; they reported no statistically significant difference between imaging and physical measurements. Their mean difference between actual and 3Dbased linear measurements was $0.83 \%$ as compared with $-1.13 \pm 1.47 \%$ in the present study. In the present study, $40 \%$ of measurements had an average difference of less than one millimeter, $70 \%$ had an average difference of less than $1.5 \mathrm{~mm}$ and $90 \%$ had an average difference of less than $2 \mathrm{~mm}$. These absolute differences compare favorably with those reported by additional authors. $[48,49]$

For two dimensional analyses, the only sagittal measurement where lateral cephalograms were inaccurate was $\mathrm{Na}-\mathrm{Ba}$. This inaccuracy is most likely due to the intrinsic difficulty in locating Basion on a lateral cephalogram. Geelen et al. [87] compared the reproducibility of cephalometric landmarks on conventional films and PSP images displayed both as hard copy and on computer screen and found Basion to have the third highest envelope of identification intrarater error (after Porion and Orbitale) with a mean deviation of $1.28 \pm 1.06 \mathrm{~mm}, 1.46$ $\pm 1.54 \mathrm{~mm}$ and $1.99 \pm 1.67 \mathrm{~mm}$ respectively. The anatomic location of Basion, which is situated between muscle and parenchyma, is considered to be an area of the image of high anatomic, 
structural noise, where there is a low signal to noise ratio. The gray areas of the image are resultantly blurred therefore making anatomic landmark identification more difficult.

We anticipated differences in cephalometric dimensions obtained from bilateral planes compared to skull measurements. This is because of the concept of linear projective transformation.[88] This concept explains that due to the position and orientation of equidistant lines in $3 \mathrm{D}$ space, that these lines are projected onto the film plane as different lengths due to inherent geometric projection errors. So any measurement made on the film is not correct when compared to the "Anatomic Truth."

For two dimensional measurements, mean absolute and mean percentage intrarater measurement error for skull dimensions $(.49 \pm .22 \mathrm{~mm})$ were significantly lower than PSP $(.93 \pm$ $.44 \mathrm{~mm})$ or CBCT LC $(1.19 \pm .39 \mathrm{~mm})$. Mean percentage measurement error for skull dimensions $(.66 \pm .27 \%)$ were significantly lower than PSP $(1.39 \pm .77 \%)$ or CBCT LC $(1.75 \pm .60 \%)$. This difference may be due to the fact that all skull landmarks were physically located with an indelible marker, serving as a fiducial reference point for physical measurements. The digitization of landmarks on PSP and CBCT lateral cephalograms was performed three times independently by the PI and therefore it was necessary to re-locate landmarks and re-measure distances with each tracing. The lack of a digital indelible landmark position for PSP and CBCT lateral cephalometric radiographs contributed to the overall increased mean absolute measurement error for these two modalities. This result is also unexpected because of the inherent resolution differences between PSP images and CBCT derived images. PSP cephalometric images have an inherent spatial resolution of 300 dpi whereas $\mathrm{CBCT}$ images have a $0.4 \mathrm{~mm}$ voxel size (63.5 dpi). However Held et al. (2001) found that the ability to identify landmarks did not differ significantly between cephalometric images scanned at resolutions ranging from 600 to 75 dpi.

There are numerous factors which should be considered when applying the results of this investigation to clinical situations. First and foremost this study was performed on human skulls. 
The accuracy of measurement distances between three dimensional landmarks on actual patients may be affected by a reduction in image quality due to soft-tissue attenuation, metallic artifacts and patient motion. Variation in scanning protocol such as voxel size and number of basis projection images may also influence measurement accuracy. Therefore it would be expected that the dimensional accuracy of all measurements would be somewhat less on patient derived data.

There are also some potential limitations when using 3D images derived from CBCT data. Three dimensional volumetric depictions depend on appropriate segmentation - the thresholding of bone pixel values and suppression of surrounding tissue values to enhance the structure of interest. This process is dependent on the software algorithm, the spatial and contrast resolution of the scan, the thickness and degree of calcification or cortication of the bony structure and the technical skill of the operator. In this study, the Dolphin 3D software provides a semi-manual method of segmentation, dependent on the interaction of the operator with the data to produce a visually acceptable $3 \mathrm{D}$ rendering. These limitations result in deficiencies or voids in the surface of the image. These occur in regions that are represented by few voxels or have gray values still representing bone, but outside the threshold. These areas include the posterior and anterior superior walls of the maxillary sinus, bone overlying the dentition and cortical bone of the mandibular condyle. Consequently this may lead to greater landmark identification error and subsequent measurement error. Anatomic landmarks whose accuracy may be affected by poor segmentation include A point, ANS, PNS, Porion, and Condylion.

In addition, the method of establishing dimensional truth could have potentially contributed to bias in the results. While the landmark identification and measurements on the 3D rendered images were repeated three times by a single observer, the landmark identification on the skulls was performed only once and measurements performed three times by two observers independently. This reduced the error of point identification on the skulls; however, the establishment of a consensus landmark location was necessary to provide a fiducial reference to 
which we could assess the inherent clinical inaccuracies of both landmark identification and measurement associated with the 3D image rendering.

We were unable to completely simulate soft tissue effects of attenuation on image quality in this study as this would have been problematic in positioning and orientation of the skulls. While the use of water balloons placed within the cranial cavity provided some degree of soft tissue attenuation, the lack of peripheral attenuation material may have allowed easier identification of landmarks on 3D surface rendered images.

While the results of this investigation indicate that it is possible to generate reliable and accurate simulated lateral cephalometric images from CBCT volumetric data sets, before this technique is recommended it will be necessary to compare the relative diagnostic yield from existing imaging series. In addition it is necessary to compare the measurement accuracy of 2D images obtained from $\mathrm{CB}$ volumes using dose reduction techniques such as decreasing the number of basis images. It has been reported effective dose $E_{\text {ICRP1990) }}$ and $E_{\text {(ICRP2005 draft) }}$ for the iCAT is $134.8 \mu \mathrm{Sv}$ and $193.4 \mu \mathrm{Sv}$ respectively for a 12 "' FOV scan and a $20 \mathrm{sec}$. scan. While it is hoped that a CBCT examination would never be substituted for a panoramic examination alone, in the case of orthodontic diagnosis, performance of a CBCT scan to generate a panoramic, lateral and posterior-anterior (PA) cephalometric images may be considered.[89] Dose calculations using ICRP 1990 tissue weights are $6.2 \mu \mathrm{Sv}$ for a direct digital panoramic image[2] and $3.4 \mu \mathrm{Sv}$ for 2 cephalometric images.[90] If the calculation of $\mathrm{E}$ is modified to include salivary glands then the panoramic and cephalometric doses increase to $22 \mu \mathrm{Sv}$ and $6.8 \mu \mathrm{Sv}$, respectively. Therefore a conventional digital orthodontic extraoral series (panoramic, lateral cephalaometric and PA) would provide a dose of between $9.61 \mu \mathrm{Sv}\left[E\left(_{\mathrm{ICRP} 1990)}\right]\right.$ and $28.8 \mu \mathrm{Sv}\left[E_{(\mathrm{ICRP} 2005 \mathrm{draft})}\right]$. Comparing this radiation detriment from conventional digital to $\mathrm{CBCT}$ derived simulated images using the standard number of projections ( $20 \mathrm{sec} ., 306$ projections), CBCT imaging is between $6\left[E_{\text {ICRP2005 }}\right.$ draft) $]$ and $14\left[E\left({ }_{\mathrm{ICRP} 1990)}\right]\right)$ times these conventional exposures. 


\section{CHAPTER VI}

\section{SUMMARY AND CONCLUSIONS}

The purpose of this project was twofold: 1) to compare the accuracy and reliability of linear measurements on lateral cephalograms made conventionally using photostimulable storage phosphor imaging plates (PSP) and simulated lateral cephalometric images from ray sum reconstructions of cone beam computed tomographic (CBCT) volumetric datasets of the same anatomic specimens and 2) to compare the accuracy and reliability of measurements of 3D shaded surface volumetric reconstructions.

While the ICC was high for both 2D and 3D modalities, the mean absolute and mean percentage intrarater measurement error for skull dimensions were significantly lower than PSP cephalograms, CBCT cephalograms and 3D CBCT images. Measurements on I-CAT CBCT simulated lateral images using Dolphin Software were as reliable and as accurate as PSP cephalometric measurements. We found that for most mid-sagittal measurements, simulated lateral cephalometric images produced from reconstructed CBCT volumetric dataset were similar to those from PSP images. In addition we found that these measurements were accurate, except for Ba-Na from PSP, which overestimated this dimension. For bilateral measurements, simulated CBCT LC measurements were similar to those obtained from PSP however, as expected by considerations of projective geometry, underestimated dimensions by between $4.7 \%$ to $17 \%$.

While many linear measurements between cephalometric landmarks on 3D volumetric surface renderings obtained using Dolphin 3D software generated from i-CAT CBCT datasets may be statistically significantly different from anatomic dimensions, most can be considered to be sufficiently clinically accurate $(-1.13 \pm 1.47 \%)$ for craniofacial analyses. 
While CBCT imaging provides reliable and accurate 2D simulation images and accurate and reliable 3D rendering, dose considerations with the adoption of any technique involving ionizing radiation must be considered. Conventional digital orthodontic extraoral series (panoramic, lateral cephalaomertic and PA) provide a dose of between $9.6 \mu \mathrm{Sv}\left[E_{\text {ICRP1990) }}\right]$ and $28.8 \mu \mathrm{Sv}\left[E_{\text {(ICRP2005 dratt) }}\right]$. Comparing this to the theoretical dose from CBCT i-CAT imaging using the standard number of basis projection images (306) $\left(E_{\text {ICRP1990) }}\right.$ and $E_{\text {(ICRP2005 draft }}$ of $134 \mu S v$ and $194 \mu \mathrm{S} v$ respectively), CBCT imaging still provides between $7\left[E_{(\mathrm{ICRP} 2005 \mathrm{draft}}\right]$ and $14\left[E\left(_{\text {ICRP1990) }}\right]\right)$ times more radiation detriment.

While CBCT imaging provides clinically reliable and accurate 3D volume rendered images and 2D simulation images, dose considerations demand that evidence-based selection criteria should be developed for CBCT in orthodontics that take into account the ALARA principle [65]. 


\section{REFERENCES}

1. Schulze D, Heiland M, Thurmann H, Adam G. Radiation exposure during midfacial imaging using 4- and 16-slice computed tomography, cone beam computed tomography systems and conventional radiography. Dentomaxillofac Radiol 2004;33:83-86.

2. Ludlow JB, Davies-Ludlow LE, Brooks SL. Dosimetry of two extraoral direct digital imaging devices: NewTom cone beam CT and Orthophos Plus DS panoramic unit. Dentomaxillofac Radiol 2003;32:229-243.

3. Mah JK, Danforth RA, Bumann A, Hatcher D. Radiation absorbed in maxillofacial imaging with a new dental computed tomography device. Oral Surg Oral Med Oral Pathol Oral Radiol Endod 2003;96:508-513.

4. Tsiklakis K, Donta C, Gavala S, Karayianni K, Kamenopoulou V, Hourdakis CJ. Dose reduction in maxillofacial imaging using low dose Cone Beam CT. Eur J Radiol. 2005 Jun 21 ; [In Press]

5. Swennen GRJ, Schutyser F. Three-dimensional cephalometry: Spiral multi-slice vs conebeam computed tomography. Am J Orthod Dentofacial Orthop 2006;130:410-416.

6. Farman AG, Jacobs W. Digital options for panoramic radiology. Panoramic Imaging News 2003;3(4):1-6.

7. Schulze RKW, Burkhardt Gloede M, Doll GM. Landmark identification on direct digital versus film-based cephalometric radiographs: A human skull study. Am J Orthod Dentofacial Orthop 2002; 122:635-642.

8. Farman AG, Farman TT. Extraoral and panoramic systems. Dental Clinics of North America 2000;44:257-272

9. Gregston M, Kula T, Hardman P, Glaros A, Kula K. A comparison of conventional and digital radiographic methods and cephalometric analysis software: I. Hard tissue. Semin Orthod 2004;10:204-211.

10. Kublashvili T, Kula K, Glaros A, Hardman P, Kula T. A Comparison of Conventional and Digital Radiographic Methods and Cephalometric Analysis Software: II. Soft Tissue. Semin Orthod 2004;10:212-219.

11. Malkoc S, Sari Z, Usumez S, Koyuturk AE. The effect of head rotation on cephalometric radiographs. Eur J Orthod. 2005 Jun;27(3):315-21.

12. Major P, Johnson D, Hesse K, Glover K 1994 Landmark identification error in posterior anterior cephalometrics. Angle Orthodontist 1994;64: 447-454. 
13. Major P, Johnson D, Hesse K, Glover K Effect of head orientation on posterior anterior cephalometric landmark identification. Angle Orthodontist 1996;66: 51-60).

14. Farman AG, Farman TT. A comparison of image characteristics and convenience in panoramic radiography using charge-coupled device, storage phosphor, and film receptors. J Digit Imaging, 2001;14(Suppl 1): 48-51.

15. Korner M, Weber CH, Wirth S, Pfeifer KJ, Reiser MF, Treitl M. Advances in Digital Radiography: Physical Principles and System Overview. Radiographics 2007;27:675686.

16. "Quantum Efficiency." McGraw-Hill Dictionary of Scientific and Technical Terms.

McGraw-Hill Companies, Inc., 2003. Answers.com 03 Jun. 2007.

http://www.answers.com/topic/quantum-efficiency

17. Hatcher, D.C. and C.L. Aboudara, Diagnosis goes digital. Am J Orthod Dentofacial Orthop 2004;125:512-515.

18. Mozzo P, Procacci C, Tacconi A, Martini PT, Andreis IA. A new volumetric CT machine for dental imaging based on the cone-beam technique: preliminary results. Eur Radiol 1998;8:1558-1564.

19. Farman AG, Levato C, Scarfe WC. A primer on cone beam CT. Inside Dentistry 2007(Jan): 90-93.

20. Hashimoto K, Arai Y, Iwai K, Araki M, Kawashima S, Terakado M. A comparison of a new limited cone beam computed tomography machine for dental use with a multidetector row helical CT machine. Oral Surg Oral Med Oral Pathol Oral Radiol Endod 2003;95:371-377.

21. Sukovic P. Cone beam computed tomography in craniofacial imaging. Orthod Craniofac Res 2003;6(Suppl 1):31-36.

22. Baba R, Ueda K, Okabe M. Using a flat-panel detector in high resolution cone beam CT for dental imaging. Dentomaxillofac Radiol 2004;33:285-290.

23. Hollender, L.G., Controversies in Oral and Maxillofacial Surgery, ed. E.J. Worthington P. 1994, Philadelphia: WB Saunders. pp.1-12.

24. Kjellberg H, Ekestubbe A, Kiliaridis S, Thilander B. Condylar height on panoramic radiographs. A methodologic study with aclinical application. Acta Odontol Scand, 1994 52(1): p. 43-50.

25. Katzberg, R.W..State of the art: Temporomandibular joint imaging. Ann Roy Aust Coll Dent Surg 1989:10:32-52.

26. Seligman D, Okeson, Orthodontics Occlusion and Temporomandibular Disorders, in Orthodontics and Dentofacial Orthopedics, J. McNamara and W. Brudon, Editors. 2001, Needham Press: Ann Arbor. pp. 519-543

27. Kitai N, Kreiborg S, Bakke M, Paulsen HU, Moller E, Darvann TA, Pedersen H, Takada 
$\mathrm{K}$. Three-dimensional magnetic resonance image of the mandible and masticatory muscles in a case of juvenile chronic arthritis treated with the Herbst appliance. Angle Orthod 2002:72(1):p. 81-87.

28. Blackwood HJ, Arthritis of the mandibular joint. Br Dent J 1963;115:317-326.

29. Proffit WR. Treatment planning: the search for wisdom., in Surgical Orthodontic Treatment, W.R.J. Proffit WR, Editor. 1991, Mosby-Year Book: St. Louis. pp. 158-159.

30. Ong TK, Franklin CD. A clinical and histopathological study of osteoarthrosis of the temporomandibular joint. Br J Oral Maxillofacial Surg 1996;34:186-192.

31. Dahlstrom L, Lindvall AM. Assessment of temporomandibular joint disease by panoramic radiography: reliability and validity in relation to tomography. Dentomaxillofac Radiol 1996; 25:197-201.

32. Winter A. NewTom 9000 Accuracy. 2000. Accessed June 4, 2007 http://www.endomail.com/articles/aw01 newtom.html

33. Ruf S, Pancherz H Is orthopantomography reliable for TMJ diagnosis? An experimental study on a dry skull. J Orofac Pain 1995;9:365-374.

34. Ziegler CM, Woertcher R, Brief J, Hassfeld S. Clinical indications for digital volume tomography in oral and maxillofacial surgery. Dentomaxillofac Radiol 2002;31:126-130.

35. Nakagawa Y, Kobayashi K, Ishii H, Mishima A, Ishii H, Asada K, Ishibashi K. Preoperative application of limited cone beam computerized tomography as an assessment tool before minor oral surgery. Int J Oral Maxillofac Surg. 2002;31:322-326.

36. Danforth RA, Peck J, Hall P. Cone beam volume tomography: an imaging option for diagnosis of complex mandibular third molar anatomical relationships. J Calif Dent Assoc 2003;31:847-852

37. Heiland M, Schmelzle R, Hebecker A, Schulze D. Intra-operative 3D imaging of the facial skeleton using the SIREMOBIL Iso-C3D. Dentomaxillofac Radiol. 2004;33:130132.

38. Hamada Y, Kondoh T, Noguchi K, Iino M, Isono H, Ishii H, Mishima A, Kobayashi K, Seto K. Application of limited cone beam computed tomography to clinical assessment of alveolar bone grafting: a preliminary report. Cleft Palate Craniofac J 2005;42:128-137.

39. Hatcher DC, Dial C, Mayorga C. Cone beam CT for pre-surgical assessment of implant sites. J Calif Dent Assoc 2003;31:825-833

40. Sarment DP, Sukovic P, Clinthorne N. Accuracy of implant placement with a stereolithographic surgical guide. Int J Oral Maxillofac Implants 2003;18:571-577.

41. Sato S, Arai Y, Shinoda K, Ito K. Clinical application of a new cone-beam computerized tomography system to assess multiple two-dimensional images for the preoperative treatment planning of maxillary implants: case reports. Quintessence Int 2004;35:525528. 
42. Kobayashi K, Shimoda S, Nakagawa Y, Yamamoto A. Accuracy in measurement of distance using limited cone-beam computerized tomography. Int J Oral Maxillofac Implants 2004;19:228-231

43. Mah JD, Hatcher D. Current status and future needs in craniofacial imaging. Orthod Craniofac Res 2003;6(Suppl 1):10-16.

44. Vannier MW. Craniofacial computed tomography scanning: technology, applications and future trends. Orthod Craniofac Res 2003;6(Suppl 1):23-30.

45. Maki K, Inou N, Takanishi A, Miller AJ. Computer-assisted simulations in orthodontic diagnosis and the application of a new cone beam X-ray computed tomography. Orthod Craniofac Res 2003;6(Suppl 1):95-101.

46. Baumrind S, Carlson S, Beers A, Curry S, Norris K, Boyd RL. Using three-dimensional imaging to assess treatment outcomes in orthodontics: a progress report from the University of the Pacific. Orthod Craniofac Res 2003;6(Suppl 1):132-142.

47. Aboudara CA, Hatcher D, Nielsen IL, Miller A. A three-dimensional evaluation of the upper airway in adolescents. Orthod Craniofac Res 2003;6(Suppl 1):173-17?.

48. Danforth RA, Dus I, Mah J. 3-D volume imaging for dentistry: a new dimension. J Calif Dent Assoc 2003;31:817-823.

49. Lascala CA, Panella J, Marques MM. Analysis of the accuracy of linear measurements obtained by cone beam computed tomography (CBCT-NewTom). Dentomaxillofac Radiol 2004;33:291-294.

50. Bianchi S, Anglesio S, Castellano S, Rizzi L, Ragona R. Absorbed doses and risk in implant planning: comparison between spiral CT and cone-beam CT. Dentomaxillofac Radiol 2001;30(Suppl 1):S28.

51. Halazonetis DJ. From 2-dimensional cephalograms to 3-dimensional computed tomography scans. Am J Orthod Dentofacial Orthop 2005; 127:627-637.

52. Ngan DC, Kharbanda OP, Geenty JP, Darendeliler MA. Compariso of radiation levels from computed tomography and conventional dental radiographs. Aust Orthod J $2003 ; 19: 67-75$.

53. Dus I. The Next "Revolution" American Association of Dental Maxillofacial Radiographic Technicians. http://www.aadmrt.com/static.aspx?content=currents/Dus_fall03 accessed Nov. 30, 2004

54. Hilgers ML, Scarfe WC, Scheetz JP, Farman AG. Accuracy of linear TMJ measurements with cone beam computed tomography and digital cephalometric radiography. Am J Orthod Dentofacial Orthop 2005; 1278:803-811.

55. Hajeer MY, Millett DT, Ayoub AF, Siebert JP. Current products and practices. Applications of 3D imaging in orthodontics: Part I. J of Orthod 2004;31:62-70

56. Largravere MO, Major PW. Proposed reference point for 3-dimensional cephalometric 
analysis with cone-beam computerized tomography. Am J Orthod Dentofacial Orthop 2005;128:657-660.

57. Major PW, Johnson DE, Hesse KL, Glover KE. Landmark identification error in posterior anterior cephalometrics. Angle Orthod 1994;64:447-454.

58. Athanasiou AE. Ortrhodontic cephalometry. London and Baltimore: Mosby-Wolfe; 1995.

59. Park SH, Yu HS, Kim KD, Lee KJ, Baik HS. A proposal for a new analysis of craniofacial morphology by 3-dimensional computed tomography. Am J Orthod Dentofacial Orthop. 2006; 129:600.e23-3442.

60. Broadbent BH Sr, Broadbent BH Jr, Golden WH. Bolton standars of dentofacial developmental growth. St Louis: Mosby; 1975.

61. Baumrind S, Moffitt FH, Curry S. The geometry of three-dimensional measurement from paired coplanar x-ray images. Am J Orthod 1983;84:313-322.

62. Grayson BH, McCarthy JG, Bookstein F. Analysis of craniofacial asymmetry by multiplane cephalometry. Am J Orthod 1983;84:217-224.

63. Grayson BH, LaBatto FA, Kolber AB, McCarthy JG. Basilar multiplane cephalometric analysis. Am J Orthod 1985;88:503-516.

64. Trocme MC, Sather AH, An KN. A biplanar cephalometric stereoradiography technique. Am J Orthod Dentofacial Orthop 1990;98:168-175.

65. Farman AG, Scarfe WC. Development of imaging selection criteria and procedures should precede cephalometric assessment with cone-beam computed tomography. Am J Orthod 2006;130:257-265.

66. Moshiri M, Scarfe WC, Hilgers ML, Scheetz JP, Silveira AM, Farman AG. Accuracy of linear measurements from imaging plate and CBCT-derived lateral cephalometric images. Am J Orthod Dentofacial Orthop. 2007;(In press: manuscript \# AJODO-D-0600173R1)

67. Adams GL, Hatcher DC, Miller AJ, Comparison between traditional two-dimensional cephalometry and a three-dimensional approach, Division of Orthodontics, University of California, San Francisco, AJODO, Abstract, Vol. 22, Number 1, Page 117, July 2002

68. Chidiac JJ, Shofer FS, Al-Kutoub A, Laster LL, Ghafari J. Comparison of CT scanograms and cephalometric radiographs in craniofacial imaging. Orthod Craniofac Res 2002;5:104-13.

69. Chan G, Palomo JM, Baden S, Hans MG. Accuracy and reliability of cephalometric and CBCT linear measurements. J Dent Res 86(Spec Iss B):abstract \#0770, 2007.

70. Lagravere MO, Hansen L, Harzer W, Major PW. Plane orientation for standardization in 3-dimensional cephalometric analysis with computerized tomography imaging. Am J Orthod Dentofacial Orthop 2006;129:601-604. 
71. Hildebolt CF, Vannier MW, Knapp RH. Validation study of skull three-dimensional computerized tomography measurements. Am J Phys Anthropol 1990;82:283-294.

72. Kragskov J, Bosch C, Gyldensted C, Sindet-Pedersen S. Comparison of the reliability of craniofacial anatomic landmarks based on cephalometric radiographs and threedimensional CT scans. Cleft Palate Craniofac J 1997;34:111-116

73. Nagashima M, Inoue K, Sasaki T, Miyasaka K, Matsumura G, Kodama G. Threedimensional imaging and osteometry of adult human skulls using helical computed tomography. Surg Radiol Anat 1998;20:291-297.

74. Cavalcanti MG, Rocha SS, Vannier MW. Craniofacial measurements based on 3D-CT volume rendering: implications for clinical applications. Dentomaxillofac Radiol. 2004;33:170-176.

75. Cavalcanti MG, Vannier MW. Quantitative analysis of spiral computed tomography for craniofacial clinical applications. Dentomaxillofac Radiol. 1998;27:344-350.

76. Jung H, Kim HJ, Kim DO, Hong SI, Jeong HK, Kim KD, Kim Y, Yoo S, Yoo H. Quantitative analysis of three-dimensional rendered imaging of the human skull acquired from multi-detector row computed tomography. J Digit Imaging. 2002;15:232-239.

77. Cavalcanti MG, Haller JW, Vannier MW. Three-dimensional computed tomography landmark measurement in craniofacial surgical planning: experimental validation in vitro. J Oral Maxillofac Surg 1999;57:690-694.

78. Williams FL, Richtsmeier JT. Comparison of mandibular landmarks from computed tomography and 3D digitizer data. Clin Anat. 2003;16:494-500.

79. Cavalcanti MGP, Ruprecht A, Vannier MW. 3D volume rendering using multislice computed tomography for dental implants. Dentomaxillofac Radiol 2002;31:218-223.

80. Swennen GRJ, Schutyser F. Three-dimensional cephalometry: Spiral multi-slice vs conebeam computed tomography. Am J Orthod Dentofacial Orthop 2006;130:410-416.

81. Swennen GRJ. Three dimensional cephalometric reference system. In: Swenen GRJ, Schutyser F, Hausamen JE, editors. Three dimensional cephalometry. A color atlas and manual. Heidelberg: Spinger; 2005. p.94-112.

82. Swennen GRJ, Schutyser F, Barth EL, De Groeve P, De Mey A. A new method of 3-D cephalometry. Part I: the anatomic Cartesian 3-D reference system. J Craniofac Surg 2006;17:314-325.

83. Swennen GRJ. Three dimensional cephalometric soft tissue landmarks. In: Swenen GRJ, Schutyser F, Hausamen JE, editors. Three dimensional cephalometry. A color atlas and manual. Heidelberg: Spinger; 2005. p.116-181.

84. Swennen GRJ. Three dimensional cephalometric soft tissue landmarks. In: Swenen GRJ, Schutyser F, Hausamen JE, editors. Three dimensional cephalometry. A color atlas and manual. Heidelberg: Spinger; 2005. p.186-226. 
85. Swennen GRJ, Barth EL, Schutyser F, De Groeve P, Lemaitre A. Three-dimensional (3D) cephalometry, the basics for virtual planning. J Cranio Maxillofac Surg 2004;32(Suppl 1):135.

86. Feldkamp LA, Davis LC, Kress JW. Practical conebeam algorithm. J Opt Soc Am 1984;1:612-619.

87. Geelen W, Wenzel A, Gotfredsen E, Kruger M, Hansson LG. Reproducibility of cephalometric landmarks on conventional film, hardcopy, and monitor-displayed images obtained by the storage phosphor technique Eur J Orthod. 1998;20:331-40

88. Tsao DH, Kazanoglu A, McCasland JP. Measurability of radiographic images. Am J Orthod. 1983;84:212-6.

89. Ludlow JB. Davies-Ludlow LE. Brooks SL. Howerton WB. Dosimetry of 3 CBCT devices for oral and maxillofacial radiology: CB Mercuray, NewTom 3G and i-CAT Dento-Maxillo-Facial Radiology. 2006;35(4):219-26.

90. Gijbels F. Sanderink G. Wyatt J. Van Dam J. Nowak B. Jacobs R. Radiation doses of indirect and direct digital cephalometric radiography. British Dental Journal. 2004;197(3): 149-52. 


\title{
CURRICULUM VITAE
}

\author{
Danielle R. Periago
}

I. Academic Degrees

$\begin{array}{llll}\text { Orthodontic Certificate } & \text { University of Louisville } & \text { Louisville, KY } & \text { In Progress } \\ \text { MS } & \text { University of Louisville } & \text { Louisville, KY } & \text { In Progress } \\ \text { DMD } & \text { University of Louisville } & \text { Louisville, KY } & 2005 \\ \text { BA } & \text { Oral Roberts University } & \text { Tulsa, OK } & 2000\end{array}$

II. Awards and Honors

- Summa Cum Laude Graduate: University of Louisville School of Dentistry, 2005

- American Academy of Oral Medicine Award: University of Louisville School of Dentistry, 2005

- American Academy of Oral and Maxillofacial Pathology Award: University of Louisville School of Dentistry, 2005

- Dean's Scholar: University of Louisville School of Dentistry; Fall 2005, Spring 2004, Fall 2003, Spring 2003, Fall 2002, Spring 2002, Fall 2001

- Excellence in General Pathology Award: University of Louisville School of Dentistry, 2003

- Delphi Society: University of Louisville School of Dentistry, 2003

- National Boards Part I Scholarship Winner: University of Louisville School of Dentistry, 2003

- Summa Cum Laude Graduate: Oral Roberts University, 2000

- National Spanish Honor Society: Oral Roberts University, 2000

- Award for Best Senior Thesis Defense: Modern Language Department, Oral Roberts University, 2000

- President's List (4.0 GPA): Oral Roberts University, 1996-2000 (7 semesters)

- Dean's List (3.9 GPA): Oral Roberts University, 1998 (1 semester)

- National Freshman Honor Society: Oral Roberts University, 1996-2000

- Student Association Freshman Council: Oral Roberts University, 1996

- Paul Ogal Foundation Scholarship Winner: 1996 
IV. Professional Affiliations

- American Association of Orthodontists (AAO): student member, 2005-present

- American Dental Association (ADA): member, 2005-present

- American Student Dental Association (ASDA): member, 2001-2005

- Louisville American Student Dental Association (LASDA):

Member, 2001-present

Class Representative, 2002-2003

Pre-dental Liaison, 2003-2004

- Delphi Society: member, 2003-present

- National Spanish Honor Society: member, 2000

- Oral Roberts University Student Association:

Academic Peer Advisor, 1999-2000

Dorm Representative, 1996-1997

Freshman Council, 1996

- Tri-Beta Biological Honor Society: member, 1996-1998

V. Extracurricular Activities/Community Service

- Fluent in the Spanish language

- Academic Tutor: University of Louisville, 2003-2004

General Pathology

National Boards Part I

- Smile Kentucky Program 2003-2004

- Oral Cancer Screening: Highland Community Outreach, 2004

- Kentucky State Fair Sealants Program, 2002-present

- March of Dimes

- University Community Outreach program: Oral Roberts University, 1996-2000

- Inner City Los Angeles Mission Trip: Oral Roberts University, 1998

- Bangkok, Thailand Mission Trip: Teen Mania Missions, 1995. 